University of Rhode Island

DigitalCommons@URI

Open Access Master's Theses

2013

\title{
A Difference in Perspective: A Comparison of Ecosystem and Single-Species Focused Fisheries Management
}

Catherine M. Foley

University of Rhode Island, catherine_foley@my.uri.edu

Follow this and additional works at: https://digitalcommons.uri.edu/theses

\section{Recommended Citation}

Foley, Catherine M., "A Difference in Perspective: A Comparison of Ecosystem and Single-Species Focused Fisheries Management" (2013). Open Access Master's Theses. Paper 45.

https://digitalcommons.uri.edu/theses/45

This Thesis is brought to you for free and open access by DigitalCommons@URI. It has been accepted for inclusion in Open Access Master's Theses by an authorized administrator of DigitalCommons@URI. For more information, please contact digitalcommons-group@uri.edu. 
A DIFFERENCE IN PERSPECTIVE:

A COMPARISON OF ECOSYSTEM AND SINGLE-SPECIES

FOCUSED FISHERIES MANAGEMNET

BY

CATHERINE M. FOLEY

A THESIS SUBMITTED IN PARTIAL FULFILLMENT OF THE REQUIREMENTS FOR THE DEGREE OF

MASTER OF ARTS

IN

MARINE AFFAIRS

UNIVERSITY OF RHODE ISLAND 


\section{MASTER OF ARTS IN MARINE AFFAIRS THESIS}

OF

\section{CATHERINE M. FOLEY}

\section{APPROVED:}

Thesis Committee:

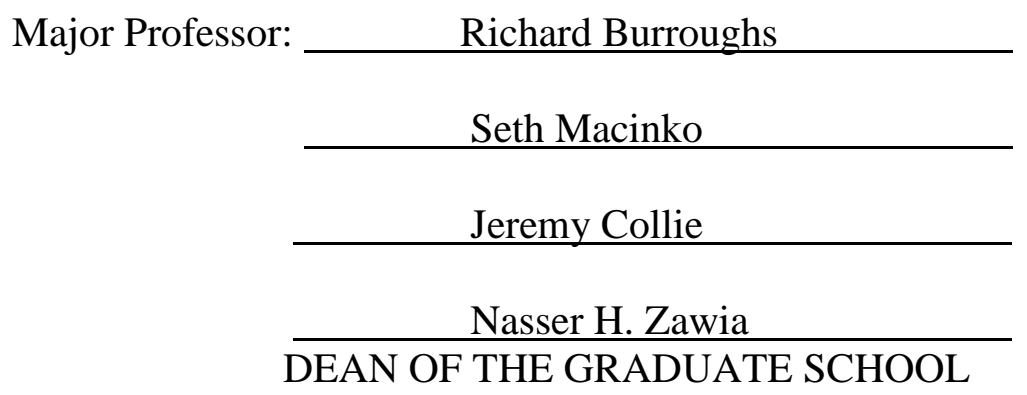

UNIVERSITY OF RHODE ISLAND 


\begin{abstract}
Currently, most fisheries management bodies utilize a narrow, single-species focus in decision-making processes. These methodologies, however, fail to recognize the interrelated nature of ecosystems, and as such are unable to produce realistic and valid estimates of sustainable yield. One proposed method of integrating ecosystem data into the decision-making process of fisheries management involves quantifying ecosystem diversity. This study evaluates historical fisheries management success in terms of changes in biological diversity and evaluates the potential use of length and species diversity measurements to aid managers in understanding fishery-induced community changes. To evaluate these relationships, a comparison of ecological and management outcomes of the Georges Bank and Eastern Bering Sea groundfish fisheries was performed. These ecosystems were selected due to the strong importance groundfish fisheries play in both regions. Fisheries on Georges Bank are generally considered to be among the world's most poorly managed and are considered to be in a state of severe decline. In contrast, Alaskan fisheries are generally considered to be among the most successfully managed in the world.

Fishery independent survey data from Georges Bank and the Eastern Bering Sea were evaluated for at least an eighteen year period. Changes in the proportion of length distributions, mean length, and maximum length of annual trawl catches were evaluated for the entire catch and particular species of interest. Annual measurements of species diversity were quantified through the use of species richness, evenness, and trophic diversity calculations and overall trends were evaluated between the ecosystems.
\end{abstract}


Results indicate that fishing pressure is correlated to fish size distributions in both ecosystems, however the relationship between fishing pressure and species diversity is slight in both ecosystems. Additionally, a surprising trend of increasing species diversity is apparent in both ecosystems, despite the simultaneous decline of several stocks on Georges Bank. Lastly, an evaluation of management approaches revealed that management of the Georges Bank region has been largely reactive, responding to immediate ecological needs of the fishery. In the Eastern Bering Sea, groundfish management has been comparatively proactive, seeking to address needs of the fishery prior to reaching critical management points. These differing management styles are apparent in the ecological assessments of both ecosystems. Frequently, the reactive management actions on Georges Bank resulted in more immediate responses in single species abundance and ecosystem diversity, while the more proactive management actions in the Eastern Bering Sea resulted in little ecological change in the system. These results highlight the importance of utilizing a proactive approach to fisheries management and suggest that changes in ecosystem and community composition should be strongly considered in all management actions to gain a more holistic perspective. Furthermore, they suggest that management goals related to the maintenance of biological diversity may not be suitable because of inadequate understanding of community dynamics. 


\section{ACKNOWLEDGEMENTS}

There are a number of people who made this research possible. I wish to thank my major professor, Dr. Richard Burroughs for his continued support. Additionally, I would like to acknowledge my thesis committee members, Dr. Seth Macinko and Dr. Jeremy Collie, for helping to shape this project.

I especially want to thank my family, for their constant love and encouragement. I would not have made it this far without their sound advice and encouraging words at exactly the right moments.

Financial support for this research was provided by the Coastal Institute Graduate Fellowship Program and a teaching assistantship through the Department of Biological Sciences. 


\section{TABLE OF CONTENTS}

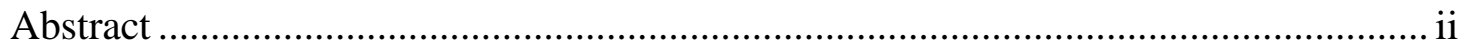

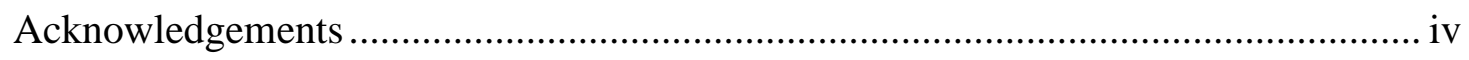

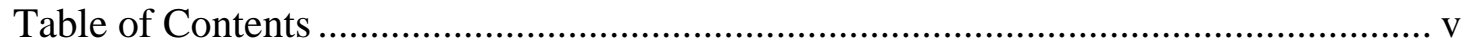

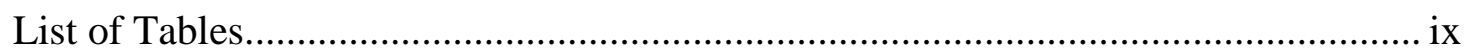

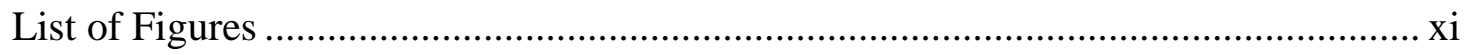

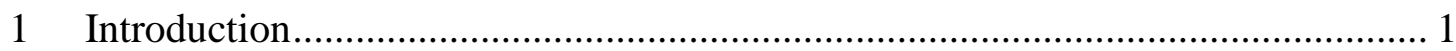

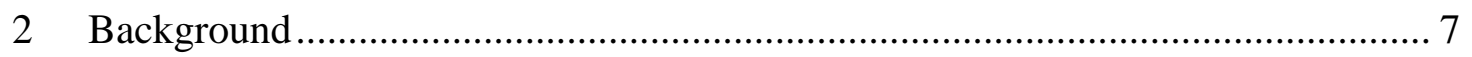

2.1 History of Fisheries Management ......................................................... 7

2.2 Management Landscape and the Role of Science ................................... 12

2.3 The State of Science in Fisheries Management......................................... 17

2.4 Diversity as an Ecosystem Assessment Tool ....................................... 21

2.5 Georges Bank Groundfish Fishery ...................................................... 27

2.6 Eastern Bering Sea Groundfish Fishery …...................................... 32

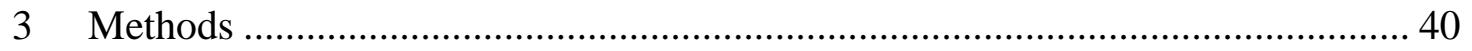

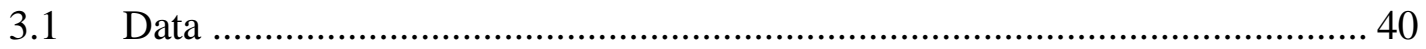

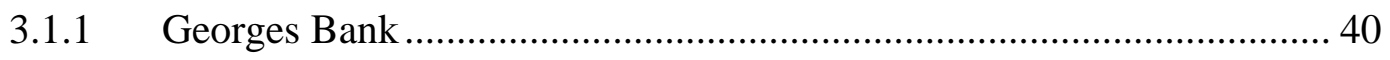

3.1.1.1 Demersal Communities............................................................ 40

3.1.1.2 Fishing Effort ............................................................. 41

3.1.1.3 Commercial Landings ...................................................... 42

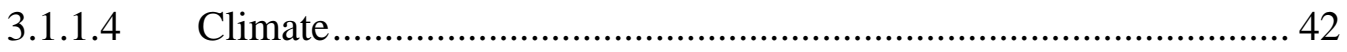

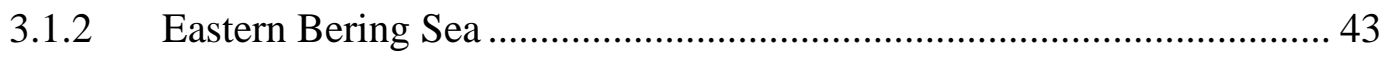

3.1.2.1 Demersal Community ..................................................... 43 
3.1.2.2 Fishing Effort............................................................................ 44

3.1.2.3 Commercial Landings................................................................... 44

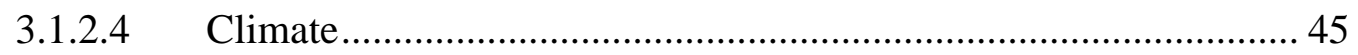

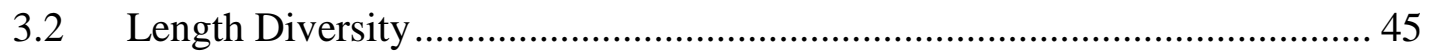

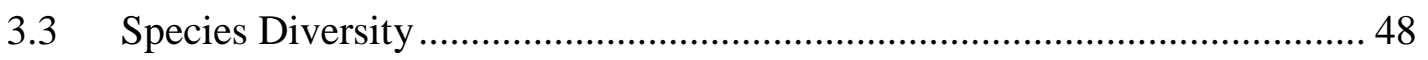

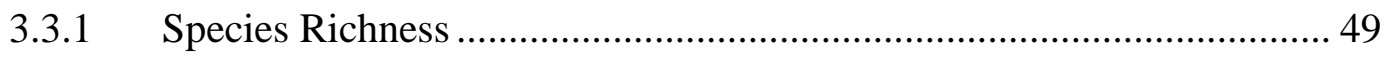

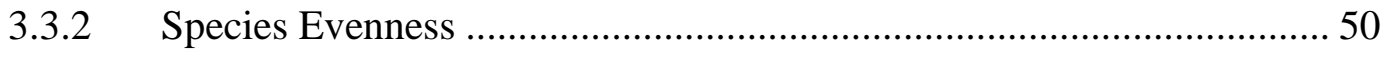

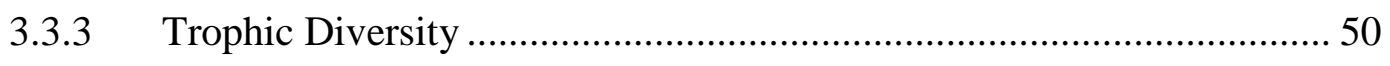

3.4 Evaluation of Changes in Community Structure .......................................... 51

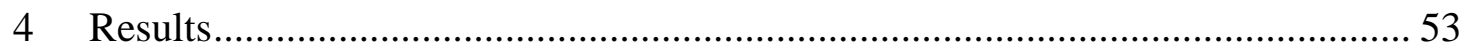

4.1 Fishing Effort \& Commercial Landings..................................................... 53

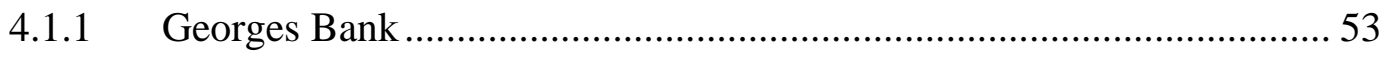

4.1.2 Eastern Bering Sea ........................................................................ 54

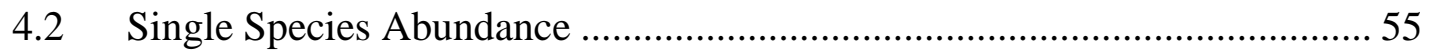

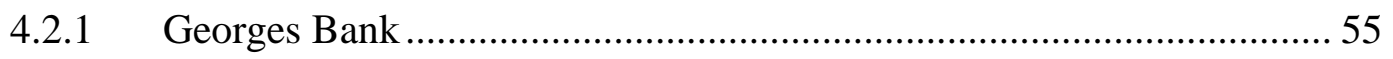

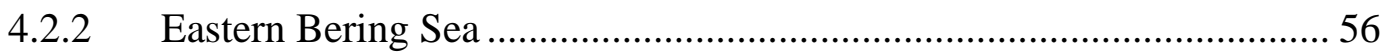

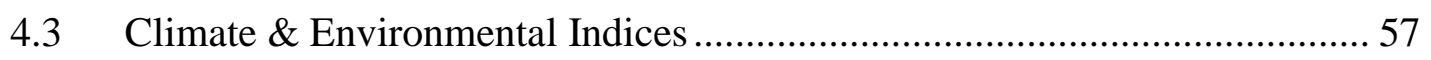

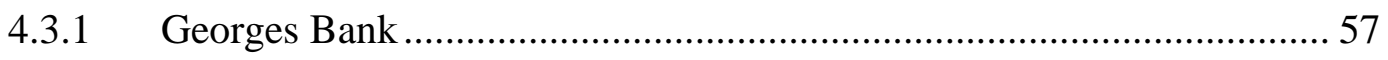

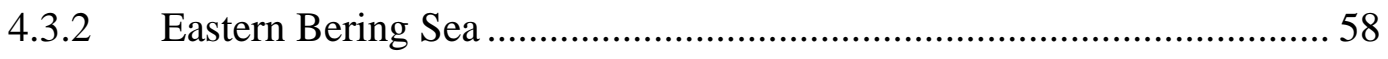

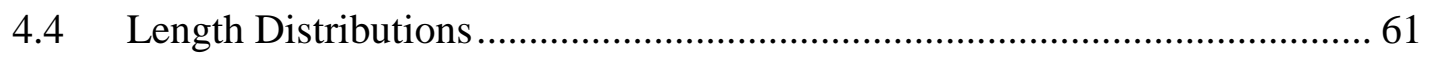

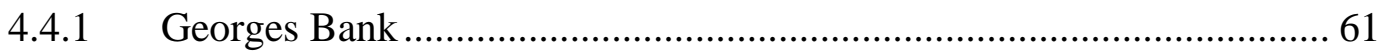

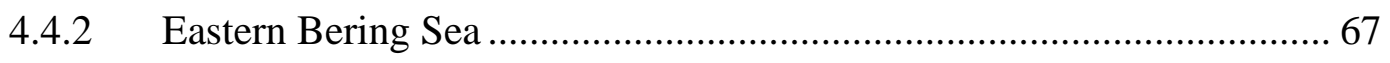

4.5 Community Diversity and Structure.......................................................... 73 


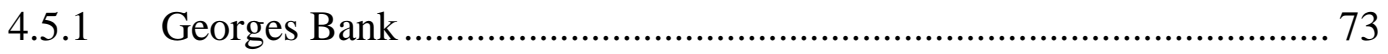

4.5.1.1 Species Richness ..................................................................... 73

4.5.1.2 Species Evenness …………………………............................. 74

4.5.1.3 Trophic Diversity …………………………............................. 75

4.5.2 Eastern Bering Sea ......................................................................... 76

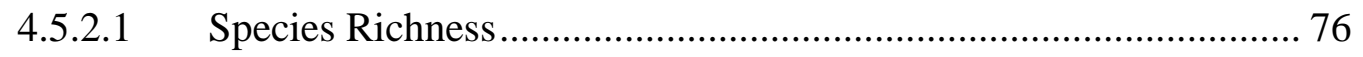

4.5.2.2 Species Evenness …………………………............................. 78

4.5.2.3 Trophic Diversity ……………………………........................... 79

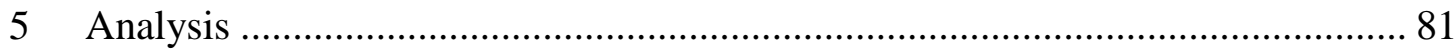

5.1 Comparison of Georges Bank and Eastern Bering Sea Ecosystems .............. 81

5.1.1 Fishing Effort and Climate Findings.................................................... 83

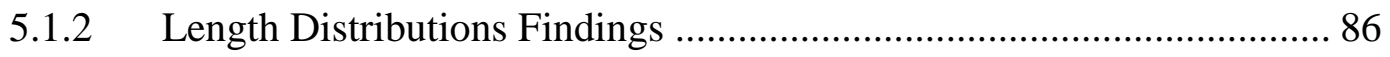

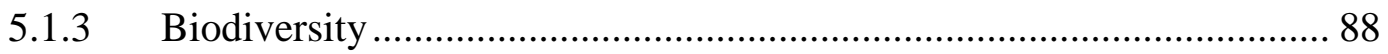

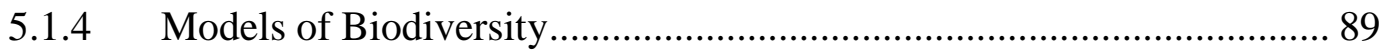

5.1.5 Themes of Ecosystem Relationships and Change.................................. 90

5.2 Ecosystem Structure and Fisheries Policies ………….................................. 92

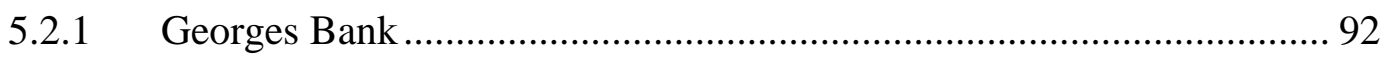

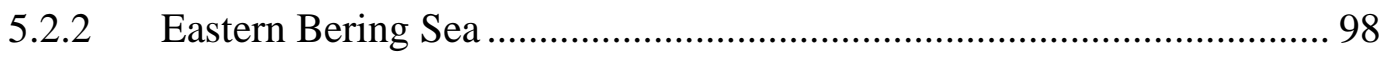

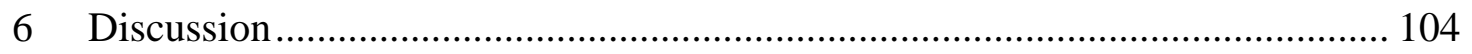

6.1 Fishing Pressure, Length Distributions, and Species Diversity .................. 104

6.2 Implications for Fisheries Management ..................................................... 107

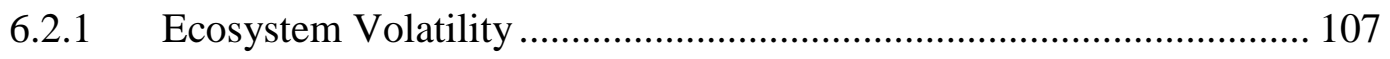

6.2.2 Unexpected Findings........................................................................ 111 
6.2.3 Importance of Historic Management ............................................. 113

6.2.4 General Management Implications ............................................. 114

6.3 Management Recommendations and Future Directions .......................... 116

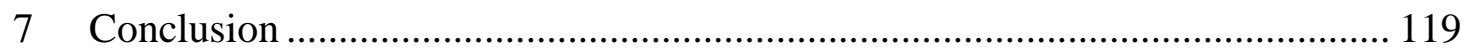

Appendix A: Supplemental Methods ............................................................. 122

Additional Species Diversity Calculations ….............................................. 122

Appendix B: Supplemental Results ........................................................... 124

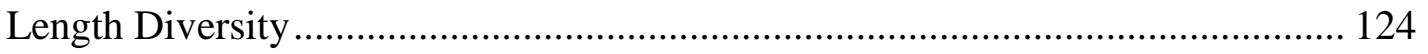

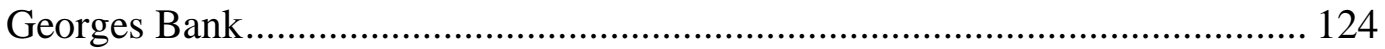

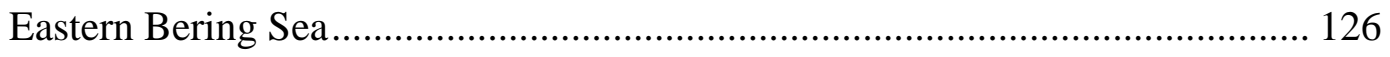

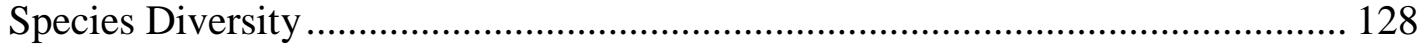

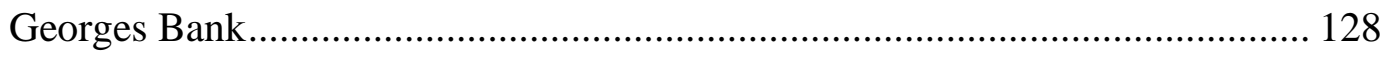

Eastern Bering Sea ...................................................................... 133

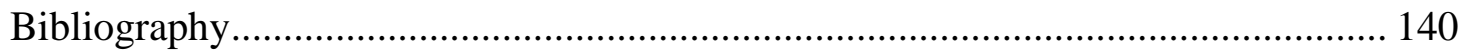




\section{LIST OF TABLES}

Table 1. National Standards for fishery conservation and management...................... 15

Table 2. Marine biodiversity \& ecosystem functions, services, and goods................. 22

Table 3. Georges Bank groundfish stock statuses........................................................ 32

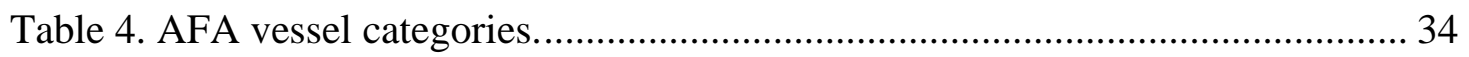

Table 5. Eastern Bering Sea stock statuses. ........................................................... 39

Table 6. Georges Bank species of commercial importance. …….................................. 47

Table 7. Eastern Bering Sea species of commercial importance. ……….................... 48

Table 8. Georges Bank Historical Biological Index multiple regression results......... 74

Table 9.Georges Bank Mean Trophic Level multiple regression results..................... 76

Table 10. EBS Historical Biological Index multiple regression results....................... 78

Table 11. Georges Bank summary correlations..................................................... 82

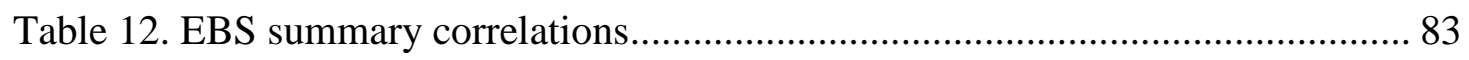

Table 13. Georges Bank significant fisheries management policies, 1976-2011 ........ 93

Table 14. EBS sugnificant management policies, 1977-2011_................................... 99

Table 15. Summary results of fish length distribution analyses ................................ 105

Table 16. Summary results of species diversity analyses ......................................... 106

Table 17. Biodiversity indices and relevant calculations used for the current study. 123

Table 18. Georges Bank all species fish length correlations. .................................... 124

Table 19. Georges Bank Atlantic cod fish length correlations. .................................. 125

Table 20. Georges Bank flatfish length correlations................................................ 125

Table 21. Georges Bank skate length correlations.................................................. 126

Table 22. EBS all species fish length correlations................................................... 126 
Table 23. EBS walleye pollock fish length correlations ..................................... 127

Table 24. EBS Pacific cod fish length correlations........................................... 127

Table 25. EBS flatfish length correlations .................................................... 127

Table 26. Georges Bank realized species richness multiple regression results ........ 129

Table 27. Georges Bank Shannon Index multiple regression results....................... 130

Table 28. Georges Bank Hurlbert Index multiple regression results ....................... 131

Table 29. Georges Bank Fish in Balance Index multiple regression results............. 133

Table 30. EBS realized species richness multiple regression results ...................... 134

Table 31. EBS Shannon Index multiple regression results .................................. 135

Table 32. EBS Hurlbert Index multiple regression results ................................. 136

Table 33. EBS Mean Trophic Level multiple regression results ............................. 137

Table 34. EBS Fish in Balance Index multiple regression results ......................... 139 


\section{LIST OF FIGURES}

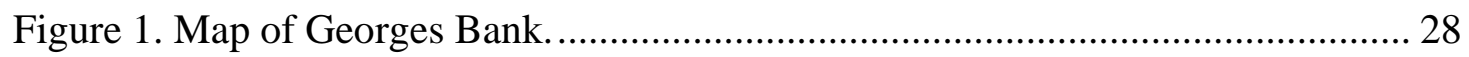

Figure 2. Alaskan groundfish fishery management areas.......................................... 33

Figure 3. Commercial fishing activity on Georges Bank, $1977-2009 \ldots \ldots \ldots \ldots \ldots \ldots \ldots \ldots . . . .54$

Figure 4. Commercial fishing activity in the Eastern Bering Sea, 1990-2008 ............ 55

Figure 5. NEFSC Northeast Bottom Trawl Survey Catches, 1975-2011 .................... 56

Figure 6. AFSC Eastern Bering Sea Trawl Survey CPUE, 1982-2011_..................... 57

Figure 7. Climatic characteristics of Georges Bank, 1977-2009................................ 58

Figure 8. Climatic characteristics of the Eastern Bering Sea, 1990-2008 …............... 60

Figure 9. Georges Bank length distribution of all species ........................................ 62

Figure 10. A Georges Bank length distributions of Atlantic cod................................. 63

Figure 11. Georges Bank length distributions of flatfish........................................... 65

Figure 12. Georges Bank length distributions of skates ................................................ 66

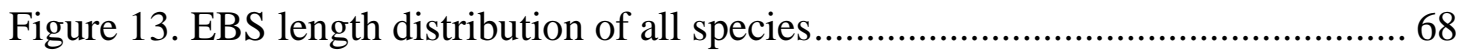

Figure 14. EBS length distribution of walleye pollock .................................................. 69

Figure 15. EBS length distribution of Pacific cod ..................................................... 70

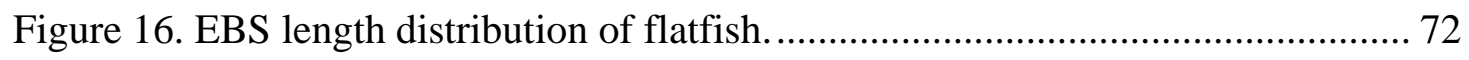

Figure 17. Georges Bank Historical Biological Index ............................................. 74

Figure 18. Georges Bank Shannon Diversity Index..................................................... 75

Figure 19. Georges Bank Mean Trophic Level...................................................... 76

Figure 20. EBS Historical Biological Index ........................................................... 77

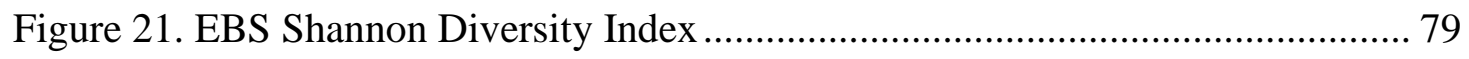

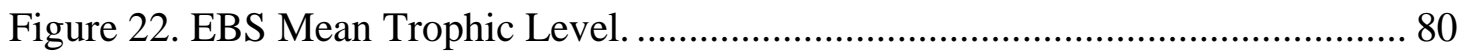


Figure 23. Changes in Eastern Bering Sea species diversity since 2004................... 91

Figure 24. Georges Bank species abundance and management actions.. ................... 96

Figure 25. Georges Bank species diversity and management actions ...................... 97

Figure 26. EBS species abundance and management actions ............................... 101

Figure 27. EBS species diversity and management actions ................................. 102

Figure 28. Georges Bank potential and realized species richness. ........................ 129

Figure 29. Georges Bank Hurlbert Evenness Index........................................ 131

Figure 30. Georges Bank Fish in Balance Index............................................ 132

Figure 31. P EBS Potential and realized species richness ................................. 134

Figure 32. EBS Hurlbert Evenness Index. ................................................. 136

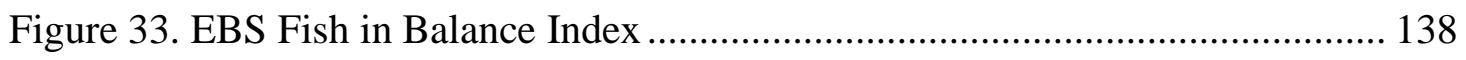




\section{INTRODUCTION}

Marine capture fisheries provide an essential service to societies and economies around the world. The industry, including fishers, processers, and wholesalers, employs approximately 35 million people worldwide and annually produces nearly 90 million metric tons of fish worth $\$ 93.9$ billion (ILO 2004; FAO 2010). Furthermore, the Food and Agriculture Organization (FAO) postulates that the majority of the diet of developing nations is reliant on seafood. The necessity for effective fisheries management, however, has often been overlooked. In a 2010 report, the United Nations' Food and Agriculture Organization estimated that 31\% of global fisheries are overexploited or depleted (The State of World Fishing, 2010). An additional $53 \%$ of stocks are considered fully exploited, with any increase in harvest resulting in overexploitation (The State of World Fishing, 2010). The resulting portrait of global fisheries is bleak and suggests that current exploitation practices may place both the ecological and social sustainability of worldwide fisheries in jeopardy. Considering both the worldwide reliance on marine capture fisheries and the dire state of many of world's fisheries, there is little debate regarding the need for fisheries management, however the method remains highly contentious.

Fisheries management has historically been dominated by a narrow, singlespecies focus in decision-making processes (Link 2002; Mace 2001). Biological determinations regarding the health and sustainability of fisheries have typically considered only the importance of target species and have ignored the effects of biotic and abiotic ecosystem processes (Pikitch 2004). The concept of managing a fishery using only the abundance of a single species, however, is controversial (Walters, et. al. 
2004). As early as the 1970s, the use of a single-species approach to management has been widely criticized (Larkin 1977). Indeed, recent fisheries management research has been focused on the importance of an Ecosystem Based Approach (EBA) to management and significant academic interest has been garnered regarding the implementation of such an approach (Ecosystem Principles Advisory Panel, 1999; U.S. Department of Commerce, 2009). An EBA to fisheries management requires a fundamental understanding of the workings of all levels of the ecosystem, and pays particular attention to the relationships between biotic and abiotic ecosystem characteristics (Pikitch, et. al. 2004).

The implementation of an EBA, however, has proven to be difficult for resource managers to accomplish. The current state of fisheries science is one of development and transition. Huge strides in our understanding of fish life history and ecology are being made daily, and laboratories across the world have sought to answer many of our fundamental questions regarding fisheries biology and ecology, however the combined effect of difficult study conditions and changing climate has made this research particularly difficult. Without a strong scientific backbone to support an ecosystem based approach, implementation of this type of fisheries management system is difficult.

Laboratories focused on the development of EBA management schemes have focused on a wide variety of interactions and characteristics to provide accurate assessments of management deficiencies and needs. Much of this research has suggested that diversity is likely to be an important component of ecosystem health. Recent studies have illustrated the importance biodiversity plays in the resilience of 
biological systems as well as a variety of other ecosystem services (Jones, et. al. 2007; Worm, et. al. 2006). Worm, et al. (2006) noted a correlation between increased biodiversity and ecosystem resiliency, including resistance to overfishing and increased recovery potential. Additional studies focused on declines in biodiversity have demonstrated significant reductions in ecosystem resiliency and subsequent environmental forcing resulting in instability (Folke, et. al. 2004). By considering this measure, fishery resource managers may be provided with a more holistic representation of fishery dynamics and allow for more effectively guided management action and overall evaluation of prior management success.

In the consideration of biological diversity, it is important to highlight the importance of diversity within and between species. To evaluate the changes in diversity within a species, the evaluation of changes in fish body sizes has frequently been proposed. Fish body size is also closely related to predator-prey interactions, respiration, and mortality (Jennings 2001). Because of these strong links, changes in body size distributions may be used to describe energy flux and community structures within an ecosystem (Jennings 2001). Comparisons of body size are also useful, because many biologists now propose that the exposure of a species to constant, size selective fishing pressure over several generations is likely to result in an evolutionary-linked shift in morphology toward a smaller body size. This theory is supported by studies which have found a strong, inverse relationship between body size and fishing pressure (Shin, et. al. 2005; Walsh, et. al. 2006). It seems likely, therefore, that systems experiencing vastly different fishing pressures will exhibit different trends in body size change across species and fisheries. Furthermore, the 
common management practice of minimum size requirements and size-based gear restrictions is likely to play an important role in shaping the communities of exploited species. As such, the study of these changes and their relationship to fishing pressure may offer valuable insight to fishery managers and should be considered during discussions of management action.

It is also essential to consider the effect of interspecies diversity on the community structure and energy flow within an ecosystem. Studies have demonstrated that higher rates of species richness and evenness, two common measurements of interspecies diversity, are strongly linked to higher rates of system resiliency and recovery from system perturbations (Jones, et. al. 2007; Worm, et. al. 2006; Folke, et. al. 2004). Species richness is defined as the number of species inhabiting an environment. Species evenness is defined as the relative proportions of each species within the ecosystem. By evaluating communities in terms of the relative abundance, evenness, and energy flow between organisms, scientists are able to determine the overall functioning of the system as well as the importance of each species and complex. Additionally, an analysis of ecosystem biodiversity changes within a fishery may allow for further discussion of changes in ecosystem composition and function. Biodiversity indices are generally calculated from fishery independent ecosystem surveys. These indices can range from simple calculations of species evenness, to more complicated calculations encompassing species richness and relative abundance measures (Shaw 2003).

The purpose of this study is to gain a broader understanding of the interaction between fishing pressure, climate, single species abundance, and system diversity. 
This may be accomplished through analyzing historic trends of ecosystem biodiversity and changes in size-distribution in two model ecosystems, Georges Bank and the Eastern Bering Sea. These ecosystems were selected due to the strong importance groundfish fisheries play in both regions. Fisheries on Georges Bank, however, are generally considered to be among the world's most poorly managed and many are considered to be in a state of severe decline (NEFSC 2012c). In a 2010 report to Congress, the National Marine Fisheries Service estimated that 33\% of the region's fish stocks are currently subjected to overfishing (2010 Report to Congress). In contrast, Alaskan fisheries are generally considered to be among the most successfully managed in the world (Sutinen 2000; Hilborn 2007). Only 3\% of Alaskan fisheries are currently overfished (2010 Report to Congress). By comparing the historic changes in system diversity between these systems, the present study will evaluate the current and past management actions and discuss the management implications associated with using a more ecosystem based approach to evaluate management policies.

The goal of this study is to answer the following questions:

1. How does fishing pressure relate to changes in fish size distribution on Georges Bank and in the Eastern Bering Sea?

2. How does fishing pressure affect single-species abundance and ecosystem biodiversity in both ecosystems?

3. What are the management implications of changes in ecosystem biodiversity and body size distributions for Georges Bank and the Eastern Bering Sea? 
I hypothesize that an increase in fishing pressure will reduce ecosystem biodiversity, single-species abundance, and mean body size in both ecosystems. Furthermore, I hypothesize that the Georges Bank and the Eastern Bering Sea will demonstrate different relationships between fishing pressure and ecosystem indicators and will produce significantly different assessments of ecosystem health and management implications. Results of this study will contribute to a better understanding of the relationship between fishing, ecosystem composition, and management options.

In the next chapter, I present background relating to the current understanding of fisheries science, management, and the particular ecosystems relevant to this study. Chapter 3 will provide a descriptions of the methods used for data collection and analysis. Significant results will be presented in Chapter 4. Chapter 5 will analyze differences in results between the Georges Bank and Eastern Bering Sea ecosystems as well as the pertinent relationships between community structure and fisheries policies. Chapter 6 will discuss the results and their implications on fisheries management. In particular, the readily apparent themes will be discussed in relation to their policy implications. Lastly, suggestions for future study improvements and directions will be outlined. 


\section{BACKGROUND}

\subsection{History OF FishERIES MANAGEMENT}

Marine capture fisheries play a pivotal role in societies and economies around the world. The industry, including fishers, processers, and wholesalers, employs approximately 35 million people worldwide and annually produces nearly 90 million metric tons of fish worth $\$ 93.9$ billion (ILO 2004; FAO 2010). While the importance of marine capture fisheries is clear, the understanding of the necessity to maintain sustainable exploitation has not always been as easily understood. Historic accounts of the inexhaustible resource represented by fish have often overshadowed more cautious attitudes regarding careful resource exploitation. In his 1873 Le Grande Dictionnaire de Cuisine, Alexandre Dumas claimed, "It has been calculated that if accident prevented the hatching of the eggs and each egg reached maturity, it would take only three years to fill the sea so that you could walk across the Atlantic dryshod on the backs of cod" (Dumas 2007). In 1883, biologist T.H. Huxley proclaimed to the London Fisheries Exhibition:

"I believe then that the cod fishery, the herring fishery, pilchard fishery, the mackerel fishery, and probably all the great sea fisheries are inexhaustible; that is to say, that nothing we do seriously affects the number of fish. Any attempt to regulate these fisheries seems, consequently, from the nature of the case, to be useless" (Huxley 1884).

At the time, this proclamation seemed to be quite accurate, supported by anecdotal evidence of fish abundance. Scientists frequently commented on the seemingly infinite reproductive potential of fish stocks. The passage of time, however, has proven these observations to be limited in scope and accuracy. Fisheries science has since 
demonstrated that the reproductive potential of fish stocks is limited by species traits, spawning characteristics and environmental factors. As such, the reproductive potential of fish is not unlimited and as such, all fisheries are exhaustible (Ryther 1969). Indeed, a plethora of studies has documented a worldwide decline in fishery and ecosystem health (Radovich 1982; Karpov, et. al. 2002; Mullon, et. al. 2005).

By the mid-1800s, belief in the exhaustibility of fishery resources began to take hold. An 1876 report commissioned by the government of Austria-Hungary commented on two conflicting arguments: (1) that "the disregard of all protective measures, and of all regulations limiting the methods of fishing, will, in the end, prove disastrous to the salt-water fisheries..." and (2) the demand for "complete freedom from all those limitations which only quench the spirit of enterprise." (Smith 1994). This discussion was further escalated in response to the decline of the New England Atlantic Halibut fishery. Tales of the abundance of the fish were common prior to the 20th century. Captain Chester Marr described an instance where, "the whole surface of the water as far as you could see was alive with halibut" (Grasso 2008, 68). Prior to the 1840s, Atlantic halibut had been considered a trash fish, and harvest was almost exclusively due to by-catch. In fact, one account describing the undesirability of halibut, explained that "the plenty of better fish makes these of little esteem..." (Grasso 2008, 68). By 1853, the New England halibut fishery was described as a, "new industry" (Sabine 1853). This industry, however, was not sustainable. Selection and pricing criteria led to the common practice of highgrading and discarding substandard catch (Grasso 2008). The simultaneous rapid increase in commercial value of Atlantic halibut, however, led to a huge increase in fishing pressure, and by 
the mid-1800s, localized near-shore depletions were common and the majority of fishing effort had moved offshore. Within ten years even offshore halibut populations had disappeared (Grasso 2008). The precarious status of Atlantic halibut remains today. In their 2012 report on the status of groundfish stocks, the National Marine Fishery Service reported that the Atlantic halibut stocks remain overfished (NMFS 2012a).

Overexploitation is a common theme in the history of fisheries management. In many fisheries, the common misconception that stocks are inexhaustible resources frequently led to an overestimation of fish abundance and stock resilience. In many cases, this confident disregard for biological references led to the complete collapse of fisheries. For the purposes of this study, fishery collapse is defined as a decline in stock abundance to less than $10 \%$ of baseline levels (Worm, et al 2006). Fisheries collapse has proven to be a significant issue, with 366 collapses occurring within the last 50 years (Mullon, et. al. 2005). Furthermore, a 2010 report by the United Nations' Food and Agriculture Organization estimated that $31 \%$ of global fisheries are overexploited or depleted (FAO, 2010). An additional 53\% of stocks are considered fully exploited, indicating that any increase in harvests will result in overexploitation (FAO, 2010). While these fisheries are not yet considered collapsed, they are dangerously near that precipice.

The precarious state of worldwide fisheries has incited global concern and has led to increased focus being paid to the issue of fisheries management. While theoretical limits in reproductive capacity and stock replenishment remain static, harvesting has continued to increase, often meeting or exceeding the biological limits 
of fish populations (Burroughs 2011). This overarching trend of increased resource utilization has necessitated management actions throughout the world, but defining the course of action is often difficult. It is generally agreed that the ultimate goal of fisheries management is to maintain a balance between harvest and the limitations of the natural system to create a sustainable industry (King 2007; Burroughs 2011). Frequently, however, this balance is elusive and managers are required to decide which is more important: future use of the resource or economic and social well-being of current resource users. In order to determine the importance of ecological, economic, and social issues in management decisions, resource managers must first determine the relative importance of each sector. In his 1998 book Fisheries in Transition, Anthony Charles differentiated between four types of sustainability: ecological, socioeconomic, community, and institutional. Ecological sustainability highlights the importance of the limits on natural systems (Charles 1998). Socioeconomic and community sustainability are focused more on the economic, social, and cultural factors associated with individuals involved in the industry, while institutional sustainability considers the long-term effects on the fishing industry as a whole (Charles 1998). While theoretically, these goals are not mutually exclusive, in practice, balancing long-term ecological and social goals is often difficult. As such, it is important for managers to understand the societal values and repercussions associated with favoring alternatives.

Once the specific goals of fisheries management are delineated, direct management actions may be implemented. The management of ecological systems requires an understanding of the biological limits of the system and their role in 
fulfilling human needs (Burroughs 2011). This poses a particular issue in fisheries management because of the highly variable nature of many fish stocks, and their importance to the cultural and social well-being of coastal communities and resource users. Traditionally, fisheries management has relied on a relatively limited suite of tools designed to control the inputs into the industry and the outputs of the fishery. Traditional input controls include restrictions on fishing gear, as well as geographic and temporal restrictions on fishing activity. Output controls are more focused on the size and type of fish extracted. This includes restrictions in the total allowable catch (TAC), and limits on the size and sex of harvested fish. While these management tools are still in use today, an impetus of economic research in the mid-1900s, suggested that limiting effort may provide a more accurate means of controlling fish harvest. Management geared toward controlling the fishing effort applied to a system has gained significant attention and support over the latter half of the $20^{\text {th }}$ century. Regulations have ranged from limiting the number, size, and speed of boats allowed to enter the fishery to restricting the number of fishing days permitted.

While these tools offer useful mechanisms to manage a fishery, they have proven to be quite ineffective if implemented prior to the definition of clear management goals. If the goal of management is to emphasize ecological conservation, strict limits in output of the fishery (TAC) must be observed and the regional ecosystem must be monitored to ensure no unintentional adverse effects of harvesting are experienced. If the goal of management is to ensure the sustainability of the social, cultural, and economic well-being of coastal fishing communities and individuals, management actions should not only consider the immediate effect on the 
present community, but also the long-term effects future generations will experience. Additionally, management actions should be considered in the context of each individual within a community, present and future. If there are no fish, there can be no fishery. If there is no fishery, there can be no fishing community. Lastly, if the goal of management is to ensure industry sustainability, management goals should be considered in a broader context. It is important to consider the actions of the fishery as a whole and how the environment, individuals, and community interact within the fishery. When considered in this light, it becomes apparent that specific goals of management must be carefully weighed with the projected outcomes prior to implementation.

\subsection{Management Landscape And The Role OF Science}

The early history of fisheries management in the United States is sporadic, with isolated management actions occurring primarily at the local level and generally only implemented in response to specific concerns regarding potential stock collapse. Many of these early management actions were developed in response to concerns regarding the health of New England fisheries (Smith 1994). Prior to the development of formal, federally funded fish surveys of the 1930s, evaluations of stock health in this region were largely anecdotal and early management attempts were focused on supplementing stocks rather than the management of resource exploitation (Serchuk and Wigley 1992). Management efforts in the Western Atlantic became more focused in the period between World War I and II. During this time, haddock catches were in serious decline, eliciting increasing concern over the health of Georges Bank fish stocks. Even this concern, however, failed to result in compulsory management 
measures. While some fishermen adopted voluntary gear restrictions, no mandatory gear restrictions were implemented by national or international management bodies until 1953 (Serchuk and Wigley 1992).

A rapid increase in the amount of scientific data available to resource managers during the early 1970s spurred a dramatic increase in management efforts, resulting in seasonal and area fishery closures beginning in 1970, the first implementation of a TAC in 1973, and increases in gear restrictions in 1974 (Serchuk and Wigley 1992). The most significant management measures, however, were the result of the 1976 Magnusson-Stevens Fishery Conservation and Management Act (FCMA). Prior to the FCMA, management of fisheries off the United States coast was limited, as national jurisdiction extended only three miles (Bakkala 1993). Under the FCMA, however, the United States claimed extended jurisdiction in regards to fisheries resource management. By implementing extended jurisdiction, the US federal government claimed control of all fishery resources between 3 and 200 nautical miles offshore. The FCMA also established a total of eight regional fishery management councils, overseen by the National Marine Fisheries Service (NMFS), a branch of the National Oceanic and Atmospheric Administration (NOAA). Each council is responsible for overseeing the management of fishery resources within its jurisdiction and comprises fishery stakeholders of representative states and agencies. Among their responsibilities, the Councils are responsible for developing Fishery Management Plans (FMPs) outlining regulations and conservation measures for individual fisheries. Specifically, the FCMA outlines ten national standards which must be maintained in all management actions (Table 1). While the National Standards provide guidelines to 
be upheld in all management actions, they fail to explicitly identify the specific goals of management. As such, fishery managers are given enormous latitude in the specific actions permitted. Additionally, in order to provide technical guidance to council members, a Scientific and Statistical Committee (SSC), comprised of experts in the sciences and social sciences, was established for each region. The purpose of these committees is to play an advisory role in the decision-making process and to consult on issues of particular scientific complexity. Additionally, NMFS staff scientists, policy analysts, and legal counsel are available for consultation. 
Table 1. Magnuson Stevens Fishery Conservation and Management Reauthorization Act (2006) National Standards for fishery conservation and management.

\section{National Standard for Fishery Conservation and Management}

Conservation and management measures shall prevent overfishing while

1 achieving, on a continuing basis, the optimum yield from each fishery for the United States fishing industry.

2 Conservation and management measures shall be based upon the best scientific information available.

To the extent practicable, an individual stock of fish shall be managed as a unit 3 throughout its range, and interrelated stocks of fish shall be managed as a unit or in close coordination.

Conservation and management measures shall not discriminate between residents of different States. If it becomes necessary to allocate fishing privileges among

4 various United States fishermen, such allocation shall be (A) fair and equitable to all such fishermen; (B) reasonably calculated to promote conservation; and (C) carried out in such manner that no particular individual corporation, or other entity acquires and excessive share of such privileges.

Conservation and management measures shall, where practicable, consider

5 efficiency in the utilization of fishery resources; except that no such measure shall have economic allocation as its sole purpose.

6 Conservation and management measures shall take into account and allow for variations among, and contingencies in, fisheries resources, and catches.

7 Conservation and management measures shall, where practicable, minimize costs and avoid unnecessary duplication.

Conservation and management measures shall, consistent with the conservation requirements of the Act (including the prevention of overfishing and rebuilding of overfished stocks), take into account the importance of fishery resources to

8 fishing communities by utilizing economic and social data that meet the requirements of paragraph (2), in order to (A) provide for the sustained participation of such communities, and (B) to the extent practicable, minimize adverse economic impacts on such communities.

Conservation and management measures shall, to the extent practicable, (A)

9 minimize bycatch and (B) to the extent bycatch cannot be avoided, minimize the mortality of such bycatch.

10 Conservation and management measures shall, to the extent practicable, promote the safety of human life at sea. 
Overall, the FCMA appears to be strongly supportive of the role science plays in the development of management actions. The second National Standard specifically outlines the role of science in management. The standard states, "Conservation and management measures shall be based upon the best scientific information available". The establishment of the SSC for the express purpose of consulting on all scientific initiatives further supports the idea that science plays a strong role in fisheries management. Identifying the specific role it should play, however, is often difficult. While it is clear that policy makers recognize its importance, FCMA was structured in a way that created tension between scientific and economic goals. Indeed, following the 2006 reauthorization of FCMA, regional councils were charged with four new management goals:

1. End overfishing

2. Promote market-based fishery management approaches

3. Improve fisheries science and increase the role of science in decisionmaking

4. Enhance international cooperation with regard to fisheries management

This juxtaposition of enhancing market-based management and increasing the role of science in decision-making seems to further confuse the goals of management and demonstrates the confusion FCMA creates regarding the establishment of clear management goals. 


\subsection{The STAte OF SCIENCE IN Fisheries Management}

Management of natural resources is unique, in that often, policy makers are required to make decisions regarding the biological status of resources and implement them through the modification of human behavior. This presents a unique challenge because managers are required to understand the policy and science underlying management decisions. Historically, fisheries management techniques have been very focused on the population dynamics of commercially valuable species (Link 2002). While it may be intuitive to evaluate the health of commercially targeted fish stocks, studies have demonstrated that it is important to evaluate fisheries in a broader context (Pikitch, et al. 2004). Even in the early years of fisheries management in the US, the need to consider the effect of fisheries on the entire ecosystems was evident. Spencer Baird, the first commissioner of the US Commission of Fish and Fisheries, recognized the need to consider more than just single-species abundance. He purported that our understanding of fishery dynamics, “...would not be complete without a thorough knowledge of their associates in the sea, especially of such as prey upon them or constitute their food" (Ecosystem Principles Advisory Panel 1999). The implementation of this ecosystem approach, however, has proven to be quite difficult. Early management focused on supplementing wild stocks with hatchery-raised juveniles, and more recent management actions tend to focus on limiting the number of fish extracted rather than evaluating ecosystem impacts.

By evaluating fisheries only in terms of target species, managers have overlooked possible competing interactions as well as unintended consequences of fishing. Pikitch, et al (2004) suggested that fisheries management without a holistic 
outlook on ecosystem processes often results in habitat destruction, incidental mortality of nontarget species, shifts in morphology, or changes in ecosystem structure (Pikitch et al 2004). Researchers have noted that over $90 \%$ of the annual mortality of white marlin, a species considered by some to be threatened, is due to incidental catch in the swordfish and tuna longline fisheries (Pikitch, et al 2004). Numerous studies have demonstrated a link between the use of unrestricted bottom fishing gear and the destruction of benthic habitat (Collie, et al 2000; Hiddink, et al 2006). A 2004 study by Olsen, et al demonstrated a trend of rapid evolution of morphological characteristics in northern cod associated with increased fishing effort. Lastly, countless studies have documented instances of trophic cascades induced by overexploitation of high-level predators. An especially relevant and well-documented example of a trophic cascade is that of the Atlantic Cod (Gadus morhua) in the Northwest Atlantic, documented by Frank, et al in a 2005 analysis.

While the use of a single-species approach to management has been widely criticized as early as the 1970 s, however alternative measures have not always been apparent (Larkin 1977). Recent fisheries management research has been focused on the importance of ecosystem based fisheries management (EBFM) (Ecosystem Principles Advisory Panel, 1999; USDC, 2009). This approach requires a fundamental understanding of the workings of all levels of the ecosystem, and pays particular attention to the relationships between members of the ecosystem and between species and their environment (Pikitch, et. al. 2004). In a 1999 report to Congress, the Ecosystem Principles Advisory Panel suggested that for a comprehensive fisheries management approach, managers would be required to understand four principle 
interactions: (1) interactions between target stocks and predators, competitors, and prey species; (2) effects of climate and weather on fisheries biology and ecology, (3) interactions between fish and their habitat; and (4) effects of fishing on fish stocks and habitats (Ecosystem Principles Advisory Panel 1999). These four interactions highlight the basic units with which to consider human-induced effects on ecosystems and potential impacts of fisheries on their ecosystem.

Through the evaluation of ecosystem interactions, managers will be able to assess the effect of fisheries on the environment as a whole and determine the specific management needs of an ecosystem. Pikitch, et al. (2004) proposed four goals of EBFM:

1. Avoid ecosystem degradation

2. Minimize risks of irreversible change

3. Maintain long-term socioeconomic benefits without compromising ecosystems

4. Develop a fundamental knowledge of ecosystem processes and the consequences of human actions

While theoretically, EBFM is an admirable goal, and will surely serve to advise management in a positive direction, the implementation is often difficult. Fishery dynamics are notoriously difficult to study, with countless interactions among species, and between species and their environment (Fulton, et al 2003). Studies have demonstrated that the ability to predict ecosystem behavior is limited (Ruckelshaus, et al 2008; Walther 2010). Additionally, it has been made clear that ecosystems have 
definitive thresholds and limits, and when exceeded, major system restructuring is imminent and often irreversible (Casini, et al 2009; Ecosystem Advisory Panel 1999). This is particularly concerning considering the length of time many ecosystems have been exploited and the extent to which many have been harvested. Indeed, these observations suggest that it is essential to consider repercussions of overexploitation at the ecosystem level rather than only at the species level. This concept was supported in the 2006 Magnuson Stevens Fishery Conservation and Management Reauthorization Act. The reauthorization charged managers to determine the "state of science for advancing the concepts and integration of ecosystem considerations in regional fishery management" (Section 406).

The implementation of an EBFM, however, has proven to be difficult for resource managers to accomplish. The current state of fisheries science is one of development and transition. Huge strides in our understanding of fish life history and ecology are being made daily, and laboratories across the world have sought to answer many of our fundamental questions regarding fisheries biology and ecology. The combined effect of difficult study conditions and changing climate, however, has made this research particularly difficult. Without a strong scientific backbone to support an ecosystem based approach, implementation of this type of management system is difficult. In a 2009 report to Congress, the National Marine Fisheries Service (NMFS) highlighted the need for increased scientific research to support the goals of EBFM. Specifically, NMFS highlight the need to gain a fundamental understanding of basic ecosystem principles and how environmental variation affects fish stocks (USDC 2009). Many scientists have attempted to elucidate this link, however the 
relationship remains unclear for many federally managed fisheries (Hinckley, et al 1996; Pauly, et al. 2002; Attrill et al. 2002). While the implementation of EBFM has been difficult, there are several fisheries throughout the world that are currently being managed using many of the principles of EBFM (Ruckelshaus, et al 2008). While these management models generally do not incorporate all of the elements of EBFM, they modify the principles according to what is currently known (Ruckelshaus, et al 2008).

\subsection{Diversity AS An ECOSYSTEM ASSESSMENT ToOL}

Laboratories focused on the development of EBFM systems have evaluated a wide variety of interactions and characteristics to determine management deficiencies and needs. Much of this research has suggested that diversity is likely to be an important component of ecosystem health. Recent studies have illustrated the importance biodiversity plays in the resilience of biological systems as well as a variety of other ecosystem services (Jones, et. al. 2007; Worm, et. al. 2006). Worm, et al. (2006) noted a correlation between increased biodiversity and ecosystem resiliency, including resistance to overfishing and increased recovery potential. Additional studies focused on declines in biodiversity have demonstrated significant reductions in ecosystem resilience and subsequent environmental forcing resulting in instability (Folke, et. al. 2004). Additionally, the importance of marine biodiversity in various ecosystem functions, services, and goods has been documented (Table 2). By considering biodiversity as a measurement of ecosystem health and function, resource managers may be provided with a more holistic representation of fishery dynamics and allow for more effectively guided management action. 
Table 2. The role marine biodiversity in sustaining ecosystem functions, services, and goods. From Heip, et al. 1998.

\begin{tabular}{|lc|}
\hline Ecosystem Functions & $\begin{array}{c}\text { Role of Marine } \\
\text { Biodiversity }\end{array}$ \\
\hline Primary production & High \\
Carbon storage & Low \\
Carbon flow to higher trophic levels & High \\
Nutrient cycling & High \\
\hline Ecosystem Services & Low / Medium \\
\hline Gas and climate regulation & High \\
Disturbance regulation & Medium / High \\
Erosion and sedimentation control & High \\
Remineralization & High \\
Waste treatment and disposal & High \\
Biological control of nuisance species & High \\
Monitoring of global change and bio- & High \\
indication of ecosystem health & \\
Recreation, tourism, and education & High \\
\hline Ecosystem Goods & High \\
\hline Habitat and refuge & High \\
Food resources & High \\
Raw materials & High \\
Genetic resources & \\
Natural heritage & \\
\hline
\end{tabular}

The concept of marine diversity has garnered significant attention since the 1950s. Studies have evaluated the relative importance of diverse systems and have identified global trends in diversity (Sanders 1968; Gray 2001). Overwhelming evidence has supported two primary observations: (1) marine diversity is the highest at the tropics and decreases poleward, and (2) marine diversity tends to increase with 
depth and bathymetric complexity (Gray 2001). It is important, however, to consider diversity in a broader context than only global changes in species composition. Biodiversity may be evaluated at the population level by examining the length diversity of a population. For the purposes of this study, length diversity is defined as the variance in fish length within a population. In contrast, it is also possible to evaluate species diversity at the community level by quantifying the species diversity. Species diversity is a general term to describe the number of species present in a population, however several indices of species diversity incorporate measurements of relative abundance and species evenness (Vellend and Geber 2005). Studies and hypotheses have suggested that anthropogenic disturbances to marine communities are likely to cause changes in both length and species diversity.

Changes in length diversity are quantified by measuring changes proportion of large- and small-bodied individuals within a population over time. In fisheries research, phenotypic forcing has been witnessed in the body size of commercially targeted species. Studies have demonstrated that commercially exploited fish populations frequently reach maturation at an earlier age and smaller size than natural populations (Law, 2000; Trippel 1995; Kuparinen and Merila 2007). Olsen, et al. (2004) demonstrated that prior to the collapse of the Canadian Atlantic cod fishery in the early 1990s, regional cod stocks had been experiencing a shift toward earlier maturation and smaller size. Furthermore, the researchers statistically accounted for confounding variables including differential mortality and phenotypic plasticity, suggesting that the observed changes in body size were directly influenced by fishing mortality (Olsen, et al 2004). Laboratory studies have further supported the hypothesis 
of fishery induced shifts in fish length specta. Conover, et al. (2009) performed a laboratory-based simulation of the effects of size-selective fishing mortality. Results indicated that within five generations, two-fold differences in weight and length between exploited and natural populations are possible (Conover, et al. 2009). Together, this evidence clearly documents changes in the length spectra in exploited populations.

Numerous studies have also documented changes in the structure of demersal communities as a result of fishing pressure. In a 1988 study, Pauly documented the structural changes to a groundfish community in the Gulf of Thailand following the rapid expansion of a trawl fishery. Pauly described a steep decline in the abundance of large, long-lived fishes and observed a simultaneous increase in invertebrate abundance (Pauly 1988). A study of the Georges Bank groundfish community revealed a dramatic shift in dominant species following an increase in fishing effort during the 1960s and 1970s (Fogarty and Murawski 1998). Fogarty and Murawski (1998) demonstrated a shift from a gadoid and flatfish dominated system to a system dominated by small elasmobranchs following this increased fishing effort. Analyses suggested that this shift was likely to be a second-order effect of reduced gadoid and flatfish abundance, creating decreased competition (Fogarty and Murawski 1998). Lastly, in an evaluation of the changes in community structure of the North Sea, Rijnsdorp, et al. (1996) compared species diversity in the period between 1906-1909 and 1990-1995. The researchers reported a decrease in species diversity and evenness and a trend of decreasing body size in flatfish and roundfish (Rijnsdorp, et al. 1996). These observed shifts in community structure suggest that the exploitation of these 
ecosystems is capable of generating severe and potentially lasting impacts on demersal community structure and species diversity.

With increasing attention being paid to these issues of anthropogenic community changes, several policy directives have emerged supporting the use of biodiversity in management efforts. At the international level, several political actions have been initiated to promote the importance of sustaining marine biodiversity. In 1993 the Convention on Biological Diversity (CBD) entered into force with the goal of ensuring the worldwide protection and conservation of biological diversity (CBD 2011). Parties to the convention include the United States, all European Union states and 166 additional countries (CBD 2011). At the tenth meeting, the Conference of Parties to the CBD adopted a new ten-year plan for biodiversity management. The plan includes 20 Aichi Biodiversity Targets to achieve by the year 2020. Among these is Target 6:

"By 2020 all fish and invertebrate stocks and aquatic plants are managed and harvested sustainably, legally, and applying ecosystem based approaches so that overfishing is avoided, recovery plans and measures are in place for all depleted species, fisheries have no significant adverse impacts on threatened species and vulnerable ecosystems and the impacts of fisheries on stocks, species and ecosystems are within safe ecological limits" (CBD 2010)

These targets were further elucidated at the Sixteenth Meeting of the Subsidiary Body on Scientific, Technical, and Technological Advice (SBSTTA) of the CBD. The SBSTTA has highlighted the need for further improvements in current fisheries management worldwide and commented on the importance of implementing EBFM in all fisheries worldwide (SBSTTA 2012). 
In October of 1995, the Food and Agriculture Organization (FAO), a division of the United Nations (UN) passed a resolution instituting a Code of Conduct for Responsible Fisheries (FAO 1995). The Code of Conduct was developed in collaboration with member states and fishery management experts to describe the general principles of responsible fisheries, as well as guidelines for the responsible operation and management of fisheries conducted by all member states (FAO 1995). The Code of Conduct expressly states that responsible fisheries management should consider the maintenance of present and future biodiversity. Additionally, mandates regarding management actions provide that "biodiversity of aquatic habitats and ecosystems is conserved... [and] adverse environmental impacts on the resources from human activities are addressed and, where appropriate, corrected." (FAO 1995, 7.2.2)

In the United States, the incorporation of biodiversity-based measures in marine policy is not as clearly defined. In an effort to proactively deal with issues of overfishing and habitat degradation, Congress mandated the formation of the Ecosystem Advisory Panel, a group organized by NMFS to assess the science supporting EBFM and develop recommendations for its incorporation into national policy. In a 1999 report to Congress, the Panel concluded that the use of ecosystem principles is essential in the management of fishery resources. To aid in the achievement of EBFM in United States fisheries, the Panel outlined eight principles of ecosystem operation which should be considered in the development of goals focused on ecosystem sustainability. In particular, the Panel recognized that, "diversity is important to ecosystem functioning" (Ecosystem Advisory Panel 1999, 1). Furthermore, the Panel recommended that all fisheries should be governed by regional 
Fisheries Ecosystem Plans (FEP), designed to incorporate the effect of fishing pressure on all aspects of the ecosystem. As a component of the FEP, the report called for the development of indices of ecosystem health, specifically stating the importance of biodiversity in these measures. The report summarized their findings by claiming that, "because we cannot currently predict all of the ecosystem effects of fishing, we should be watching for evidence of such changes so that it is possible to react if the changes are adverse..." (Ecosystem Advisory Panel 1999, 35). Overall, it is clear that the international community believes in the importance of sustaining biological diversity in exploited ecosystems. The specific changes within ecosystems and the methods employed to monitor and sustain diversity, however, remain unclear.

\subsection{GEORGES BANK GROUNDFISH FISHERY}

In New England, fishing has played an important role in regional history. Colonization of the area in the 1600s was greatly dependent on the coastal fisheries of Maine and Massachusetts (Serchuk and Wigley 1992). In his diary, one colonist of Cape Cod observed that "...the schools of mackerel, herrings, cod, and other fish that we daily saw as we went and came from shore were wonderful...” (Brereton 1972). By the early 1700s, New England fishermen had established an offshore industry, with the first excursion to Georges Bank occurring in 1748. The historic fishing grounds of Georges Bank are located in the Northwest Atlantic between Cape Cod, Massachusetts and Nova Scotia (Figure 1). Of particular significance is the Georges Bank cod fishery, which has accounted for more catches (by weight) than any other groundfish in the region (Serchuk and Wigley 1992). Indeed, some argue that the cod has influenced American history more than any other species of fish (Ryan 1979). 


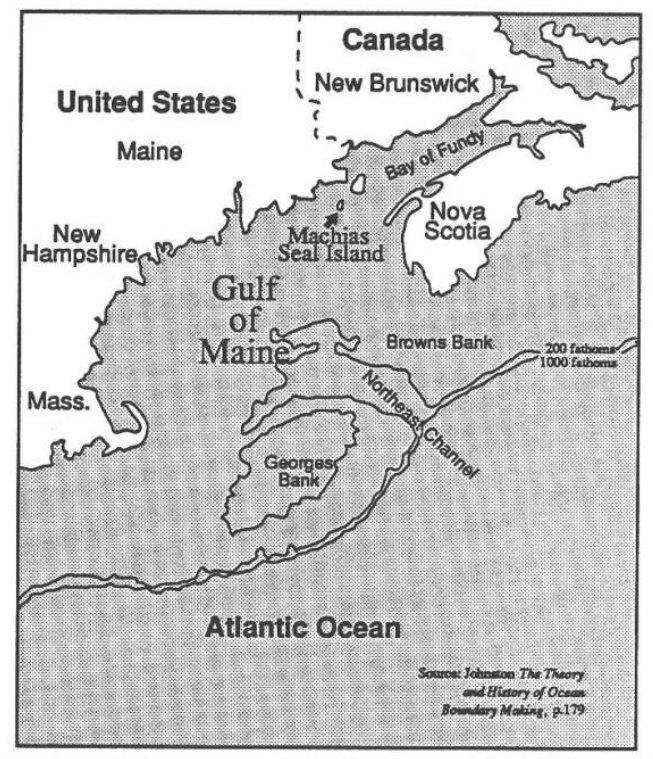

Figure 1. Map of Georges Bank. Source: Johnston 1988

In the Northeast United States, the groundfish industry remains relatively small-scale with strong generational transfers of occupation (NEFMC 2011). As such, the New England groundfish fleet remains a small, yet profitable industry using a broad range of gear types, including hook, longline, gillnet, and trawlers (NEFMC 2011). The groundfish ex-vessel value of the fleet was nearly $\$ 60$ million in 2009 , providing income to over 100 coastal communities. In 2010, 1,347 vessels were issued limited access groundfish permits, however only 450 of those vessels generated revenue from a groundfish trip (Kitts, et. al. 2012).

Prior to 1976, the Georges Bank groundfish fisheries were dominated by foreign, offshore, factory trawlers (Anderson 1998). The implementation of the Magnuson-Stevens Fishery Conservation and Management Act (FCMA) in 1976 resulted in a dramatic shift in both fishing effort and management. Distant-water fleets were virtually eliminated from New England waters. Factory trawlers were 
replaced with numerous, technologically advanced steel stern-trawlers (NEFSC 2011). Early management by the New England Council primarily focused on the expansion of domestic fishing fleets while maintaining the "traditional freedom and flexibility of fishermen" (Whitmore 2010). During this time government programs offering lowinterest financing for the construction of new fishing vessels were available to US fishermen (NEFSC 2011). As a result of these policies, between 1976 and 1984 trawling effort doubled (NEFSC 2011). The first groundfish FMP was developed in 1985 with the goal of implementing "initial measures to prevent stocks from reaching minimum abundance levels, defined as those levels below which there is an unacceptable high risk of recruitment failure" (NEFMC 1985). The Council initially used a management system inherited from prior international groups, primarily utilizing a TAC, limited gear restrictions, and unenforced fishery closures, however, in an attempt to alleviate fear of early closures, the Council began to implement input controls, designed to limit fishing effort. The application of gear regulations, minimum fish sizes, and seasonal closures, however, proved relatively ineffective, as fishing effort continued to increase while landings decreased. In 1994, Amendment 5 to the NE Groundfish FMP was implemented. This amendment served to restrict access to the fishery, established the days-at-sea (DAS) program, which limited the number of days a vessel was able to fish, and instituted daily trip limits for groundfish landings (NEFMC 1993; Whitmore 2010). The 1996 passage of the Sustainable Fisheries Act further magnified the issue of overfishing and highlighted the need to reduce fishing effort and end overfishing. (Whitmore 2010). 
Until 2010, the NE Groundfish Fishery had primarily been managed with soft quotas, gear restrictions, minimum fish size, closed areas, and DAS. Amendment 13 to the NE Groundfish FMP, implemented in 2004, introduced a new management concept: sectors. A pilot sector management program began shortly thereafter. The Sector Management system was expanded in 2010 under Amendment 16. This amendment allowed all fishermen to voluntarily establish sectors, a concept similar to a fishermen's cooperative. Fishermen choosing not to enroll in a sector are managed under the previous effort controls which include trip limits, seasons, and closed areas (Kitts, et. al. 2011). In 2010, the first year of the extended Sector program, nineteen sectors operated, representing $54 \%$ of the total groundfish permits issued and $98 \%$ of the historical fishing effort of the region (Kitts, et. al. 2011).

Currently, the status of Northeast groundfish stocks is precarious. By the early $20^{\text {th }}$ century it had become clear that fish stocks were declining (Smith 1994). In a 2010 report to Congress, NMFS estimated that $33 \%$ of New England fish stocks are currently subjected to overfishing (Table 3 ). Of the principal groundfish species, Atlantic cod has historically been among the most economically and socially important (Serchuk and Wigley 1993). Atlantic cod stocks, which were once among the most abundant species in the region, now represent only $5-10 \%$ of the regional biomass - a decrease of 25-30\% from historic levels (Link, et. al. 2008). Georges Bank yellowtail flounder, another commercially valuable species in the groundfish fishery, has also experienced a dramatic decline recently. A past assessment had resulted in the estimate of a very strong 2005 year class (Legault, et. al. 2011). More recent assessments, however, have suggested that this was an overestimation. 
Additionally, the 2007-2008 year-classes yielded only moderate numbers and the 2009 year-class is the weakest in the available time-series (Legault, et. al. 2011). These findings have led to growing concern regarding the GB yellowtail population in addition to the cod stock (NEFMC 2012c). The status of other groundfish stocks is not as uniform. Several species, including Acadian redfish and American plaice are currently recovering from overfished states, while others, including Georges Bank haddock and pollock are not overfished and overfishing is not occurring. Research suggests that for the Georges Bank ecosystem to return to their pre-fishing assemblages, a dramatic change in the system's energy flow would be necessary (Collie, et. al. 2009). 
Table 3. Georges Bank (GB) stock statuses of the species managed under the Northeast Multispecies Groundfish FMP. Source: NMFS 2012a.

\begin{tabular}{|c|ccc|}
\hline Species & Stock & $\begin{array}{c}\text { Overfishing? } \\
\text { Fishing mortality is } \\
\text { above threshold }\end{array}$ & $\begin{array}{c}\text { Overfished? } \\
\text { Biomass is below } \\
\text { threshold }\end{array}$ \\
\hline Acadian Redfish & GB & No & No (rebuilding) \\
American Plaice & GB & No & No (rebuilding) \\
Atlantic Cod & GB & Yes & Yes \\
Atlantic Halibut & NW Atlantic & No & Yes \\
Haddock & GB & No & No \\
Ocean Pout & NW Atlantic & No & Yes \\
Offshore Hake & NW Atlantic & Unknown & Unknown \\
Pollock & GB & No & No \\
Red Hake & GB & No & No \\
Silver Hake & GB & No & No \\
White Hake & GB & Yes & Yes \\
Windowpane Flounder & GB & Yes & Yes \\
Winter Flounder & GB & No & No (rebuilding) \\
Witch Flounder & NW Atlantic & Yes & Yes \\
Yellowtail Flounder & No & Yes \\
\hline
\end{tabular}

\subsection{EASTERN BERING SEA GROUNDFISH FiSHERY}

Alaskan fisheries, including those in the Northwest Pacific and Bering Sea, are generally considered to be among great success stories in fisheries management and are characterized by what is generally considered a more sustainable level of fishing pressure (Hilborn 2007; Hall and Mainprize, 2004). Contributions of these commercial fisheries have also played an important role in Alaskan history. Economist George Rogers even declared that, "fisheries was the key to statehood..." (State of Alaska 
2009). Currently, Alaska is one of the world's leading seafood producers, with only eight countries producing greater harvests (Goldsmith 2008). In 2011, Alaskan catches were greater than 2 million metric tons, much of which was extracted from the Eastern Bering Sea (Fissel, et al. 2012). Additionally, economists estimate that these fisheries create between 38,000 and 53,000 jobs within the state (Goldsmith 2008; Warren 2010). The importance of Alaskan commercial fisheries is clear and the continued success of the industry leads many experts to cite it as a prime example of successful fisheries management (Hilborn 2007).

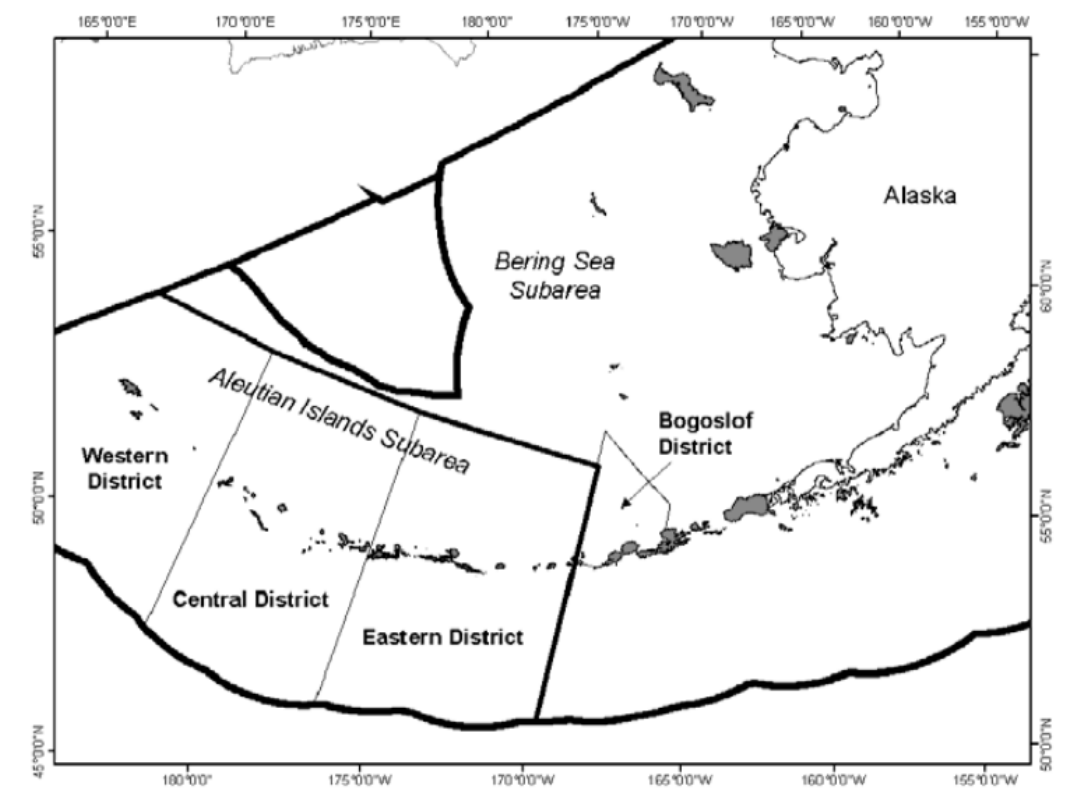

Figure 2. Alaskan groundfish fishery management areas. The northern extent of the region is managed according to the Bering Sea/Aleutian Islands FMP. The southern extent, east of the Eastern Aleutian Islands Subarea is managed according to the Gulf of Alaska FMP. Source: NPFMC 2012.

The Eastern Bering Sea fishing industry is dominated by the groundfish fishery (Figure 2). In 2011, the Alaskan commercial fleet caught 2.07 million metric tons, an increase of $30 \%$ from catches in 2010 . Annually, these landings are roughly five times higher than all other species combined and account for approximately $49 \%$ of the exvessel value of all Alaskan commercial fisheries (Fissel et al. 2012). In 2011, 275 
vessels were actively fishing federal TAC allotments (Fissel et al. 2012). Most vessels tend to be large, the majority greater than 90 feet in length, however the majority of trawling vessels unaffiliated with the pollock fishery tend smaller (Witherell, et al. 2012). The highly industrialized nature of the pollock fishery has led to the development of a relatively specialized fleet, consisting of two types of harvesting vessels and several categories of support vessels (Table 4). Catcher vessels are those used only for harvesting fish. Catcher/Processor vessels are those used for (or equipped to be used for) both harvesting and processing fish to make it suitable for consumption, use, or storage. The majority of groundfish are caught using bottom trawl gear, however, hook and line and pots are also used (Fissel et al. 2012). The majority of groundfish fishing vessels in the Bering Sea and Aleutian Islands are owned by out-of-state interests, primarily from the Pacific Northwest (Fissel et al. 2012).

Table 4. AFA vessel categories for the Bering Sea/Aleutian Islands pollock fishery.

\begin{tabular}{c|l|} 
Catcher Vessel & $\begin{array}{l}\text { Vessel that is used for catching fish that does not process fish } \\
\text { on board }\end{array}$ \\
\hline \multirow{2}{*}{ Catcher/Processor } & $\begin{array}{l}\text { Vessel that is used for, or equipped to be used for catching fish } \\
\text { and processing that fish }\end{array}$ \\
\hline Mothership & $\begin{array}{l}\text { Vessel that receives and processes groundfish from other } \\
\text { vessels and are not equipped to catch groundfish }\end{array}$ \\
\hline
\end{tabular}

Overall, the commercial fishing industry is the largest private employer in the State of Alaska (Sepez, et. al. 2005). In recent decades, however, the fishing industry, including fishing, processing, transportation, and dock/harbor work, has declined. Between 1993 and 2003, employment in commercial fishing declined from 32,000 jobs to 17,500 jobs, representing a loss of $55 \%$ and the average crew member employment has declined to only 1.8 years (Sepez, et. al. 2005). It is important to note 
however, that the jobs created by this rationalized fishery are generally more permanent, relying on year-round rather than seasonal employees, than those of the prior derby fishery (J. DiCosimo, pers. comm. 15 Aug 2012). Crews are primarily composed of men (86\%), and most are either Alaskan (59\%) or Washington residents (29\%) (Sepez, et. al. 2005). Fish processing alone generates an estimated 18,675 jobs annually, representing \$235.9 million in wages in 2000 .

Commercial exploitation of the Eastern Bering Sea groundfish began in 1864, when the first sailing schooner entered the region in search of Pacific cod (Bakkala 1993). By 1882, an annual cod fishery had been established (Bakkala 1993). Throughout the 1920s and 1930s, commercially exploited species in the Eastern Bering Sea grew to include a Pacific halibut, walleye pollock, and yellowfin sole (Bakkala 1993). Each of these fisheries, however, remained relatively small-scale until the mid-1950s (Bakkala 1993). In 1954, Japan commenced a large-scale distant-water fishery operation targeting groundfish in the Eastern Bering Sea (USDC 2004). This effort represented the first instance of industrialized, at-sea processing in the region. Fishing effort increased throughout the 1950s and 1960s, with several other nations, including the United Soviet Socialist Republic (USSR) the Republic of Korea, Taiwan, Poland, Germany, and Portugal, commenced distant-water fishing operations (USDC 2004). By the early 1970s, declines in catch became evident and were presumed to be due to unsustainable fishing pressure (Bakkala 1993). Throughout this period, management of commercial catches was limited and was primarily established by individual countries (Bakkala 1993; USDC 2004). In the mid-1970s, the US became party to bilateral agreements with the USSR and Japan which established 
catch quotas and some seasonal and area closures, to be monitored and enforced by respective countries (USDC 2004).

The passage and implementation of FCMA in 1976 represented a dramatic milestone in Bering Sea fishery management. By 1977, preliminary groundfish FMPs had been established, specifying optimum yields for nine demersal species including walleye pollock, Pacific cod, and flatfish (USDC 2004). These initial management plans allocated fishing privileges to Japan, the USSR, South Korea, Taiwan and Poland, however by 1987 foreign fishing in the region had been virtually eliminated (USDC 2004). On January 1, 1982, the North Pacific Fishery Management Council (NPFMC) implemented the first groundfish FMP (USDC 2004). The initial FMP was focused primarily on three goals: (1) setting sustainable harvest limits on target species, (2) controlling bycatch, and (3) ensure social, economic, and environmental benefits. To support these goals, the NPFMC outlined a series of provisions including the establishment of total allowable catch (TAC) for each species, temporal and area closures, and compulsory monitoring and reporting (Bakkala 1993). The implementation of FCMA, also served to effectively limit distant-water fishing operations in the region (Bakkala 1993). The Act prohibits foreign fishing in the fishery management zone unless prior authorization and permitting has been sought (USDC 2004). Additionally, only excess TAC, unharvested by US flagged vessels is available to foreign fishing operations in the US EEZ (NPFMC 2012).

Throughout the 1980s and 1990s, management of Alaskan fisheries included provisions designed to promote national fishing interests and limit foreign fishing effort (USDC 2004). Particularly noteworthy was the implementation of Amendment 
12 in 1989, which implemented a limited access scenario, requiring all vessels to acquire appropriate permits for all fishing activity in the Bering Sea (NPFMC 2012). The same year, an early closure of the pollock fishery near the Shelikof Strait following very high catches by the offshore catcher/processer fleet (USDC 2004). This early closure of the fishery effectively prevented the inshore fishing and processing sector from realizing its expected profit (USDC 2004). This initiated a battle between the inshore and offshore processing sectors and inspired managers to consider measures to ensure the viability of both sectors (USDC 2004). To further highlight the need for sector allocations, the NPFMC estimated that by 1991 there was enough fishing capacity to harvest and process almost double the annual TAC (Criddle 2008).

In 1992, the NPFMC enacted Amendment 18, which specifically allocated the annual TAC to inshore and offshore processing components of the walleye pollock and Pacific cod fisheries. Allocation battles continued throughout the 1990s, leading to growing concern in the commercial fleet. Between 1994 and 1998, half of the catcherprocessor vessels targeting groundfish either declared bankruptcy or were forced to sell out of the fishery (APA 1999). To address the increasing concern regarding the inshore-offshore allocations, a coalition was formed consisting of US fishing vessels associated with both the inshore and offshore sectors (Criddle 2008). This coalition took the issue to the Congressional level and eventually resulted in the passage of the American Fisheries Act (AFA) of 1998 (Criddle 2008). Goals of the AFA are all directly related to the management of walleye pollock resources and include the limitation of access to fishing and processing sectors, the creation of fishery 
cooperatives, and the continued monitoring of resources. Specifically, AFA provisions requirements include:

1. A minimum of $75 \%$ US controlling interest of all fishing vessels

2. Moratorium on new entries to the pollock fishery

3. The buyout of unused fishing capacity

4. Inshore/offshore allocation scheme

5. Increased observer coverage

6. Quasi-individual fishing quota (IFQ) program for the processing sector

7. Share accumulation caps

In essence, the AFA created a limited entry program for the pollock fishery and specified TAC allocations to sectors of the fishery. Initial reports of the AFA functioning suggest that the legislation has resulted in increased utilization rates and economic returns, decreased bycatch, and increased management precision (Criddle 2008).

The remainder of Bering Sea groundfish trawlers is managed under the Amendment 80 catch share program. Amendment 80, implemented in July of 2007, allocates all non-pollock groundfish species among the Bering Sea trawl sectors (NPFMC 2012). Vessels in the non-AFA fleet primarily target Pacific cod (Witherell 2012). Amendment 80 also included provisions protecting non-AFA vessels from encroachment by the AFA pollock industry. Sideboard limits were established which essentially prevent AFA vessels from harvesting a large portion of the non-pollock groundfish TAC (Witherell 2012). 
While historically, the distant-water fishing fleet is believed to have contributed to dramatic declines in groundfish abundance, currently all thirteen species and complexes managed under the Bering Sea/Aleutian Islands Groundfish FMP are considered healthy (Table 5). None are currently overfished, having a biomass greater than minimum stock size threshold (MSST), nor are they experiencing overfishing, having a fishing mortality below maximum fishing mortality threshold (MFMT).

Table 5. Eastern Bering Sea stock statuses of species managed under the Bering Sea/Aleutian Islands Groundfish FMP. Stocks with ranges covering the Bering Sea and Aleutian Islands (BSAI) and stocks with a range limited to the Eastern Bering Sea (EBS) are indicated. Source: NMFS 2012a.

\begin{tabular}{|clcc|}
\hline Species / Species Complex & Stock & $\begin{array}{c}\text { Overfishing? } \\
\text { Fishing mortality is } \\
\text { above threshold }\end{array}$ & $\begin{array}{c}\text { Overfished? } \\
\text { Biomass is below } \\
\text { threshold }\end{array}$ \\
\hline Alaska Plaice & BSAI & No & No \\
Atka Mackerel & BSAI & No & No \\
Arrowtooth Flounder Complex & BSAI & No & No \\
$\begin{array}{c}\text { Blackspotted and Rougheye } \\
\text { Rockfish Complex }\end{array}$ & BSAI & No & No \\
$\begin{array}{c}\text { Flathead Sole Complex } \\
\text { Rock Sole Complex }\end{array}$ & BSAI & No & No \\
Greenland Halibut & BSAI & No & No \\
Northern Rockfish & BSAI & No & No \\
Pacific Cod & BSAI & No & No \\
Pacific Ocean Perch & BSAI & No & No \\
Walleye Pollock & BSAI & No & No \\
Yellowfin Sole & EBS & No & No \\
Sablefish & BSAI & No & No \\
\hline
\end{tabular}




\section{METHODS}

\subsection{DATA}

\subsubsection{Georges Bank}

\subsubsection{Demersal Communities}

To evaluate community structure on Georges Bank, data from the Northeast Spring Bottom Trawl Survey were evaluated. The Northeast Spring Bottom Trawl Survey is an annual, fishery-independent study conducted by the Northeast Fishery Science Center (NEFSC) of the National Marine Fisheries Service (NMFS). This dataset, beginning in 1968, represents one of the longest running, scientifically managed, fishery-independent surveys of the region (Survey Working Group 1998). While the Autumn dataset has frequently been utilized more commonly in relative abundance analyses, the Spring dataset was employed in the present study due to its increased sensitivity to juvenile abundance and to maintain a more consistent comparison with the Eastern Bering Sea data (Survey Working Group 1998).

Trawls were conducted aboard either the R/V Albatross IV or R/V Delaware II, both mid-sized stern trawlers (Survey Working Group 1998). Between 1973 and 1981 a modified 41 Yankee trawl was used, and since 1982 a standard 36 Yankee

trawl has been employed (Survey Working Group 1998). All trawls have utilized a $1.25 \mathrm{~cm}$ mesh and roller gear (Survey Working Group 1998). The Spring Bottom Trawl Survey employs a stratified random sampling design where stations are allocated to strata in rough proportion to area. Stations are randomly assigned to specific locations within each stratum. For each trawl, species composition and length 
distribution data is collected. The present study evaluated thirty six years of data (1975-2011) from stations geographically located on Georges Bank.

The gear and vessels used in this survey have not remained constant over the duration of the program, however the NEFSC has standardized all results to provide reasonably consistent measurements of species abundance (Survey Working Group 1998). Statistical analysis of the standardization methods have supported their continued use, as they maintain a high correlation with sample statistics and frequently yielded reduced standard error from untransformed data (Survey Working Group 1998). Survey data are considered to be the most accurate regarding demersal species abundance, and are considered acceptable for management applications (Survey Working Group 1998). Studies suggest, however, that the precision of data for flounder species may be lower than other demersals due to the sampling methodology (Survey Working Group 1998). For the purposes of this study, issues regarding flounder capture are not likely to adversely affect results because absolute changes in flatfish abundance will not be discussed. Instead, all comparisons will be in terms of relative abundance between years.

\subsubsection{Fishing Effort}

A dataset of demersal fishing effort was provided by the NEFSC. In this dataset, fishing effort is defined as the number of standard days fished for demersal species on Georges Bank. This demersal effort data was available for thirty four years (1977-2010). 


\subsubsection{Commercial Landings}

Commercial landings data was obtained from the National Marine Fisheries Service regional landings database. Annual landings data for the New England region was used. Historically, Georges Bank fisheries have accounted for more catch by weight than any other regional groundfish fishing grounds (Serchuk and Wigley 1993). As such, this landings data is likely to be an adequate proxy for Georges Bank populations.

\subsubsection{Climate}

To evaluate the effect of climate change on community composition and fishery landings, a series of climate indices were used. Of particular interest were datasets describing environmental factors typically associated with climate change. Georges Bank bottom temperature readings were obtained from the NEFSC Spring Bottom Trawl Survey. Annual mean bottom temperatures were calculated from all available Georges Bank data. To supplement these data, an index of global surface temperature was utilized. This dataset provides an estimate of global surface temperature anomalies relative to a baseline period of 1951-1980. Global temperature data was accessed from the Earth Systems Research Laboratory of the NOAA. An index of North Atlantic Oscillation (NAO) was used to evaluate longer-term cyclic changes in climate. The NAO is strongly correlated to weather variability in the North Atlantic, particularly in winter and spring months. As such, its use in determining climate variability associated with the Northeast Spring Bottom Trawl Survey is likely significant. The NAO Index was obtained from the Climate Prediction Center of the National Weather Service. Lastly, a dataset of the annual number of storms in the 
North Atlantic was evaluated. Recent studies have suggested that an increased number of storms on fish nursery grounds may affect species recruitment (Helbig, et al 1992; Checkley, et al 1988). As such, annual number of North Atlantic storms was evaluated. This dataset was obtained from the NOAA Earth System Research Laboratory.

\subsubsection{Eastern Bering Sea}

\subsubsection{Demersal Community}

To evaluate community structure in the Eastern Bering Sea (EBS), data from the Alaska Fishery Science Center (AFSC) Eastern Bering Sea Trawl Survey was used. The EBS Trawl Survey is an annual, fishery-independent survey conducted by the AFSC, a branch of NMFS. The survey covers 140,350 square nautical miles of the EBS continental shelf between St. Mathew's Island $\left(60^{\circ} 50^{\prime} \mathrm{N}\right)$ and the Alaska Peninsula at depths ranging from 20 to $200 \mathrm{~m}$. Beginning in 1971, the EBS annual bottom trawl survey provides one of the most comprehensive fishery-independent datasets of Alaskan demersal community composition.

The survey is conducted each summer, utilizing two chartered fishing vessels covering roughly the same area. Trawls are conducted in thirty minute intervals within $20 \times 20$ nautical mile sampling grids to encompass a total of 376 stations. The overall sampling density for the region equates to roughly one station per $1,322 \mathrm{~km}^{2}$. In the regions surrounding St. Matthew and the Pribilof Islands, high density sampling occurs to provide a more comprehensive assessment of community composition. Due to concerns regarding groundfish migratory behavior, all surveys are completed from east to west. Surveys are conducted utilizing standard 83-112 Eastern otter trawls with 
chain extensions on the lower wing at a target tow speed of $1.54 \mathrm{~m} / \mathrm{sec}$. For each trawl, species composition, length distributions, and age structure data are collected. Rather than collecting abundance data, as in the Northeast Bottom Trawl Survey, the EBS Survey records data in terms of relative abundance. All data are reported in the relative units of catch per unit effort (CPUE). Mean CPUE for was calculated as number per hectare. For each trawl, the total area surveyed was calculated by multiplying the distance towed by the mean net opening during the trawl. The present study evaluated twenty nine years of data (1982-2011).

\subsubsection{Fishing Effort}

Fishing effort was evaluated from an index of bottom trawl fishing effort in the Bering Sea developed by the AFSC. Fishing effort was defined as the number of observed trawls in the Bering Sea bottom trawl fishery. This is assumed to be representative of the majority of groundfish fishing effort in the region due to regulations mandating $100 \%$ observer coverage for all vessels greater than $49 \mathrm{~m}$ in LOA and more limited coverage on smaller vessels (Witherell, et al 2000). Studies have demonstrated that this observer coverage data provides an accurate assessment of the fishery (Witherell, et al 2000). The bottom trawl effort data was available for nineteen years (1990-2008).

\subsubsection{Commercial Landings}

Commercial landings data was obtained from the NMFS regional landings

database. Annual landings data for the Alaska region was used. As landings from the Gulf of Alaska region are generally considered to be nominal in comparison and have 
remained relatively constant during the present study period, this data is assumed to be representative of landings from the Eastern Bering Sea alone (DiCosimo 2001).

\subsubsection{Climate}

To evaluate the effects of climate change on changes in community composition and fishery landings, a series of climate indices were used. Several measurements of temperature were obtained. Annual mean bottom and sea surface temperature readings from the AFSC EBS Trawl Survey were calculated. The Alaskan Index is a measure of atmospheric circulation related to ice cover variations and storm frequency in the Bering Sea. Alaskan Index values compare annual measurements of the Alaskan center strength with a baseline. Positive values of the Alaskan Index indicate periods of more frequent storms and increased ice cover in the Bering Sea (Fang and Wallace 1994). Lastly, ice cover and retreat also represent a significant environmental and climatological presence in the EBS ecosystem. As such, an index of both ice cover and ice retreat were evaluated. The ice cover index compares annual ice cover to the mean ice cover of 1981-2000 and generates an index of anomalies. Negative values indicate reduced ice cover relative to the mean. Positive values indicate increased ice cover relative to the mean. The ice retreat index is calculated as the number of days with ice cover after March 15th at an oceanographic reference point, Mooring $2\left(56.9^{\circ} \mathrm{N}, 164.1^{\circ} \mathrm{W}\right)$. Both the ice cover and ice retreat indices are accessible through the Bering Sea Climate Website.

\subsection{LENGTH DiVERSITY}

To evaluate the diversity within species, changes in the size composition of species were evaluated. To evaluate overall changes in fish size, all records of length 
for all species and years were divided into quartiles. Using the length ranges associated with each quartile, the number of fish within each range and the percentage of the total catch was calculated annually. Mean and maximum lengths were calculated annually for each ecosystem. Changes in fish sizes were also evaluated for individual species. The nine species and species complexes of greatest commercial importance to each region were identified according to the 2011 annual catch reports (Table 6, Table 7). In each ecosystem, the three species/complexes with the highest catch were evaluated for changes in length distributions. For each species complex, the length ranges were established according to the quartile method described previously. Number and percentage of fish per quartile, mean length, and maximum length was calculated annually for each species. 
Table 6. Principal species of commercial importance in the Northeast United States, 2011. Species complexes include a list of relevant species present in the NEFSC Northeast Bottom Trawl Survey catches. List is based on the annual catch (in metric tons).

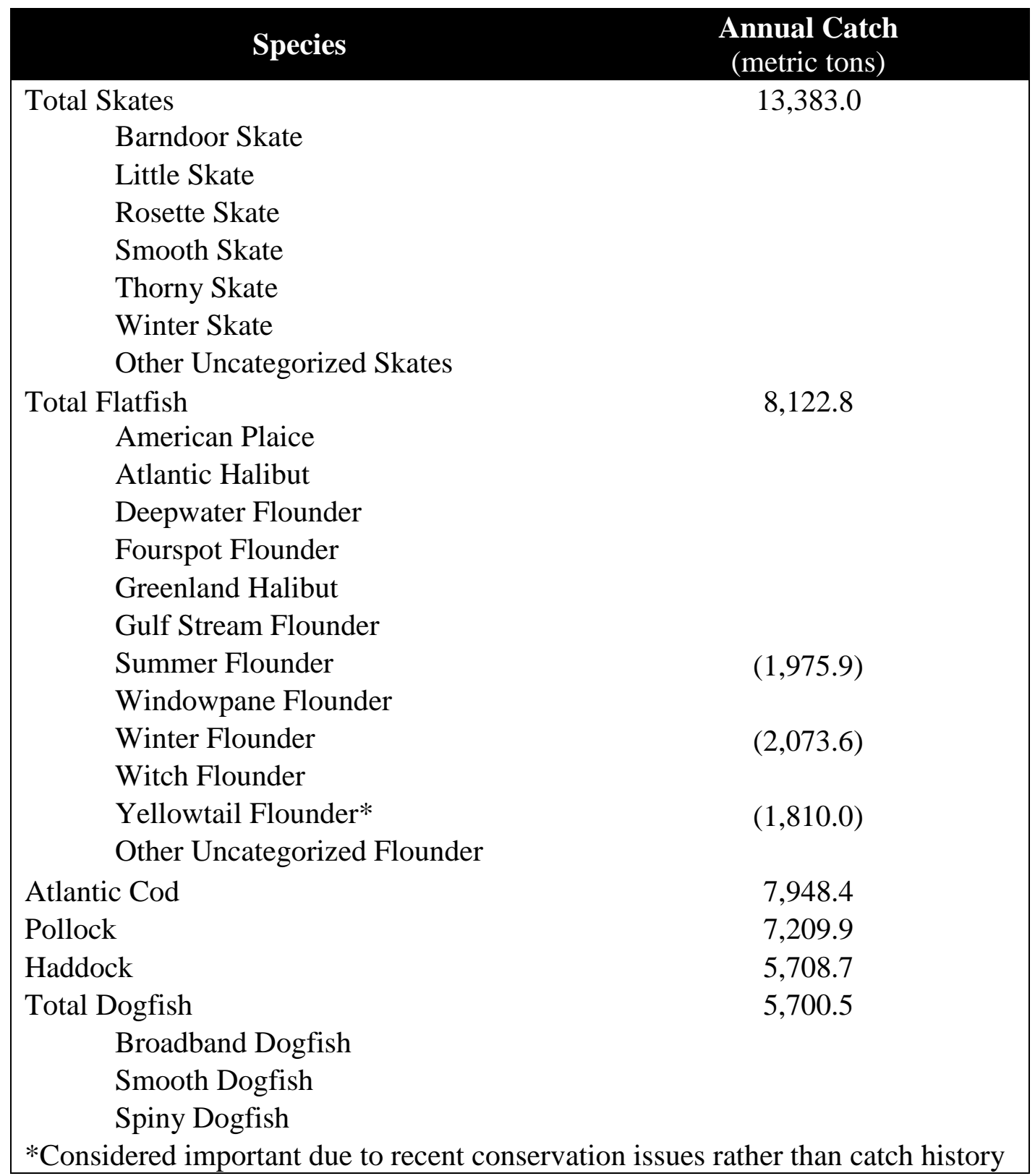


Table 7. Principle species of commercial importance in the Eastern Bering Sea, 2011. List is based on the annual catch (in metric tons) from Alaska.

\begin{tabular}{|lc|}
\hline \multicolumn{1}{|c|}{ Species } & $\begin{array}{c}\text { Annual Catch } \\
\text { (metric tons) }\end{array}$ \\
\hline Walleye Pollock & $1,274,965$ \\
Pacific Cod & 300,725 \\
Total Flatfish & 313,423 \\
Alaska Plaice & $(40,354)$ \\
Arrowtooth Flounder & \\
Bering Flounder & \\
Butter Sole & \\
Dover Sole & \\
Flathead Sole & \\
Greenland Turbot & \\
Kamchatka Flounder & \\
Northern Rock Sole & $(18,729)$ \\
Pacific Halibut & \\
Rex Sole & \\
Sakhalin Sole & \\
Sand Dab & \\
Sand Sole & \\
Slender Sole & \\
Southern Rock Sole & \\
Starry Flounder & \\
Yellowfin Sole & \\
Atka Mackerel & \\
Pacific Herring & \\
Pacific Ocean Perch & \\
\hline
\end{tabular}

\subsection{SPECIES DIVERSITY}

Macgurran (2000) defined biodiversity as "the abundance and variety of species in a defined unit of study." As such, Buckland, et. al. (2005) suggested that to adequately quantify species diversity within an ecosystem, three values must be monitored: number of species (species richness), overall abundance, and species evenness. Following these guidelines, the present study evaluated community diversity utilizing a series of biodiversity measurements designed to evaluate these three 
components, as well as trophic diversity, a somewhat controversial measure of trophic stability and diversity.

Table 8. Biodiversity indices and relevant calculations used for the current study.

\begin{tabular}{|l|l|}
\hline \multicolumn{1}{|c|}{ Index } & \multicolumn{1}{c|}{ Definition } \\
\hline $\begin{array}{l}\text { Species Richness } \\
\text { Potential Species Richness (PS) } \\
\text { Historical Biological Index (HBI) }\end{array}$ & $\begin{array}{l}\text { Total number of species in dataset } \\
H B I_{Y}=\frac{R S_{Y}}{P S}\end{array}$ \\
\hline $\begin{array}{l}\text { Species Evenness } \\
\text { Shannon Index (H) }\end{array}$ & $H=-\sum\left(P_{i} \times \ln P_{i}\right)$ \\
\hline $\begin{array}{l}\text { Trophic Diversity } \\
\text { Mean Trophic Level (MTL) } P \text { is the proportion of species } i\end{array}$ \\
$\qquad \begin{array}{c}M T L_{y}=\frac{\left(\sum_{s} C_{s y} T_{s}\right)}{\sum_{s} C_{s y}} \\
\text { where MTL is the mean trophic level for year } \\
y, T_{s} \text { is the trophic level for species } s, \text { and } C \text { is } \\
\text { the annual catch }\end{array}$ \\
\end{tabular}

\subsubsection{Species Richness}

To evaluate species richness, two indices were calculated: potential species richness and historical biological index. Potential species richness is defined as the maximum species richness possible for the ecosystem. This was calculated by summing the total number of unique species caught in each ecosystem over the duration of time series (Table 8). Historical Biological Index (HBI) is a measure of relative species richness. This index allows for the understanding that communities are inherently different in their capability and sensitivity to support species and that this differs both geographically and temporally. Given a specific temporal and geographic reference point, HBI measures the change in species richness within a community. For 
each ecosystem, annual HBI scores were calculated according to the equation in Table 8.

\subsubsection{Species Evenness}

To evaluate the relative evenness of species within each ecosystem, Shannon Index was calculated. The Shannon Index is a widely-used measure quantifying both species richness and evenness (Peet 1975). This calculation assumes that the most diverse system is one which has both a high number of species and similar abundance of each (Shannon and Weaver 1949). Shannon Index values were calculated annually for both ecosystems according to the formula in Table 8 .

\subsubsection{Trophic Diversity}

To evaluate the trophic diversity within each ecosystem, mean trophic level was calculated. Mean trophic level (MTL) is a controversial measure of the relative abundance of high level predators to low level prey species (Pauly et. al. 1998). It is theorized that this measure provides insight into the trophic composition of an ecosystem and that communities with higher mean trophic levels are likely to be closer to their undisturbed, natural state. The method of calculating MTL has become somewhat controversial in recent years. While the original index was developed using fishery catch statistics, Branch, et. al. (2011) suggested that the use of fishery independent datasets would be more appropriate and provide more insightful results. The present study used the fishery independent surveys of Georges Bank and the EBS demersal communities to calculate annual MTL values for both communities according to the equation in Table 8. For the calculation of MTL, trophic levels were

obtained from FishBase for each species within each dataset (Froese, R. and D. Pauly 2013). 


\subsection{Evaluation of Changes in Community Structure}

Changes in community structure were evaluated using several methods. Length diversity was evaluated through the quantifying the annual abundance of fish within each length quartile and calculating the annual mean and maximum fish length. This was performed for the aggregate, as well as for each species/species complex identified previously. Linear regression analyses were performed for each mean and maximum length data series. Additionally, correlation analyses were performed between mean length, maximum length, fishing effort, and commercial landings for each species/species complex in both ecosystems. Bonferroni corrections were applied to all correlation analyses to account for possible Type I errors associated with multiple correlation analyses.

Species diversity was evaluated over the entire study time period in both Georges Bank and the Eastern Bering Sea using the four indices discussed previously (Table 8) (See Appendix A for additional diversity calculations). For HBI, Shannon Index, and MTL analyses, regressions were performed to determine the overall trend in each ecosystem. Correlation analyses were performed between each diversity index, fishing effort, landings, and environmental data and significance tests were corrected using the Bonferroni correction method. Lastly, multiple regression analyses were performed for each index in both ecosystems. The regression sought to determine the overall effect of single species abundance, fishing effort, landings, and climate on changes in ecosystem diversity.

All statistical analyses were performed with Microsoft Excel, R, the $\mathrm{R}$ Commander GUI, and Python. For all statistical analyses, tests of significance will be 
at the $\alpha=0.05$ level. Effect sizes $\left(\mathrm{R}^{2}\right)$ will be evaluated as small, medium, and large for values of $0.02,0.13$, and 0.26, respectively (Harlow 2005). 


\section{RESULTS}

\subsection{Fishing EFFORT \& COMMERCIAL LANDingS}

\subsubsection{Georges Bank}

Demersal fishing pressure on Georges Bank, measured as the number of days fished, was fairly inconsistent over the time series analyzed (Figure 3A). Prior to 1985, a trend of increasing effort was apparent. Effort increased from under 200,000 days fished in 1975 to over 500,000 days fished in 1985. Between 1985 and 1992, fishing effort remained fairly constant at approximately 500,000 fishing days. In 1992, fishing effort began to steadily subside and by 2010, fishing effort had declined to below 200,000 fishing days per year. Following a period of steady increase from 1975 through 1980, commercial fishery landings in New England remained fairly constant at approximately 275,000 metric tons per year, peaking at over 350,000 metric tons in 1980 (Figure 3B). A more accurate measure of fishing effort would incorporate a measure of vessel capacity, however this data was unavailable for the present study. Weak, non-significant correlations were present between demersal fishing effort and New England commercial catches between 1977 and 2010, $\mathrm{r}^{2}(33,1)=0.10619, \mathrm{p}=$ 0.0642 . 
A.

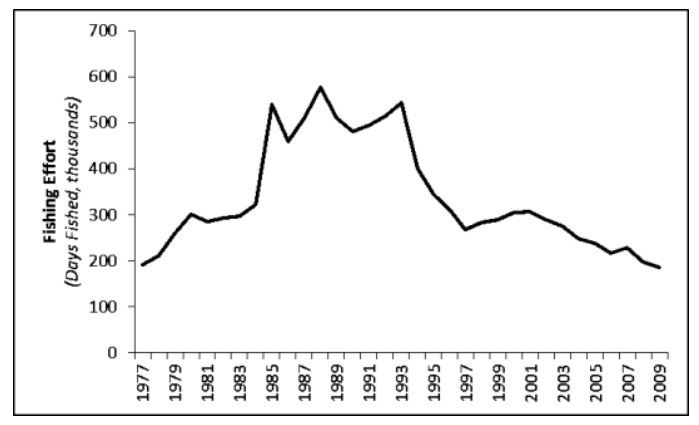

B.

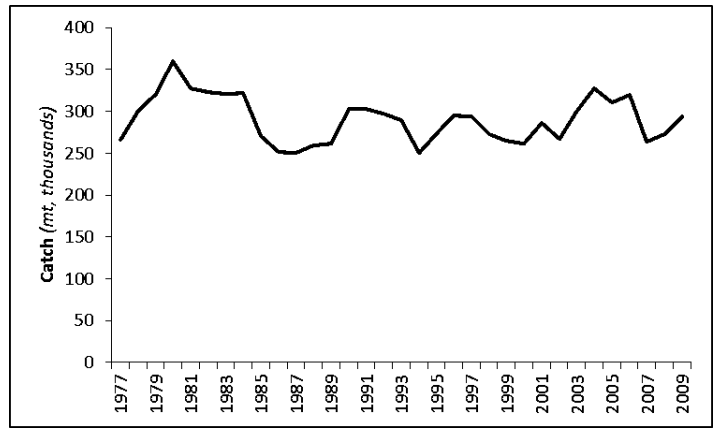

Figure 3. Commercial fishing activity on Georges Bank, 1977 - 2009. (A) Demersal fishing pressure on Georges Bank, measured as the number of annual fishing days targeting demersal species on Georges Bank. (B) Annual commercial catches from New England vessels in thousands of metric tons.

\subsubsection{Eastern Bering Sea}

Fishing effort in the Eastern Bering Sea, measured as the number of observed trawls, has declined since 1990 (Figure 4A). Since reaching a peak fishing effort in 1991 at 25,000 observed trawls, fishing effort has declined to remain fairly consistent at approximately 15,000 observed trawls since 1993. A similar trend was evident in Alaskan commercial landings data (Figure 4B). Prior to 1990, the Alaska region experienced steady increases in landings. In 1982, commercial landings were below 0.5 million metric tons. By 1992, commercial landings peaked at over 2.5 million metric tons, representing more than a four-fold increase. Since the early 1990s, commercial landings have remained fairly consistent, with a slight decline in the late 2000s. 
A.

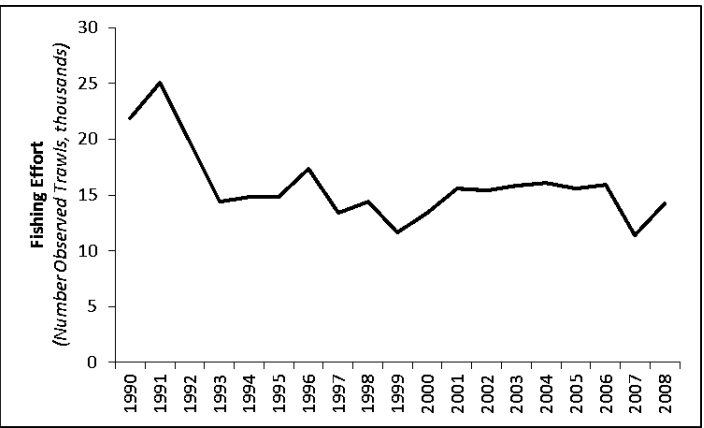

B.

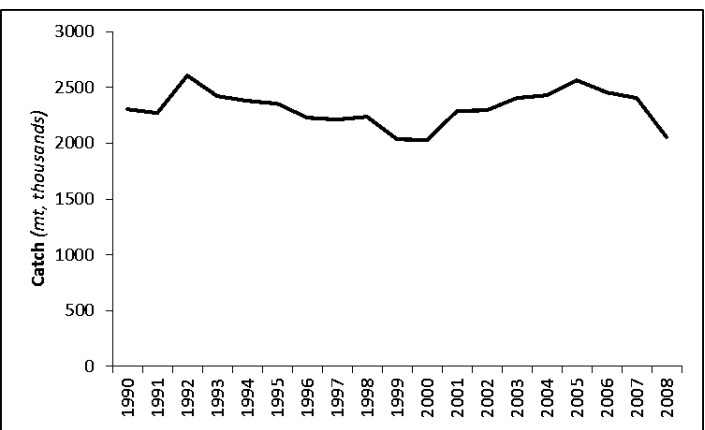

Figure 4. Commercial fishing activity in the Eastern Bering Sea, 1990-2008. (A) Bering Sea fishing effort, measured as the number of observed trawls per year. Due to fishery regulations requiring much of the fleet to maintain $100 \%$ observer coverage, these values are assumed to strongly correlate with total fishing effort (Witherell et al 2000). (B) Alaskan commercial catches.

\subsection{Single SPECIES AbUNDANCE}

\subsubsection{Georges Bank}

Single species abundance in the trawl survey was highly variable on Georges Bank (Figure 5). Most species exhibited depressed abundance in the 1980s through mid-1990s. Catches of the dogfish complex, however, were greatly increased during that time, and experienced a decline before and after that period. Additionally, catches of several species have increased since the turn of the millennium. There have been large increases in haddock catches as well as in the skate and flatfish species complexes. 


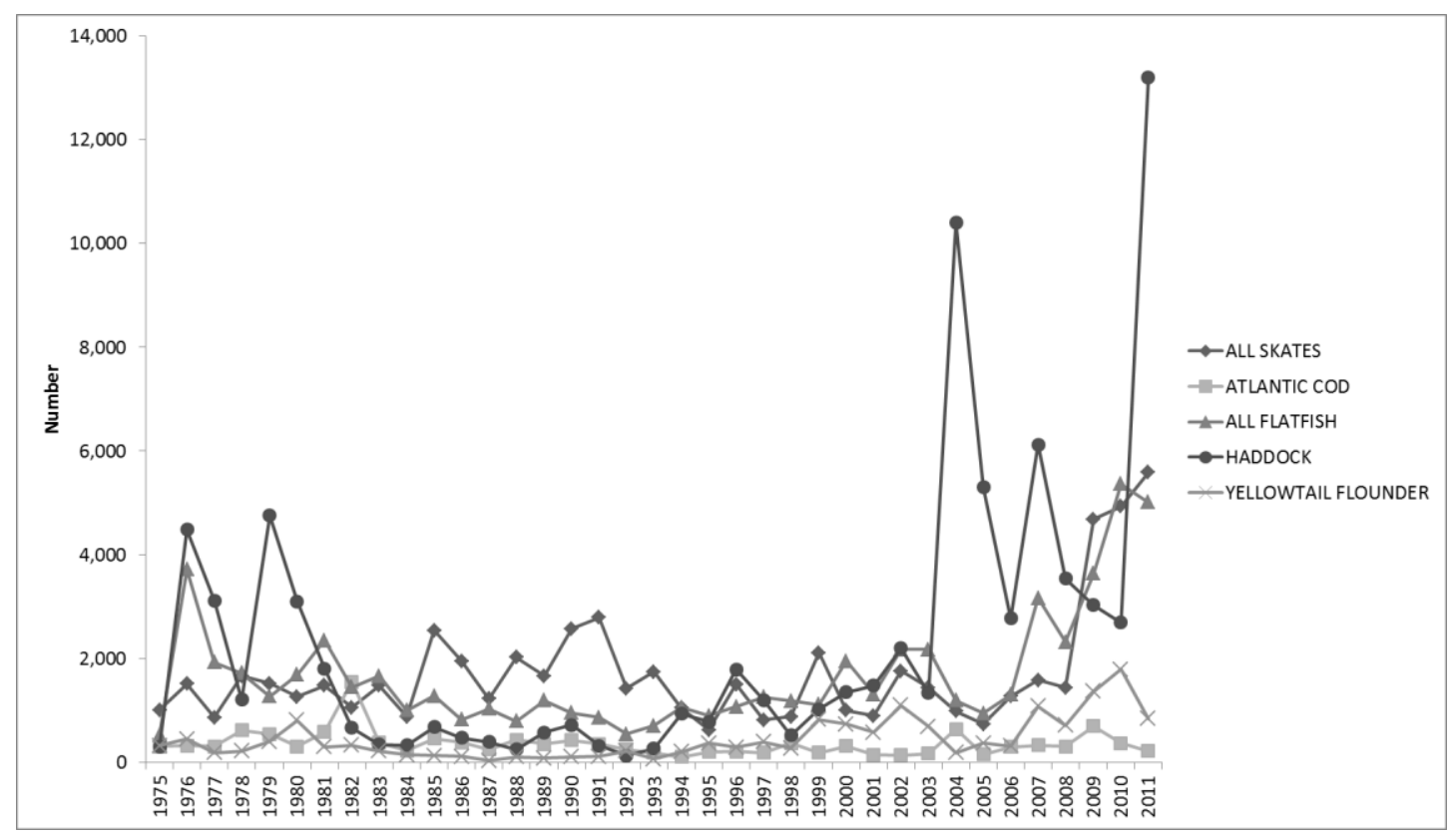

Figure 5. NEFSC Northeast Bottom Trawl Survey Catches, 1975-2011.

\subsubsection{Eastern Bering Sea}

Single species abundance in the trawl survey, measured as catch per unit effort, was highly variable between species in the Eastern Bering Sea (Figure 6). Abundance of Pacific cod and Atka mackerel were significantly higher than all other species and experienced a dramatic decline over the twenty-eight year time period. All other species, with the exception of the flatfish species complex exhibited comparatively low and stable abundances. The flatfish species complex catch per unit effort remained fairly consistent over the time series, with the exception of an isolated, six-fold increase in catch per unit effort in 2009. 


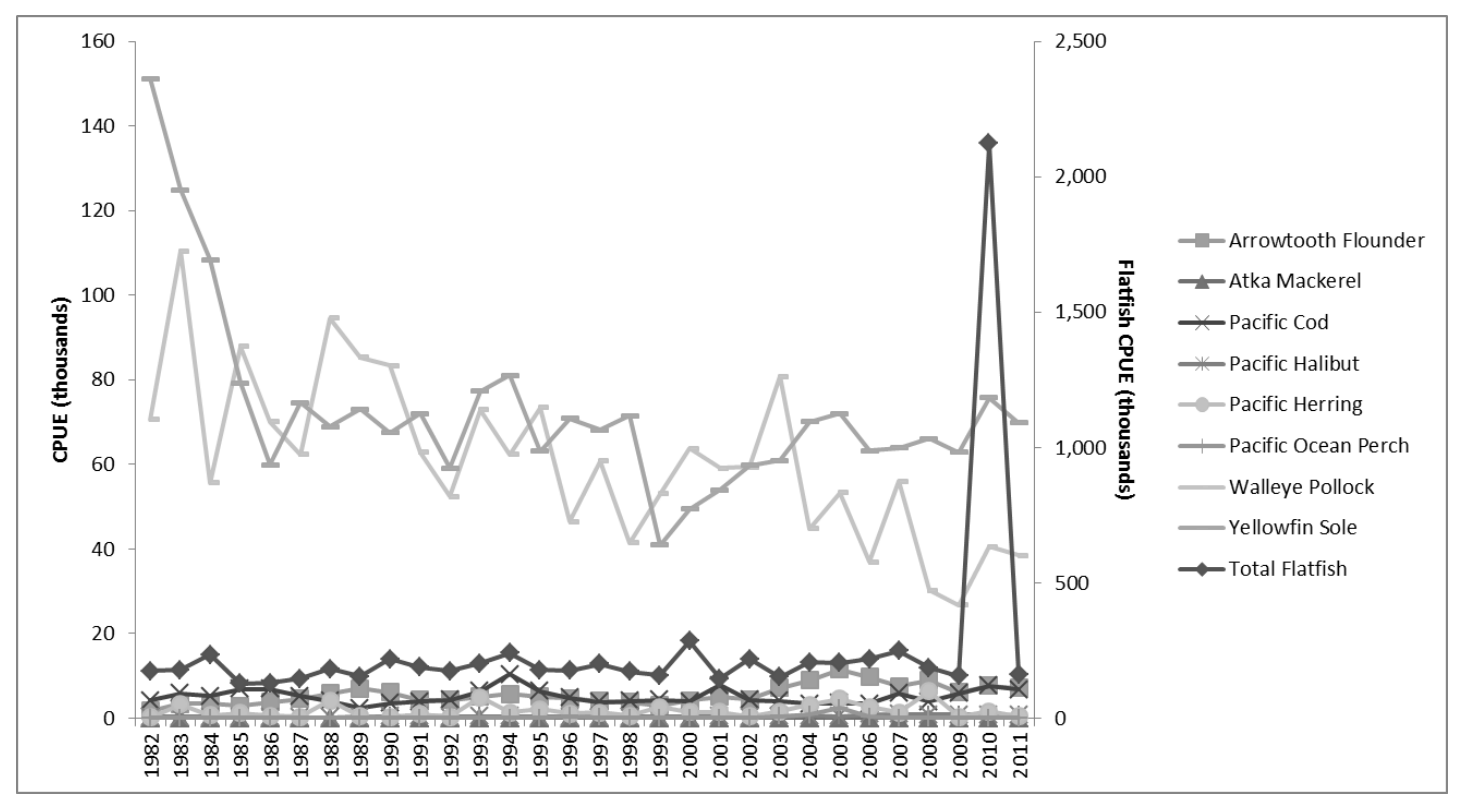

Figure 6. AFSC Eastern Bering Sea Trawl Survey Catches per Unit Effort, 1982-2011.

\subsection{Climate \& ENVIRONMENTAL INDICES}

\subsubsection{Georges Bank}

Bottom temperature readings from the NEFSC Northeast Bottom Trawl Survey are relatively consistent over the study period (Figure 7A). A minimum of $4.45^{\circ} \mathrm{C}$ was recorded in 2004 and a maximum of $7.56^{\circ} \mathrm{C}$ was recorded in 2000 . Mean bottom temperature of the time series was $6.07^{\circ} \mathrm{C}( \pm 0.72)$. Global surface temperature anomalies exhibited a prominent trend of increasing temperature over the course of the study period (Figure 7B). This index evaluates the relative changes in temperature exchange at the earth's surface. These changes could be indicative of global climatic changes and may have more wide-reaching effects than regional temperature change. A minimum of 3.75 occurred in 1978 and a maximum of 61.75 occurred in 2005 . Annual NAO values exhibited little directional shifts (Figure 7C). The number of annual storm events was also highly variable (Figure 7F). A minimum of 2 storms occurred in 1982 and a maximum of 15 storms occurred in 2005. 
A.

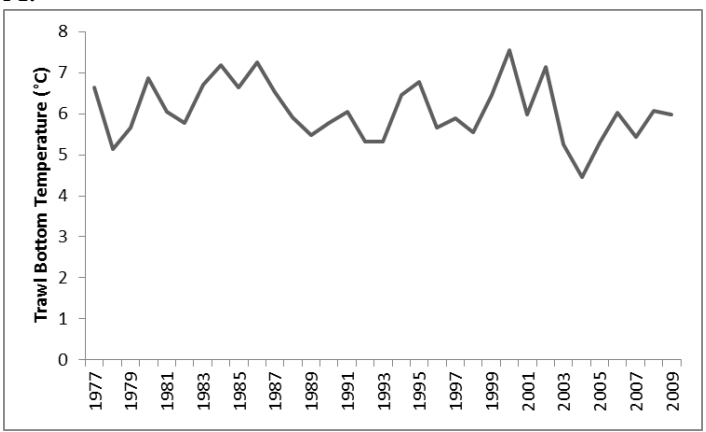

C.

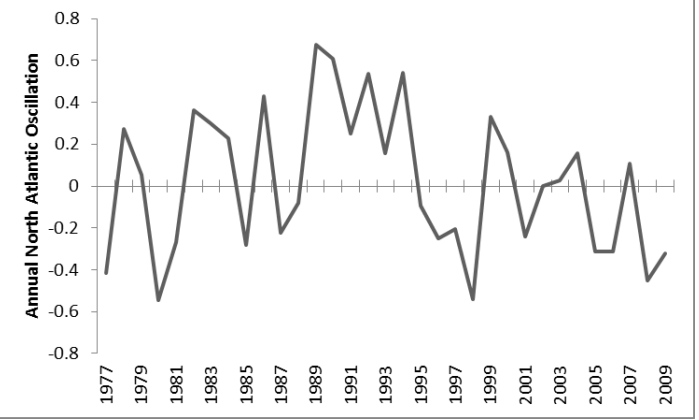

B.

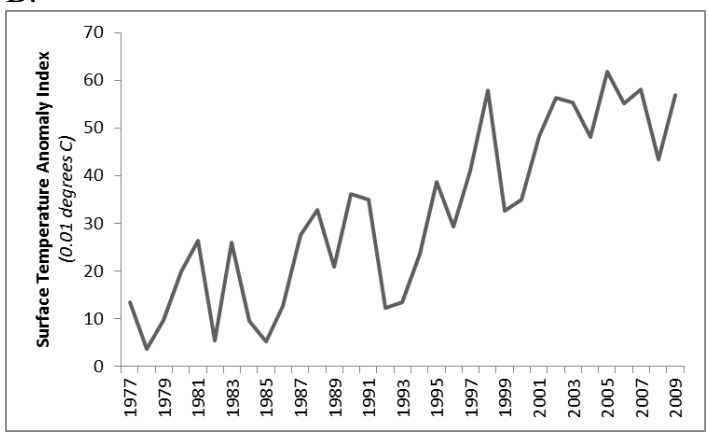

D.

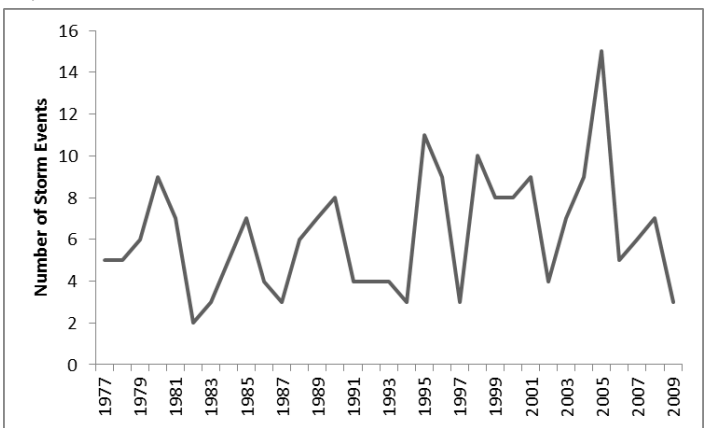

Figure 7. Climatic characteristics of Georges Bank, 1977-2009. Six measurements are displayed: mean bottom temperature recorded from the NEFSC Northeast Bottom Trawl Survey (A), global air surface temperature anomalies (B), mean annual North Atlantic Oscillation (C), and annual number of storm events (D).

\subsubsection{Eastern Bering Sea}

Bottom temperature readings from the EBS Trawl Survey dataset are fairly consistent and all fall within a three degree range (Figure 8A). A minimum of $0.75^{\circ} \mathrm{C}$ was recorded in 1999 and a maximum of $3.63^{\circ} \mathrm{C}$ was recorded in 2003. Mean bottom temperature of the time series was $2.23^{\circ} \mathrm{C}( \pm 0.86)$. Surface temperature readings from the EBS Trawl Survey ranged from a minimum of $3.85^{\circ} \mathrm{C}$ in 1999 to a maximum of $8.50^{\circ} \mathrm{C}$ in 2004 (Figure $8 \mathrm{~B}$ ). Mean surface temperature for the study period was $6.68^{\circ} \mathrm{C}( \pm 1.21)$.

Alaskan Index, a measure of atmospheric circulation in the Bering Sea, was highly variable, ranging from a maximum of 1.35 in 1996 to a minimum of -1.68 in 1992 (Figure 8C). Ice Cover Index (ICI), a measurement of anomalies in ice cover, 
revealed high variability (Figure 8D). A general declining trend of ice cover was apparent, with the exception of a dramatic increase in 2008. The minimum ICI value of -1.77 was recorded in 2005 and a maximum ICI of 3.71 was recorded in 2008 . Ice Retreat Index (IRI), a measure of anomalies in spring ice retreat, was highly variable (Figure 8E). Recordings of 0 were frequent, particularly in the period between 2000 and 2005. A maximum of 51 was recorded in 1999.

Three more standardized measurements of basin-wide temperature fluctuations were also evaluated. Summer bottom temperature was moderately consistent, ranging from a minimum of $0.83^{\circ} \mathrm{C}$ in 1999 to a maximum of $3.81^{\circ} \mathrm{C}$ in 2003 (Figure 8). Mean May sea surface temperature was also highly variable (Figure 8G). A generally declining trend is evident in May sea surface temperature, however a period of above average temperature was evident between 2001 through 2005. A minimum temperature of $0.59^{\circ} \mathrm{C}$ was recorded in 2008 and a maximum of $3.52^{\circ} \mathrm{C}$ was recorded in 2003. Mean winter sea surface temperature exhibited a strongly increasing trend until 2003, and was subsequently followed by a period of decreasing temperature through 2008 (Figure 8H). A minimum winter sea surface temperature was recorded in 2008 at $-4.69^{\circ} \mathrm{C}$. Maximum winter sea surface temperature was recorded in 2001 at $2.51^{\circ} \mathrm{C}$. 
A.

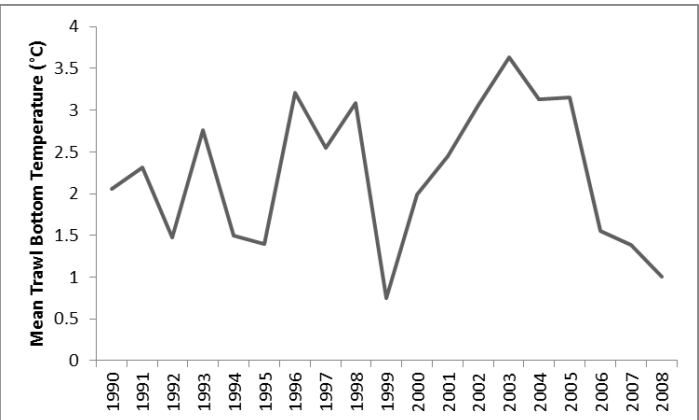

C.

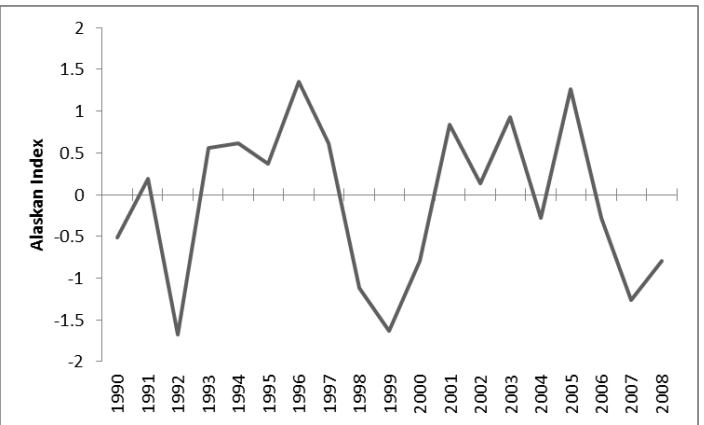

E.

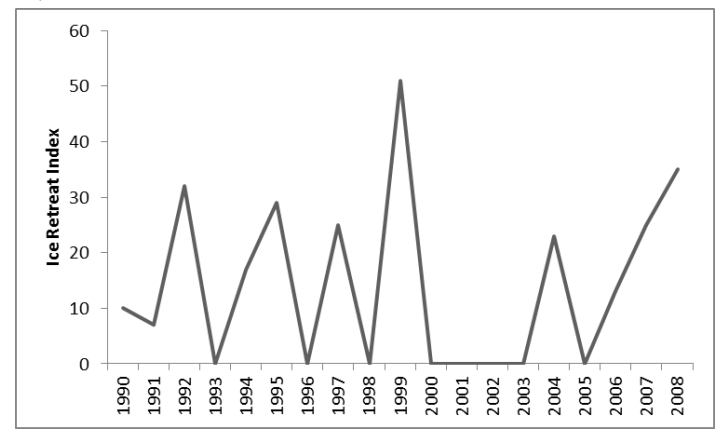

G.

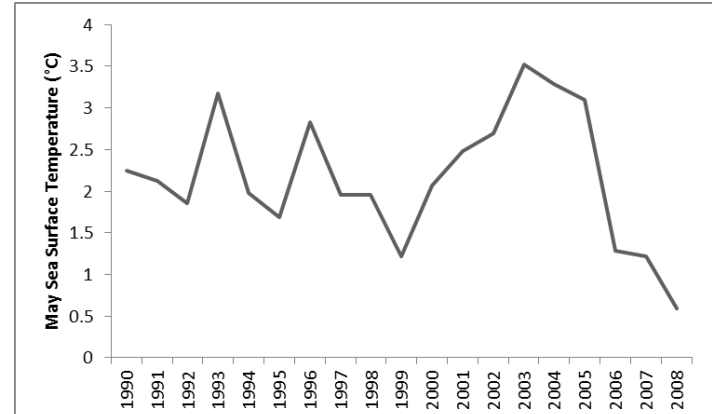

B.

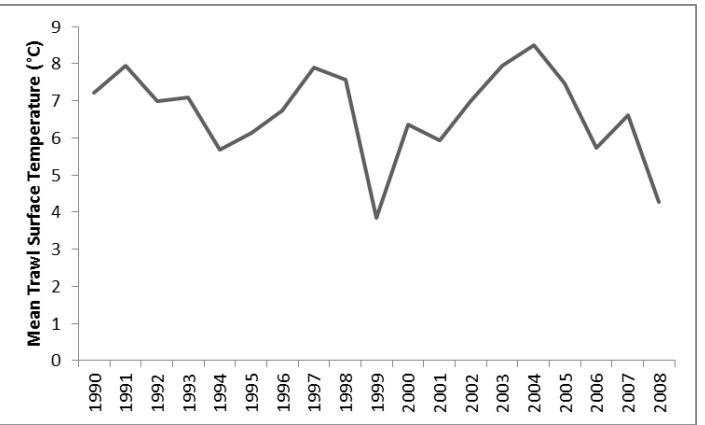

D.
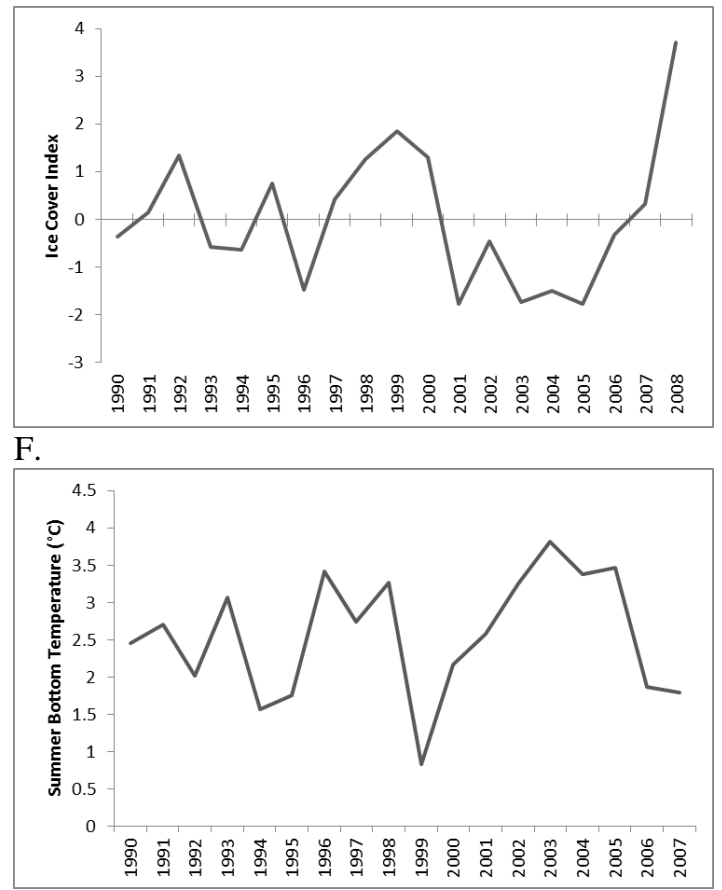

H.

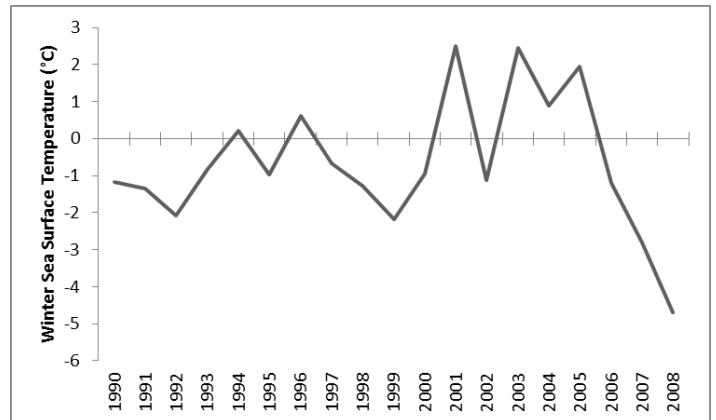

Figure 8. Climatic characteristics of the Eastern Bering Sea, 1990-2008. Eight measurements are displayed: mean bottom temperature recorded from the EBS Trawl Survey (A), mean surface temperature recorded from the EBS Trawl survey (B), Alaskan Index (C), Ice Cover Index (D), Ice Retreat Index (E), standardized summer bottom temperature (F), standardized May sea surface temperature $(\mathrm{G})$, and standardized winter sea surface temperature $(\mathrm{H})$. 


\subsection{LENGTH DistributionS}

\subsubsection{Georges Bank}

Analysis of changes in length distributions on Georges Bank indicate that overall, relative body length proportions remain fairly constant over the duration of the present study, however there was significant annual variability (Figure 9A). Between 1977 through 1993, larger body sizes appeared to dominate total catches of the NEFSC Northeast Bottom Trawl Survey. Beginning in 1994 through 2011, however, smaller body sizes became more prevalent. While variability in annual maximum and mean length were apparent, an overall declining trend of both mean and maximum length were evident (Figure 9B). In twenty of the 37 years evaluated, an Atlantic cod was the largest individual caught. Statistical analyses revealed a strong and significant correlation between annual mean length of all species and demersal fishing effort, $\mathrm{r}(33)=0.6615, \mathrm{p}=0.00005($ Appendix B $)$. 
A.

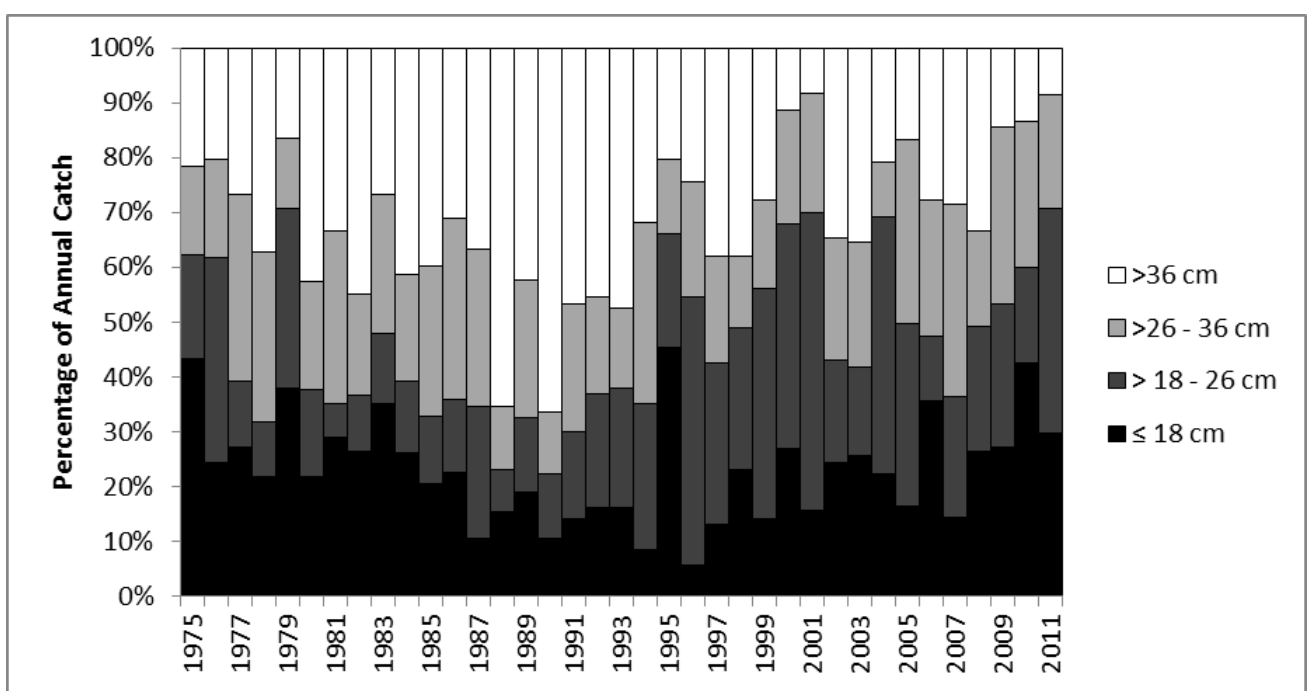

B.

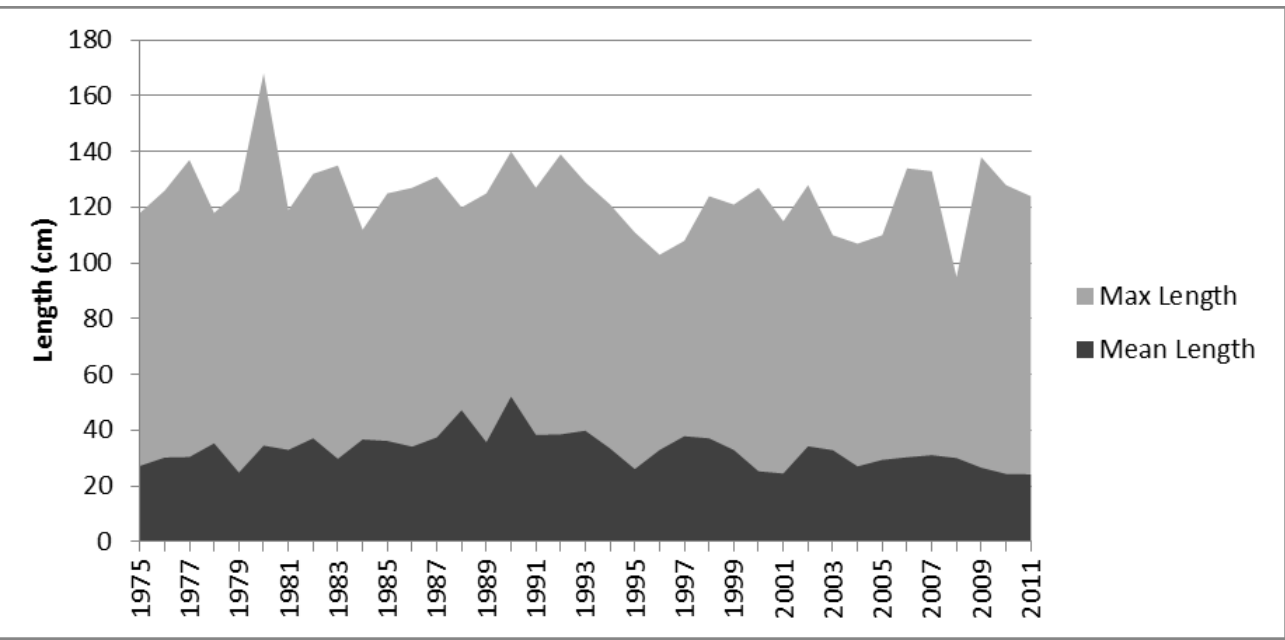

Figure 9. Length distribution of all species collected in the NEFSC Northeast Bottom Trawl Survey at Georges Bank stations, 1975-2011. (A) Distributions are represented as a percentage of the total annual catch, 1975-2011. Length bins represent the quartiles of all catches cumulatively. (B) Mean and maximum length of all species caught in the NEFSC Northeast Bottom Trawl Survey Georges Bank stations.

Body size distributions of Atlantic cod remained fairly constant over time, however annual variations were apparent (Figure 10A). Specifically, large bodied individuals comprised over $60 \%$ of annual catches in 1982 and 2003 and over $70 \%$ of annual catches in 1975 and 2004. Over the course of the study period, a distinct trend of decreasing mean and maximum length was evident (Figure 10B). Maximum body length declined from $118 \mathrm{~cm}$ in 1975 to $91 \mathrm{~cm}$ in 2011. Mean body length declined 
from $65.9 \mathrm{~cm}$ in 1975 to approximately $44.6 \mathrm{~cm}$ in 2011 . Analyses revealed a strong significant correlation between maximum cod length and demersal fishing effort, r(33) $=0.627, \mathrm{p}=0.0002($ Appendix B $)$.

A.

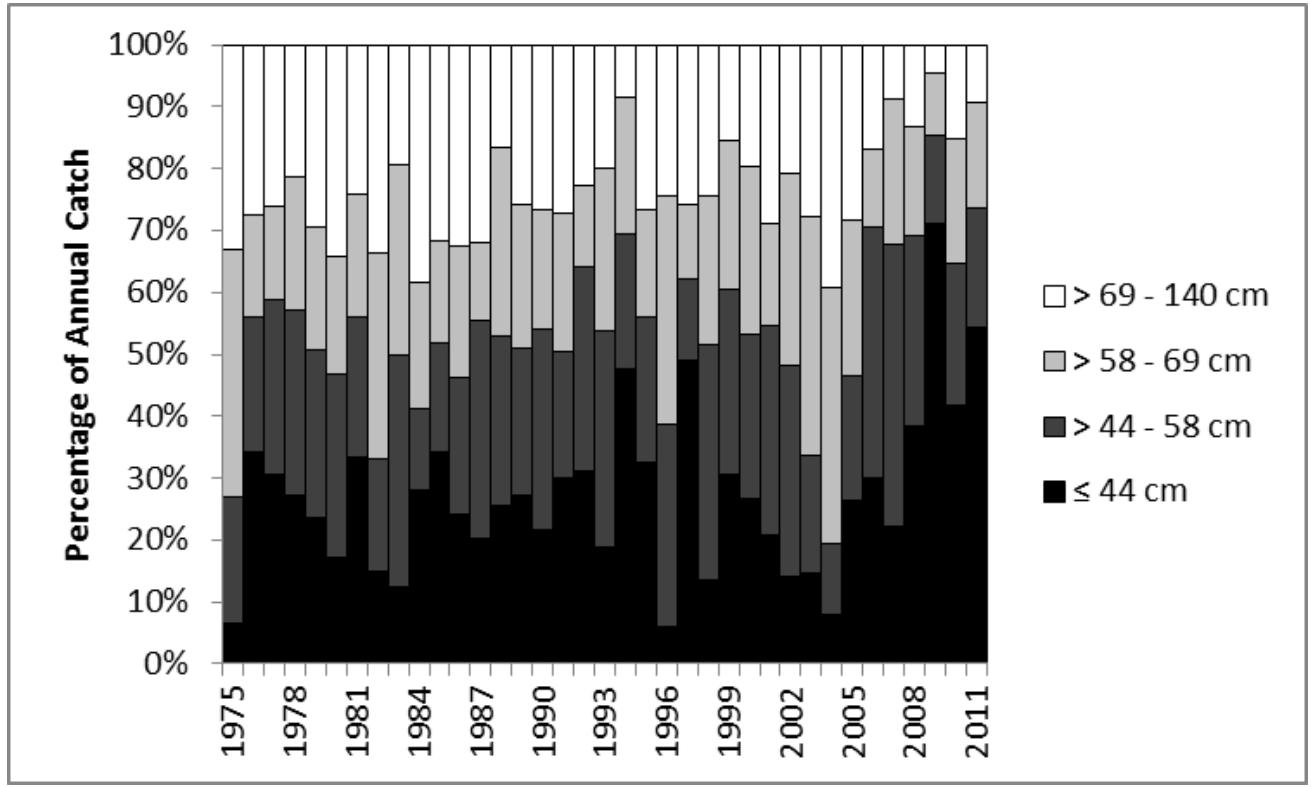

B.

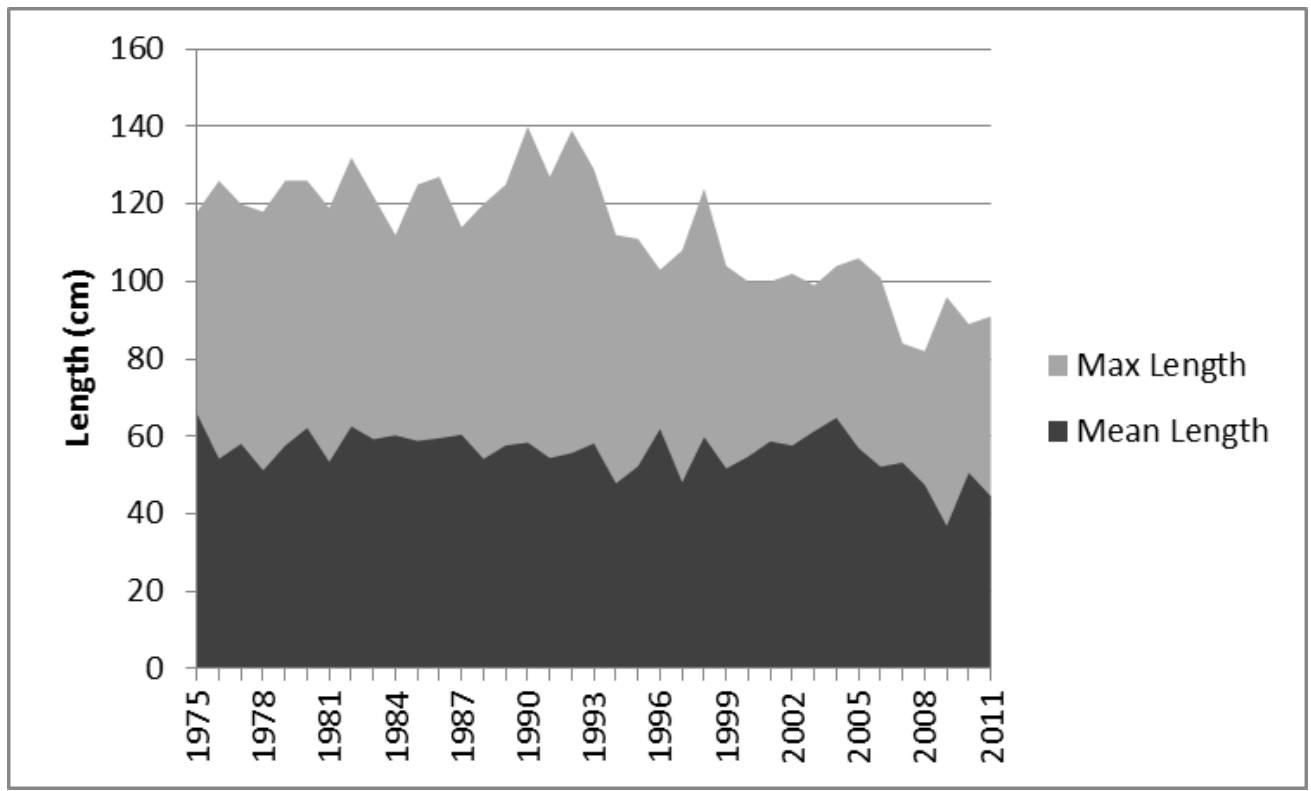

Figure 10. Atlantic cod length distribution collected in the NEFSC Northeast Bottom Trawl Survey at Georges Bank stations, 1975 - 2011. (A) Distributions are represented as a percentage of the total annual catch. Length bins represent the quartiles of Atlantic cod catches for all years. (B) Atlantic cod mean and maximum length of individuals caught in the NEFSC Northeast Bottom Trawl Survey Georges Bank stations, 1975-2011. 
Body size distributions for the flatfish species complex appear to be somewhat cyclic, with multiyear shifts in relative body length (Figure 11A). Roughly equal proportions of large and small-bodied fish were caught throughout the 1970s and between 1986 and 1998. Each of these periods is followed by a decline in abundance of small-bodied individuals. While spikes in the proportion of large- or small-bodied individuals were occasionally observed, generally the results suggest a possible cyclic trend and relatively even proportions of each group throughout the time series. Over the course of the study period, the mean and maximum length remained relatively constant (Figure 11B). Mean body length remained fairly constant at approximately 30 $\mathrm{cm}$. Maximum length was much more variable, with spikes in maximum length, frequently spanning several years at a time. There was no significant correlation between mean and maximum length, $r(33)=0.0827, p=0.6419$ (Appendix B). Statistical analyses revealed a significant correlation between New England commercial catches and maximum flatfish length, $r(33)=0.4065, p=0.0170$. 
A.

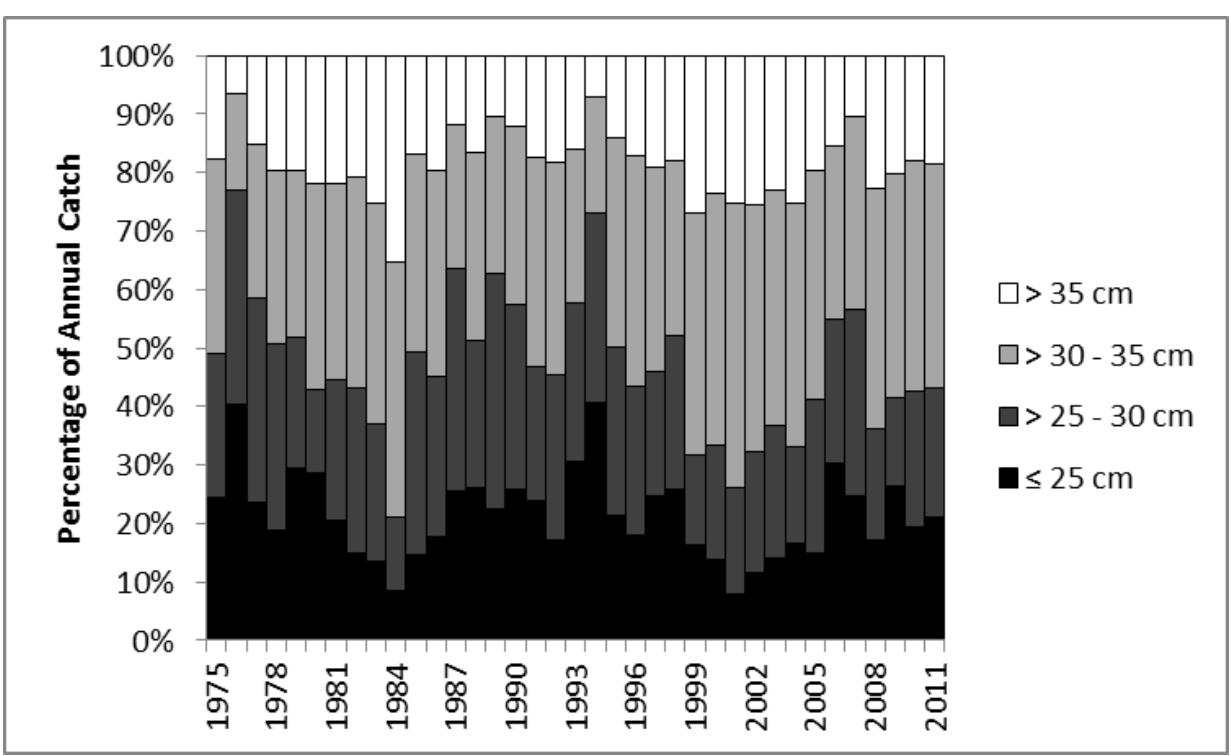

B.

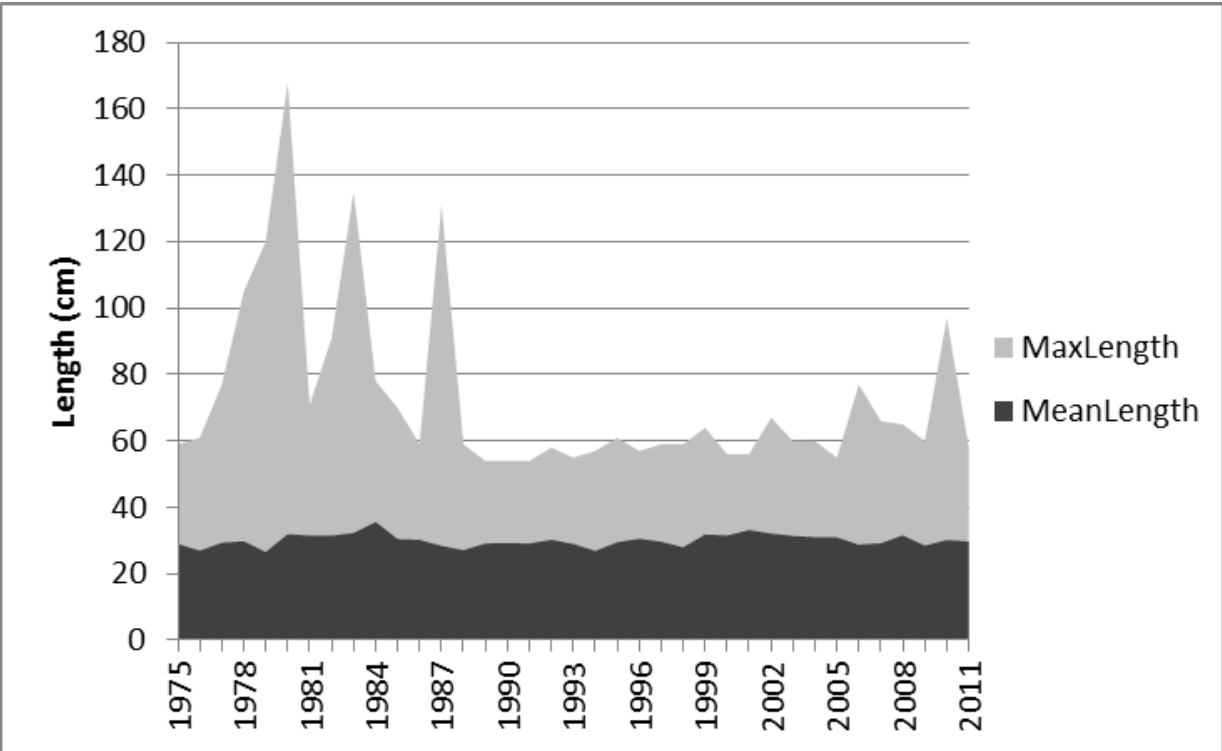

Figure 11. Flatfish length distributions collected in the NEFSC Northeast Bottom Trawl Survey at Georges Bank stations, 1975-2011. (A) Distributions are represented as a percentage of the total annual catch. Length bins represent the quartiles of flatfish catches for all years. (B) Mean and maximum length of flatfish.

Body size distributions of the skate species complex also appear to be cyclic with strong annual connectivity (Figure 12A). Proportions of large-bodied and smallbodied individuals were relatively equal throughout the time series, with slight deviations. Until the mid-1990s, mean and maximum fish length was fairly consistent with only minor annual fluctuations (Figure 12B). Between 1995 and 2011, however, 
strong fluctuations in maximum length were observed, with annual changes accounting for roughly $20 \%$ of the total body maximum length. Overall, a trend of increasing maximum length is evident, while the mean length has remained relatively stable at approximately $40 \mathrm{~cm}$. There was no correlation between mean and maximum length, $\mathrm{r}(33)=0.0114, \mathrm{p}=0.9491($ Appendix $\mathrm{B})$.

A.

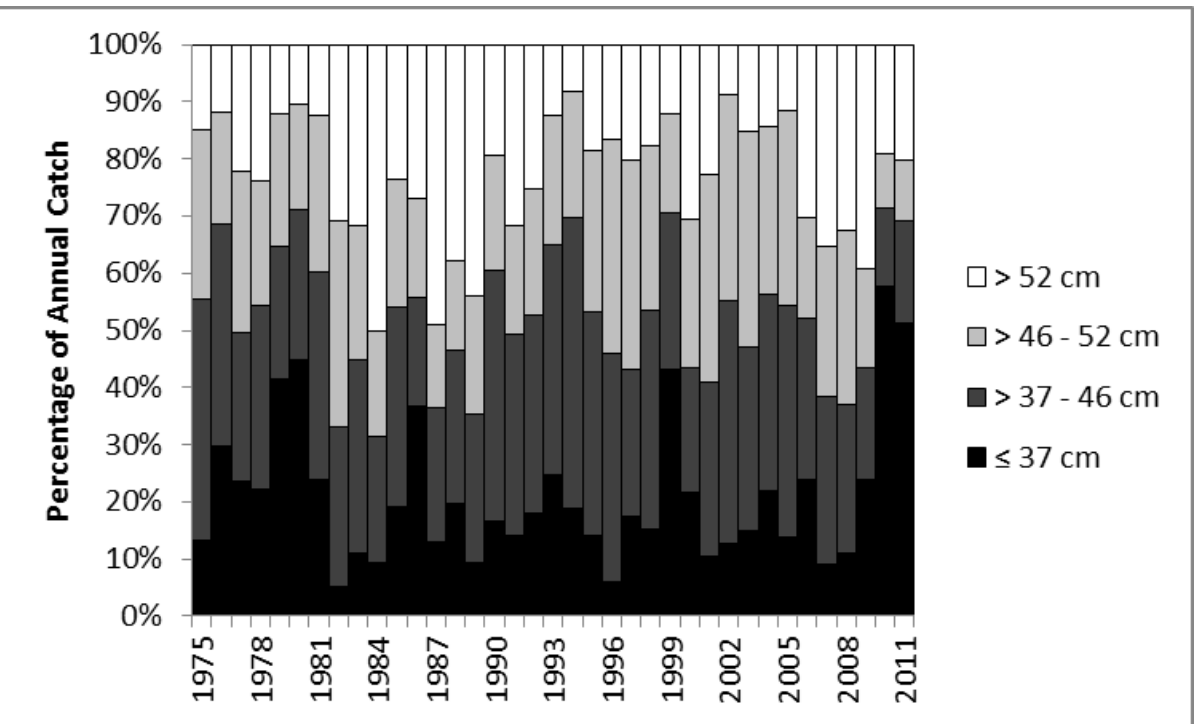

B.

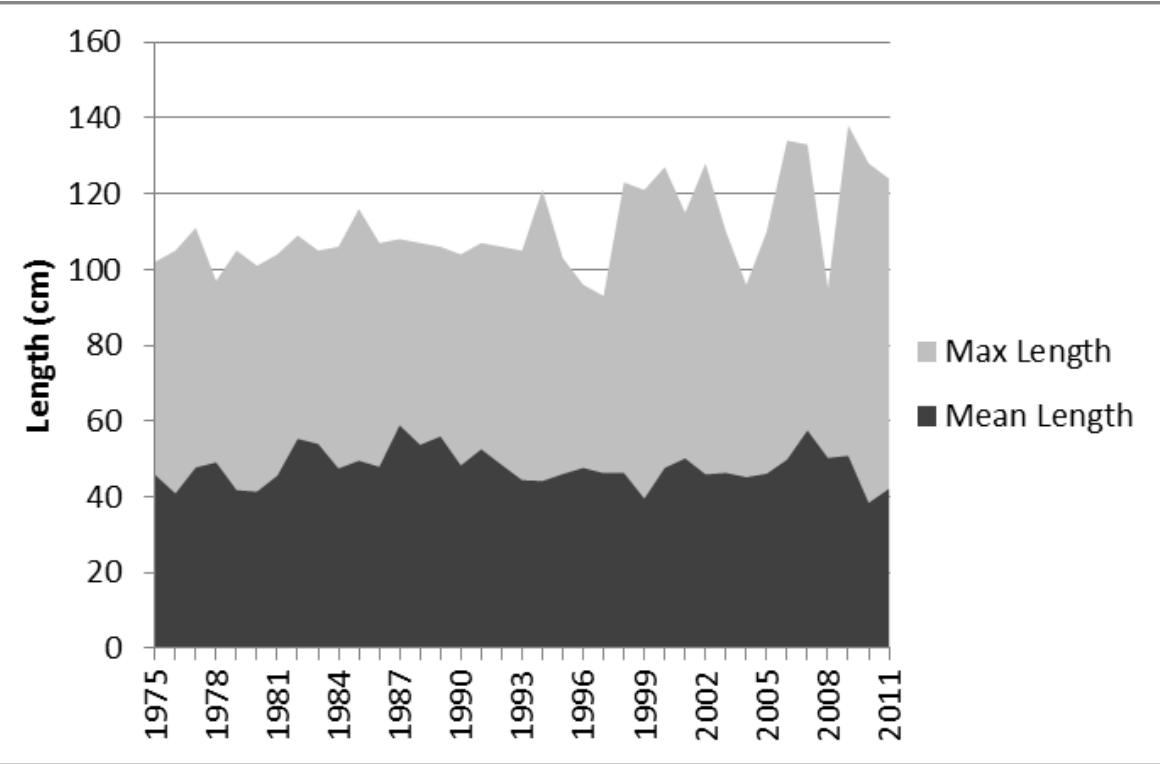

Figure 12. Skate length distributions collected in the NEFSC Northeast Bottom Trawl Survey at Georges Bank stations, 1975-2011. (A) Distributions are represented as a percentage of the total annual catch. Length bins represent the quantiles of skate catches for all years. (B) Mean and maximum length of skate species. 


\subsubsection{Eastern Bering Sea}

Analysis of changes in body size distributions in the Eastern Bering Sea suggest that overall, body sizes remained very stable over the duration to the study period (Figure 13A). Almost no annual variability is evident in body sizes of fish caught in the EBS Trawl Survey between 1990 and 2011. Mean length remained fairly stable with little annual fluctuations (Figure 13B). Maximum length, however, was more volatile with a high degree of annual variability. No significant trend of changing maximum length was evident over the study period. A strong positive correlation was present between mean and maximum length, $\mathrm{r}(18)=0.6215, \mathrm{p}=$ 0.0031 (Appendix B). Additionally, a strong negative correlation was evident between mean length and fishing effort, $\mathrm{r}(18)=-0.6258, \mathrm{p}=0.0042$. 
A.

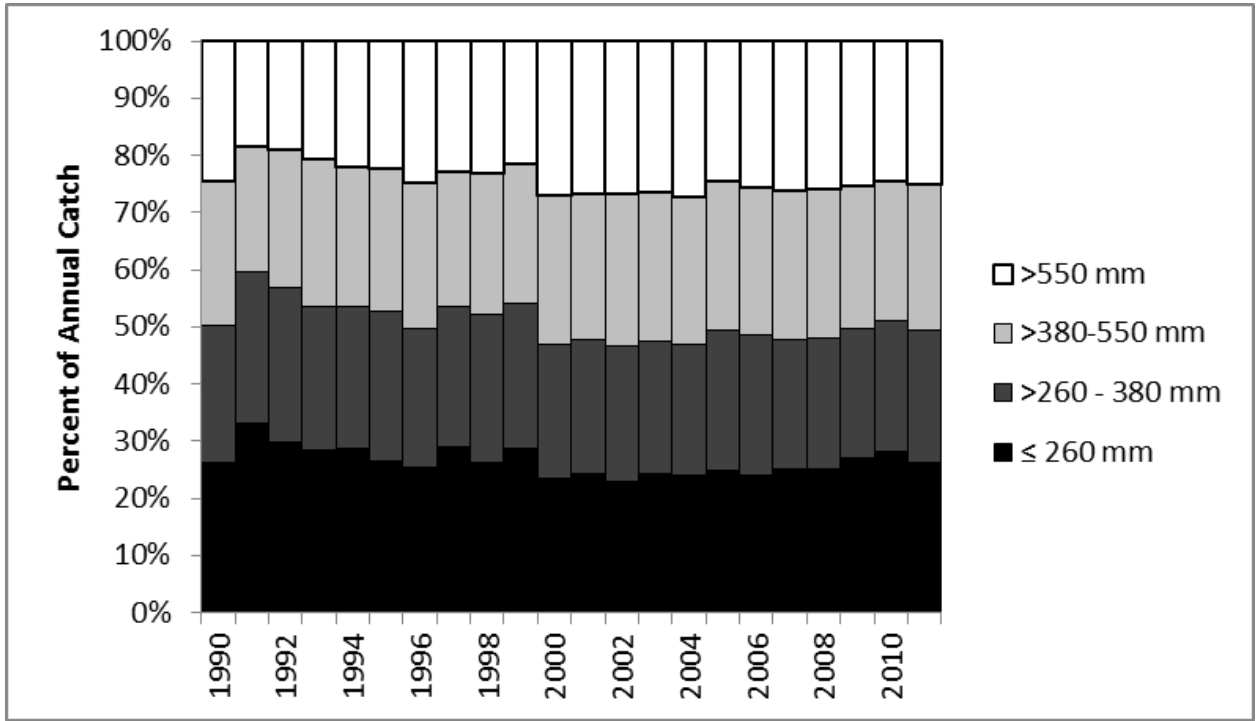

B.

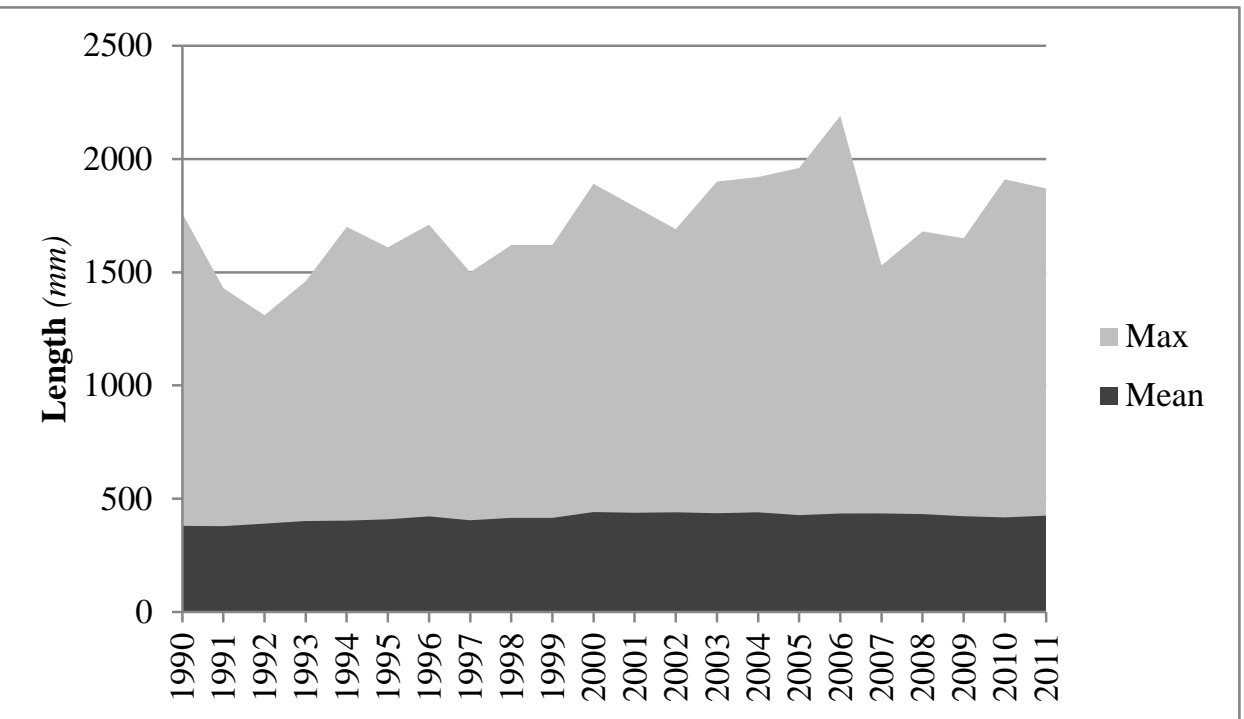

Figure 13. Length distribution of all species collected in the EBS Trawl Survey, 1990-2011. (A) Distributions are represented as a percentage of the total annual catch.. Length bins represent the quartiles of all catches cumulatively. (B) Mean and maximum length of all species caught in the survey.

Walleye pollock body sizes also remained fairly consistent over time (Figure 14A). Mean body length exhibited little annual fluctuation (Figure 14B). Maximum body length, however, displayed much greater annual variability. No significant 
correlations were evident between pollock mean or maximum size and fishing pressure or climatic variables (Appendix B).

A.

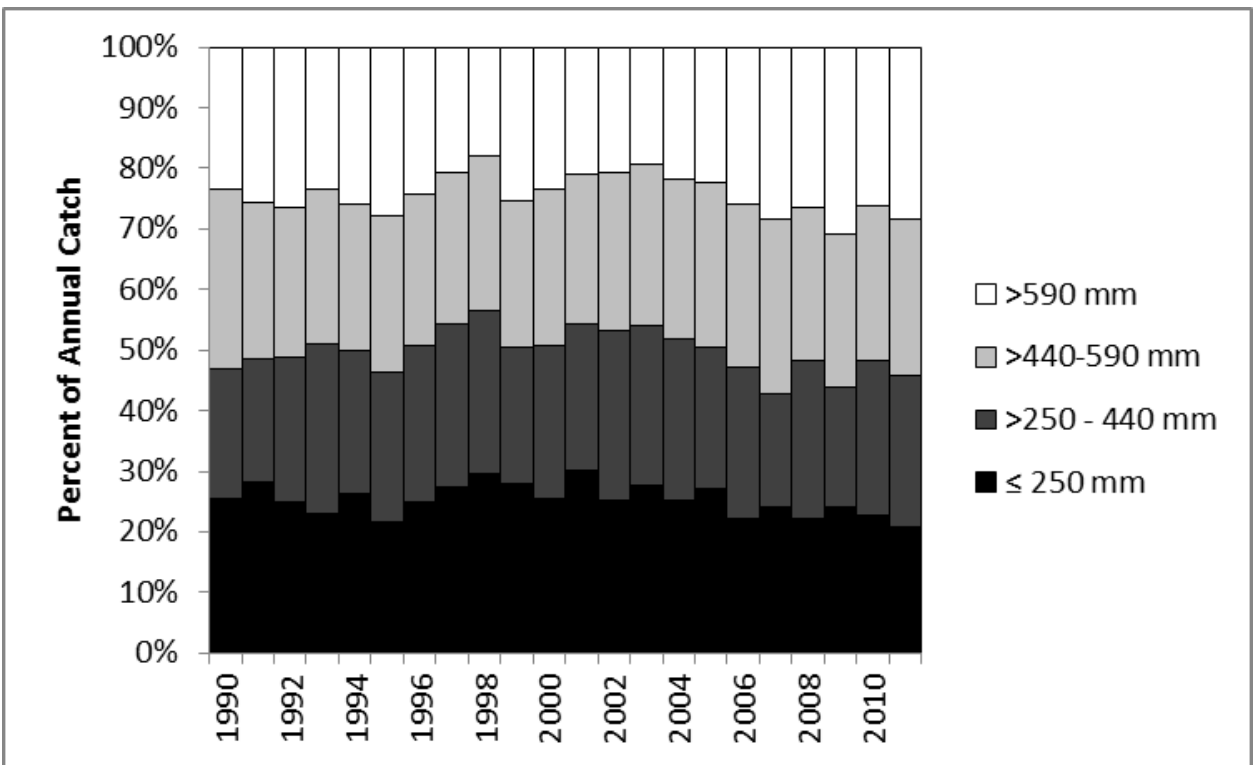

B.

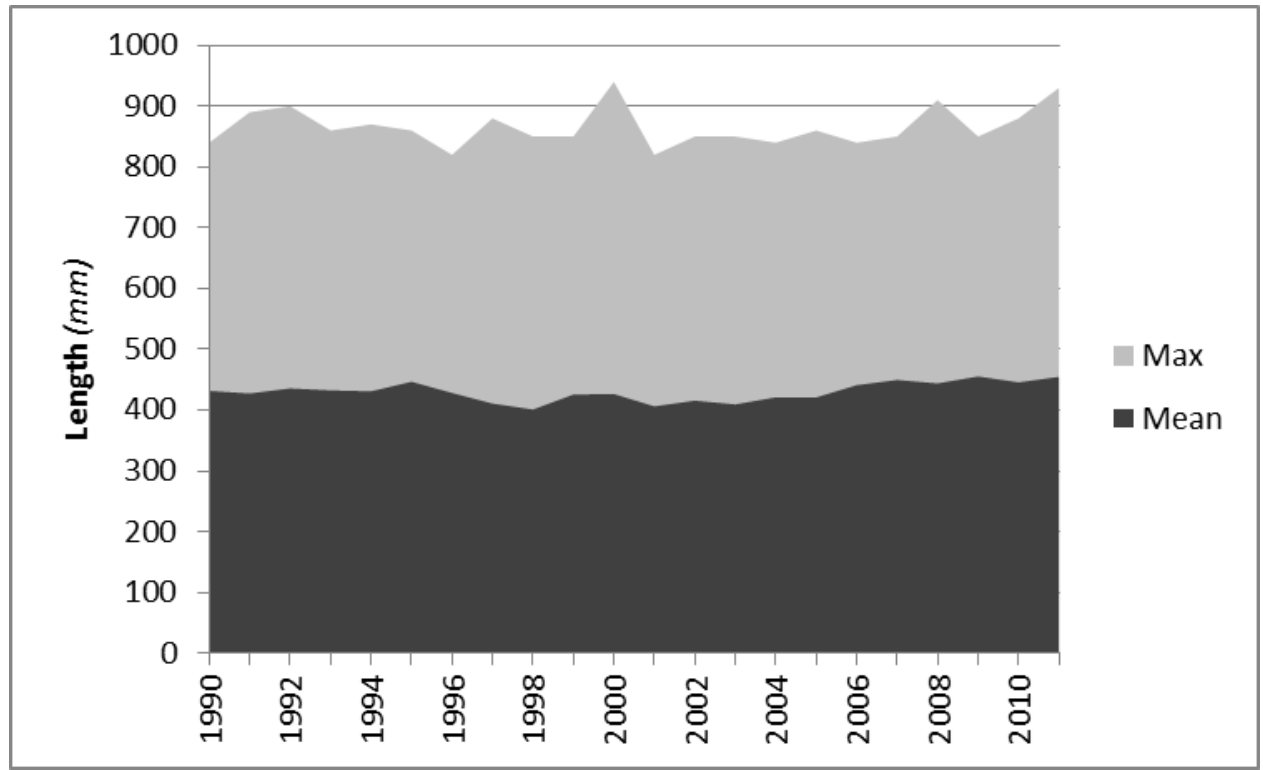

Figure 14. Length distribution of walleye pollock collected in the EBS Trawl Survey, 1990-2011. (A) Distributions are represented as a percentage of the total annual catch. Length bins represent the quartiles of all catches cumulatively. (B) Mean and maximum length of all walleye pollock caught in the survey.

Pacific cod body sizes remained consistent over the study period and only minor fluctuations in proportion of body sizes were evident (Figure 15A). Mean body size also remained consistent with little variability (Figure 15B). Maximum body size 
exhibited no overall trend of change, however there was greater annual variation in maximum length than in mean length. No correlation between mean and maximum length was evident, $\mathrm{r}(18)=0.1377, \mathrm{p}=0.7119$ (Appendix B).

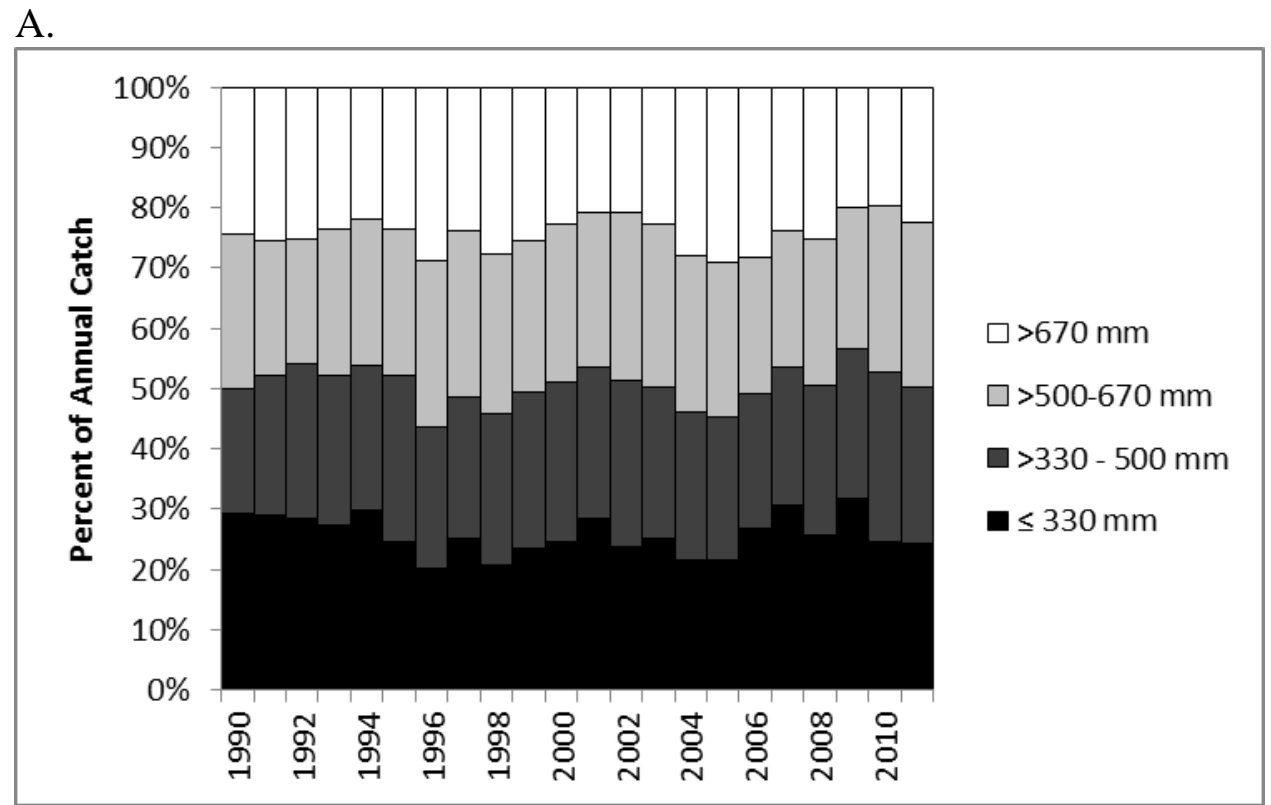

B.

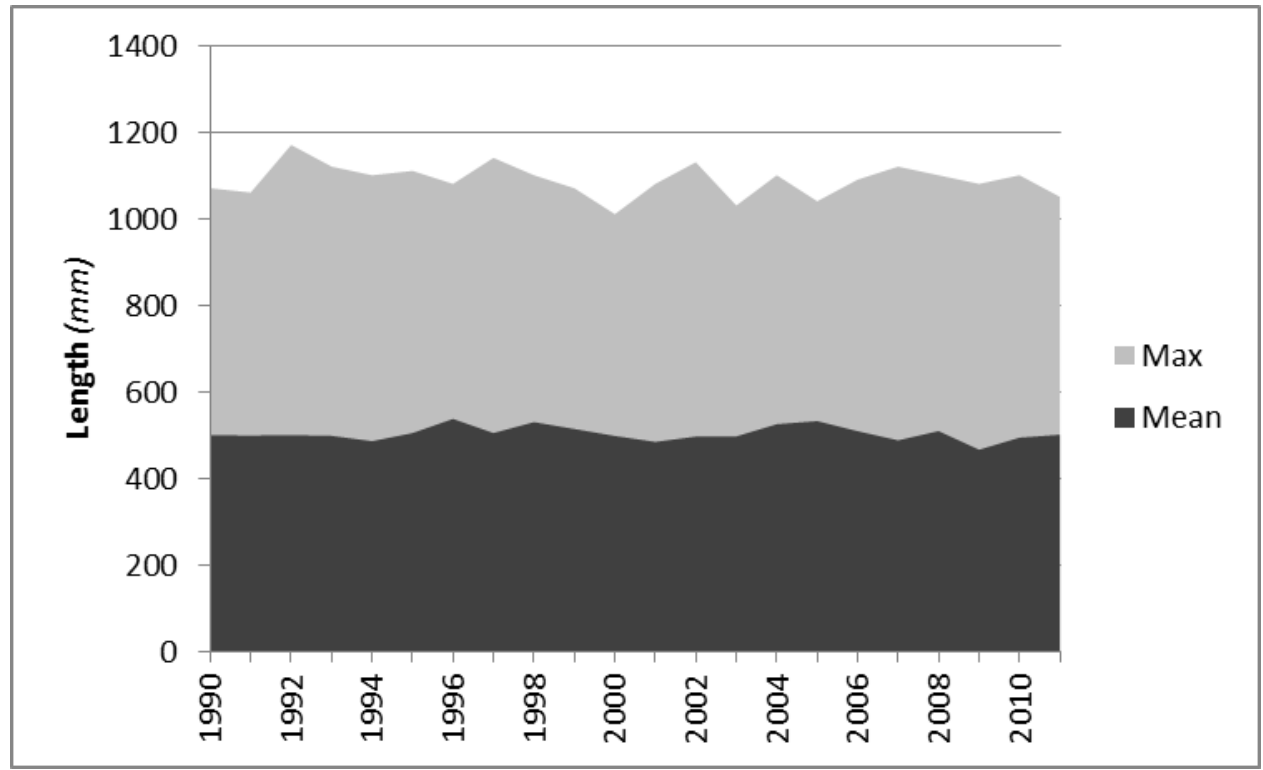

Figure 15. Length distribution of Pacific cod collected in the EBS Trawl Survey, 1990-2011. (A) Distributions are represented as a percentage of the total annual catch. Length bins represent the quartiles of all catches cumulatively. (B) Mean and maximum length of all Pacific cod caught in the survey.

A total of eighteen flatfish species were identified for evaluation of changes in flatfish body size (Table 7). Overall, body size remained relatively consistent with 
little annual variability (Figure 16A). A slight trend of decreasing relative abundance of large individuals was evident. Mean body size remained very stable over the duration of the study period with little variation (Figure 16B). Maximum length exhibited large annual fluctuations, however no significant overall change was evident. No correlation between mean and maximum length was apparent, $r(18)=$ $0.1080, p=0.6599$ (Appendix B). A strong and significant negative correlation was present between mean length and fishing effort, $r(18)=-0.7033, p=0.0008$. 
A.

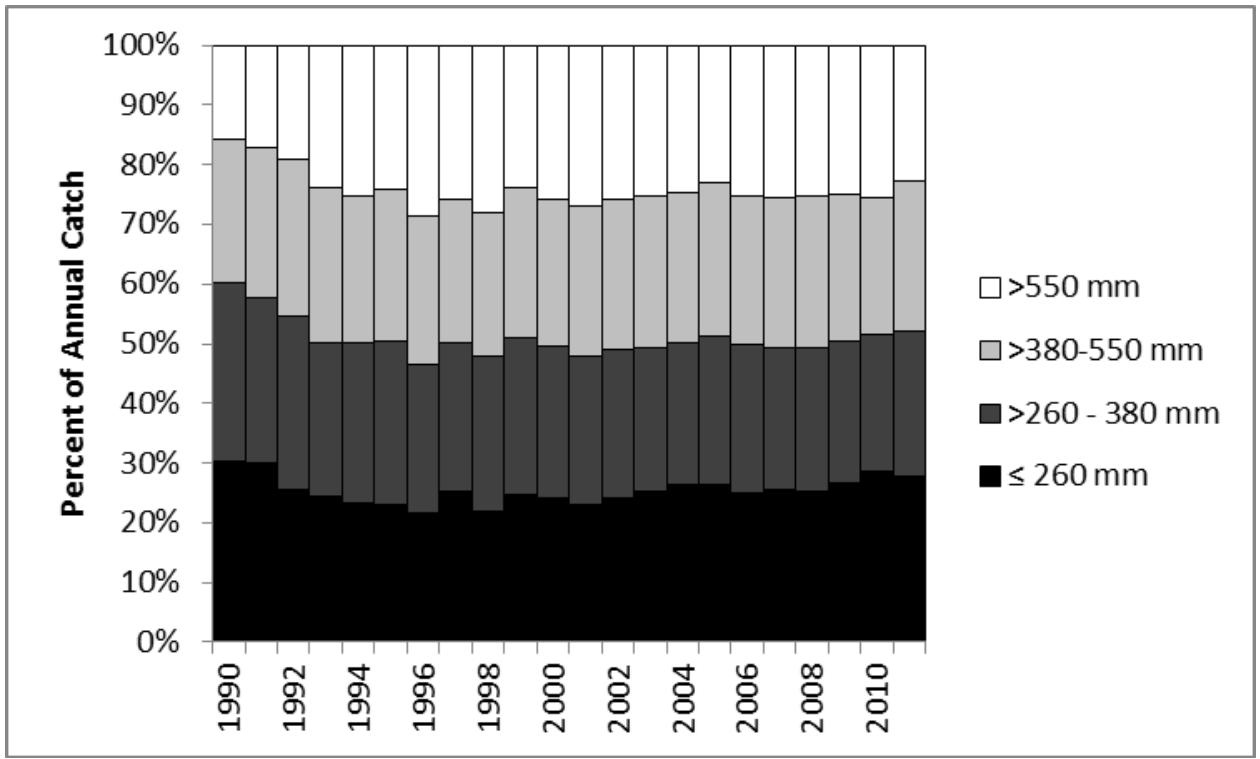

B.

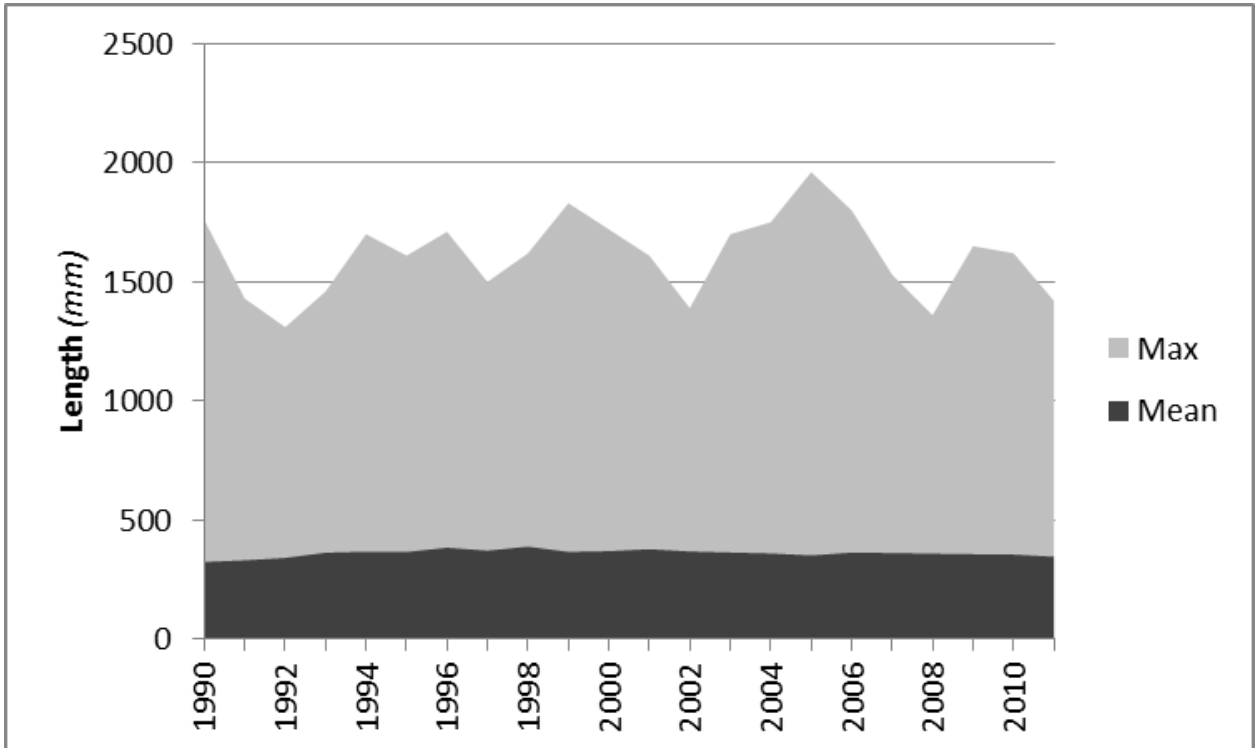

Figure 16. Length distribution of flatfish species collected in the EBS Trawl Survey, 1990-2011. (A) Distributions are represented as a percentage of the total annual catch. Length bins represent the quartiles of all catches cumulatively. (B) Mean and maximum length of all flatfish caught in the survey. 


\subsection{COMmunity Diversity AND STRUCTURE}

\subsubsection{Georges Bank}

\subsubsection{Species Richness}

The potential species richness, as estimated by the number of species represented in the NEFSC Northeast Bottom Trawl survey Georges Bank stations between 1975 and 2011 was 163 species (Figure 28). Annual Historical Biological Index (HBI) values ranged from a minimum of 0.3374 to a maximum of 0.5153 (Figure 17). Linear regression revealed a significant trend of increasing HBI by 0.0026 units per year, $\mathrm{r}^{2}(36)=0.4298, \mathrm{p}=0.00001$. Correlation analyses were conducted using Bonferroni adjusted alpha levels of 0.0024 per test. HBI was strongly correlated to global surface temperature anomalies, $\mathrm{r}(32)=0.6314, \mathrm{p}=0.0001$. No other correlations were statistically significant (Appendix C). Multiple regression of HBI, single species abundance, climate, and fishing effort yielded statistical significance level, $\mathrm{F}(32,7)=3.276, \mathrm{p}=0.01307$, and accounted for over $33 \%$ of the error $\left(\mathrm{r}^{2}=0.3324\right)$ (Table 9). Variables included in the regression were not considered multicollinear, with all correlation coefficients less than 0.43 . 


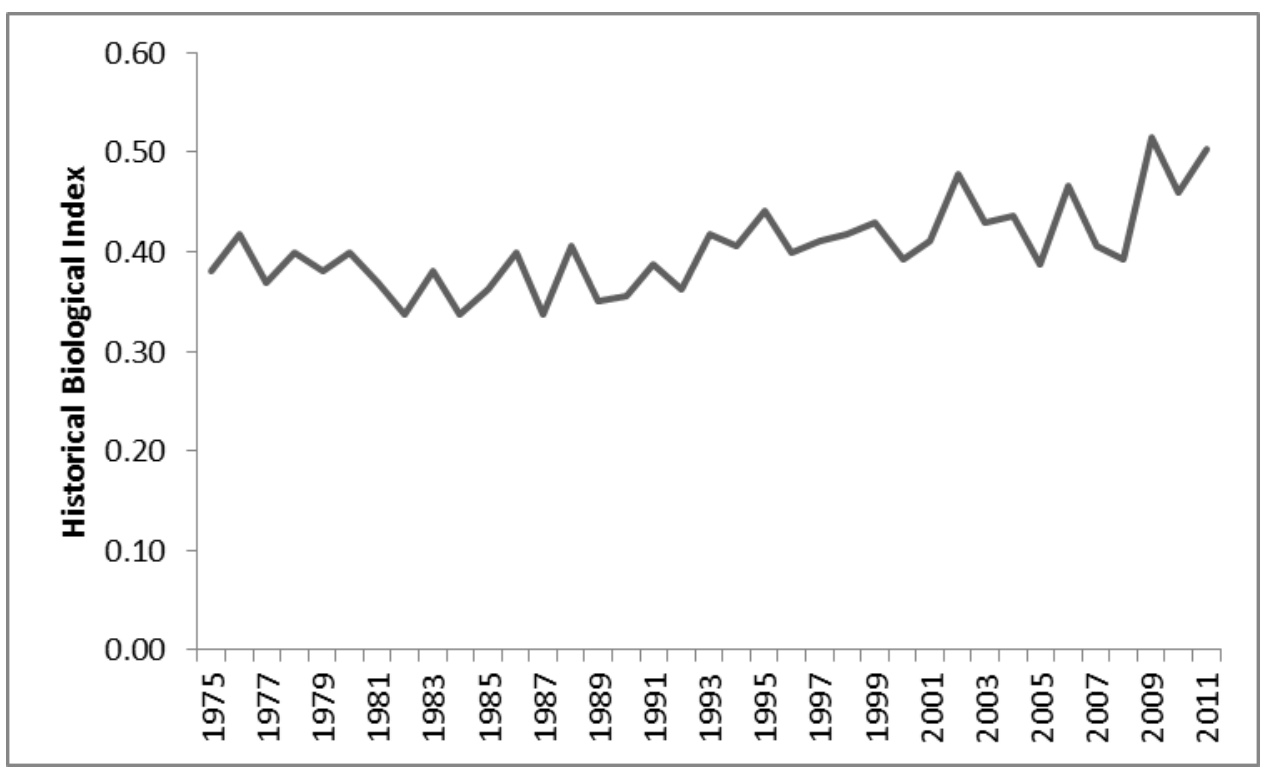

Figure 17. Historical Biological Index of catches from the NEFSC Northeast Bottom Trawl Survey Georges Bank stations, 1975-2011. This index evaluates the changes in species richness relative to the potential species richness of a community. Overall, a slight trend of increasing Historical Biological Index is evident.

Table 9. Multiple regression results to determine relationship of effort and environmental influences on Historical Biological Index values. Demersal fishing effort is defined as the cumulative number of days of bottom fishing on Georges Bank. Atlantic Cod Trawl Catch is the number of Atlantic cod caught in the NEFSC Northeast Bottom Trawl Survey. Commercial catch is the total weight of all commercial catches in New England per year. Georges Bank bottom temperature is the mean annual bottom temperature at NEFSC Northeast Bottom Trawl Survey Georges Bank stations.

\begin{tabular}{|c|c|c|c|}
\hline & $\boldsymbol{\beta}$ & $\mathbf{T}$ & p \\
\hline Intercept & $4.10 \times 10^{-1}$ & 3.471 & 0.0019 \\
\hline Georges Bank Bottom Temperature & $5.45 \times 10^{-4}$ & 0.058 & 0.9541 \\
\hline Commercial Catch & $-2.85 \times 10^{-8}$ & -0.115 & 0.9096 \\
\hline Demersal Fishing Effort & $-6.59 \times 10^{-8}$ & -1.062 & 0.2985 \\
\hline Global Temperature Anomalies & $1.35 \times 10^{-3}$ & 3.165 & 0.0040 \\
\hline North Atlantic Oscillation & $-6.76 \times 10^{-3}$ & -0.336 & 0.7397 \\
\hline Atlantic Cod Catch - Trawl & $-1.29 \times 10^{-5}$ & -0.484 & 0.6327 \\
\hline Storm Events & $-3.58 \times 10^{-3}$ & -1.490 & 0.1488 \\
\hline
\end{tabular}

\subsubsection{Species Evenness}

Annual Shannon Index values ranged from a minimum of 1.9944 in 1990 to a maximum of 2.9843 in 2003 (Figure 18). Linear regression demonstrated an insignificant trend of increasing Shannon Index value by 0.0048 units per year, $\mathrm{r}^{2}(36)$ 
$=0.0431, p=0.2175$. No correlations between Shannon Index, fishing effort, single species abundance, or climate were statistically significant. Multiple regression was not statistically significant, $F(32,7)=1.438, p=0.2347$ (Appendix B).

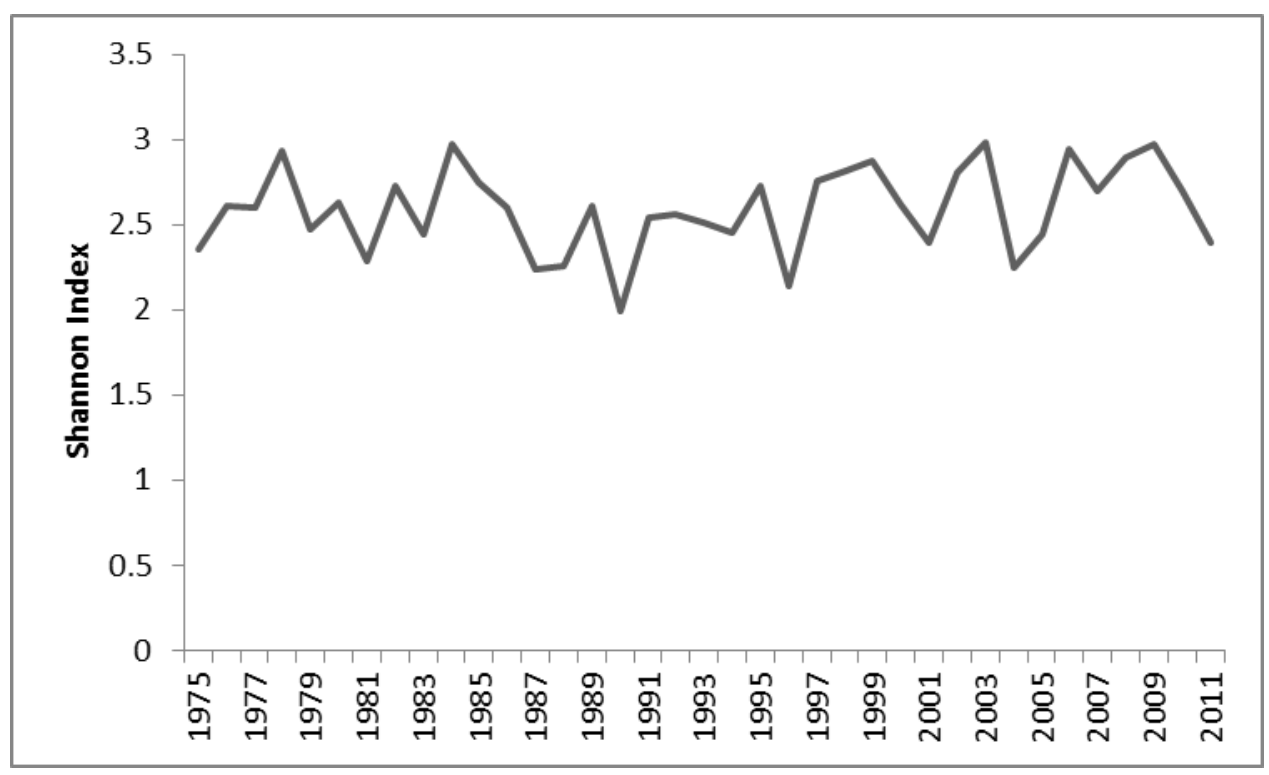

Figure 18. Shannon Diversity Index of catches from the NEFSC Northeast Bottom Trawl Survey Georges Bank stations, 1975-2011. The Shannon Index is among the most common measures of community diversity

\subsubsection{Trophic Diversity}

Annual Mean Trophic Level ranged from a minimum of 3.644 in 2000 to a maximum of 4.093 in 1990 (Figure 19). Linear regression revealed a non-significant trend of declining MTL by 0.0029 levels per year, $\mathrm{r}^{2}(36)=0.068, \mathrm{p}=0.1190$. A correlation was present with demersal fishing effort, $r(32)=0.6876, p=0.00001$ (Appendix B). Multiple regression of MTL, single species abundance, climate, and fishing effort yielded significance at the macro level, $F(32,7)=4.51, p=0.002289$, and accounted for over $43 \%$ of the error $\left(r^{2}=0.4343\right)$ (Table 10). Variables included in the regression were not considered multicollinear, with all correlation coefficients less than 0.43 . 


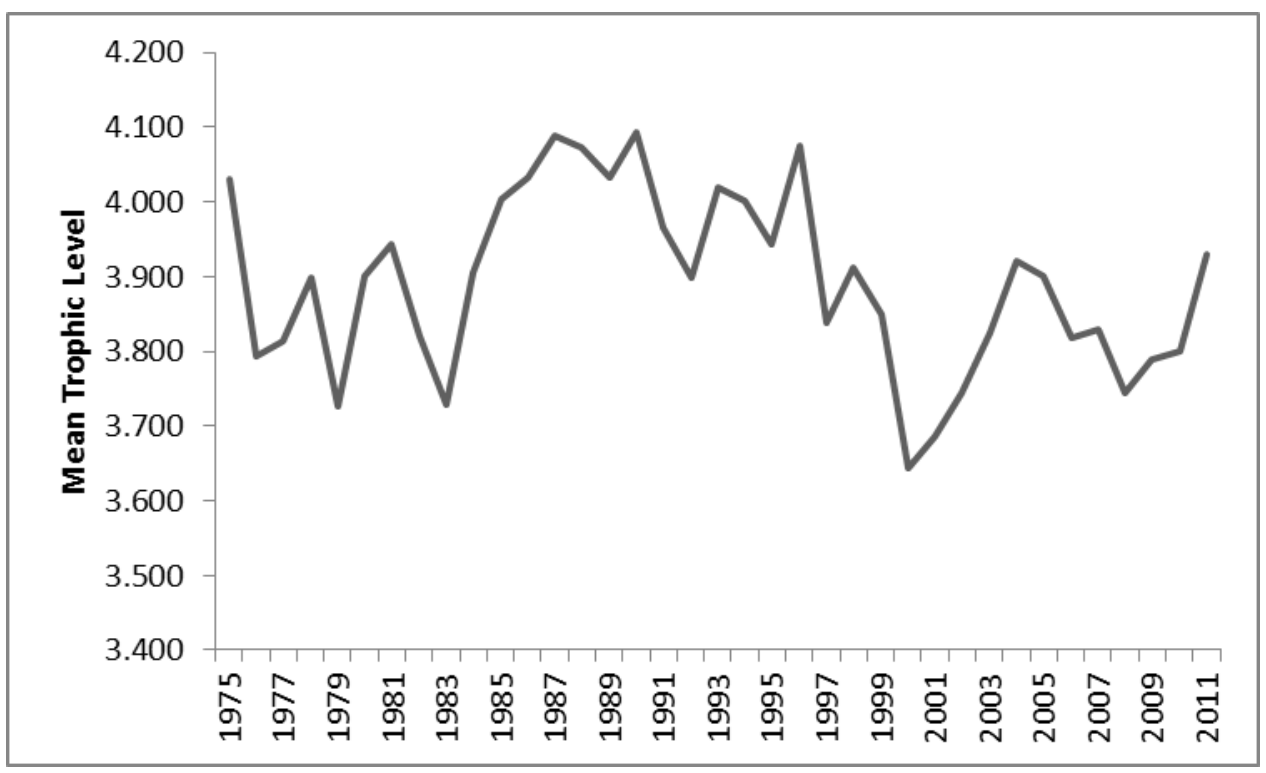

Figure 19. Mean Trophic Level of catches from the NEFSC Northeast Bottom Trawl Survey Georges Bank stations, 1975-2011. This index evaluates the trophic diversity of communities.

Table 10. Multiple regression results to determine relationship of effort and environmental influences on Mean Trophic Level values. Demersal fishing effort is defined as the cumulative number of days of bottom fishing on Georges Bank. Atlantic Cod Trawl Catch is the number of individuals caught in the NEFSC Northeast Bottom Trawl Survey. Commercial catch is the total weight of all commercial catches in New England per year. Georges Bank bottom temperature is the mean annual bottom temperature at NEFSC Northeast Bottom Trawl Survey Georges Bank stations.

\begin{tabular}{|c|ccc|}
\hline \multicolumn{1}{|c}{ Intercept } & $\boldsymbol{\beta}$ & $\mathbf{T}$ & $\mathbf{p}$ \\
\hline Georges Bank Bottom Temperature & $3.98 \times 10^{0}$ & 12.009 & $7.07 \times 10^{-12}$ \\
Commercial Catch & $-4.28 \times 10^{-2}$ & -1.630 & 0.1156 \\
Demersal Fishing Effort & $-2.49 \times 10^{-7}$ & -0.358 & 0.7233 \\
Global Temperature Anomalies & $7.23 \times 10^{-7}$ & 4.158 & 0.0003 \\
North Atlantic Oscillation & $-1.06 \times 10^{-3}$ & -0.884 & 0.3853 \\
Atlantic Cod Catch - Trawl & $-4.15 \times 10^{-2}$ & -0.736 & 0.4686 \\
Storm Events & $-2.34 \times 10^{-6}$ & -0.031 & 0.9753 \\
\hline & $6.29 \times 10^{-3}$ & 0.935 & 0.3587 \\
\hline
\end{tabular}

\subsubsection{Eastern Bering Sea}

For all correlation analyses of species diversity in the Eastern Bering Sea, Bonferroni adjusted alpha levels of 0.0014 were used.

\subsubsection{Species Richness}

The potential species richness, as estimated by the number of species represented in the EBS Bottom Survey between 1982 and 2011 was 193 species 
(Figure 31). Historical Biological Index values demonstrated minor annual fluctuations between the years of 1981 and 2011 (Figure 20). During this time period, HBI reached a minimum of 0.3886 in 1989 and a maximum of 0.5959 in 2010, with a mean of 0.4800 . Linear regression revealed a significant trend of increasing HBI at a rate of 0.0035 units per year, $\mathrm{r}^{2}(30)=0.3492, \mathrm{p}=0.000585$. Strong correlations were evident between HBI and EBS surface temperature, $\mathrm{r}(19)=-0.8685, \mathrm{p}=0.000001$, Multiple regression analysis of HBI, single species abundance, climate, and fishing effort yielded statistical significance, $F(18,9)=12.84, p=0.0 .0004$, and accounted for over $85 \%$ of the variance $\left(r^{2}=0.8555\right)$ (Table 11). Variables included in the regression were not considered multicollinear, with all correlation coefficients less than 0.7 .

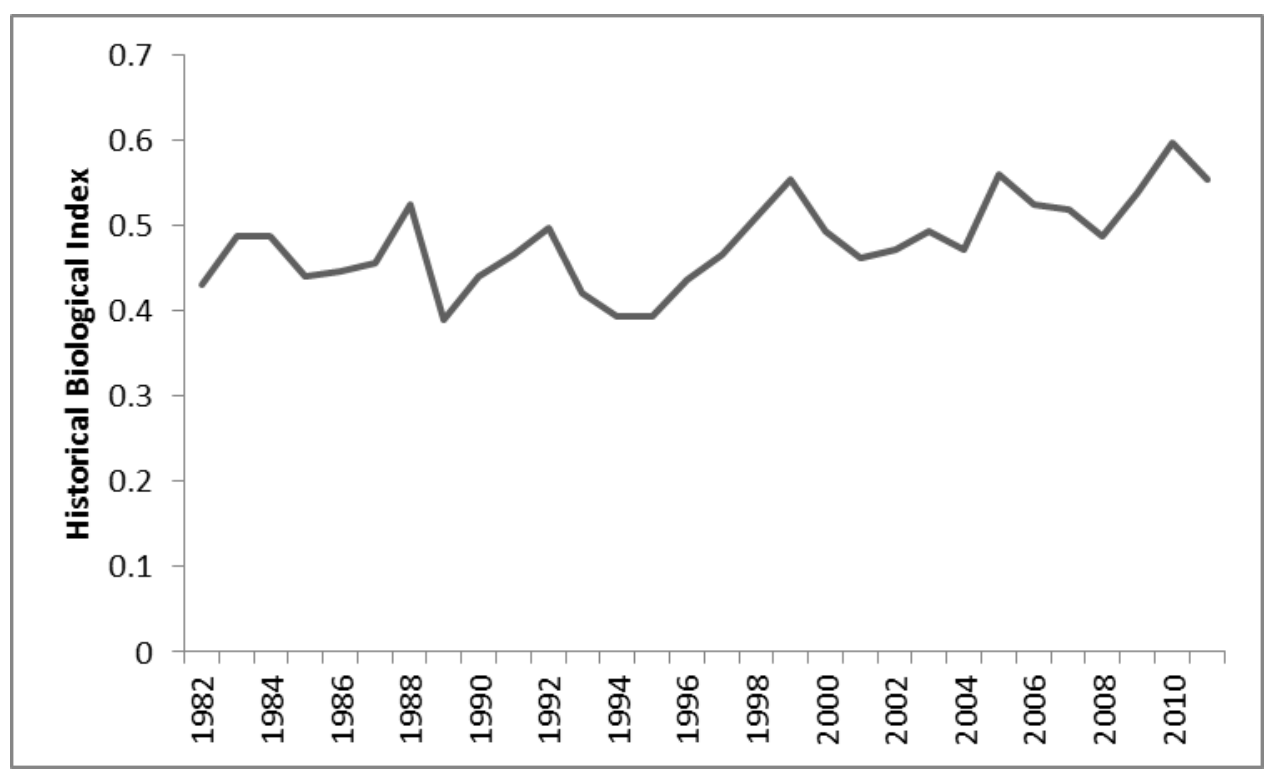

Figure 20. Historical Biological Index of catches from the AFSC Eastern Bering Sea Trawl Survey, 1982-2011. This index evaluates the changes in species richness relative to the potential species richness of a community. 
Table 11. Multiple regression results to determine relationship of effort and environmental influences on Historical Biological Index. Pacific Cod Trawl Catch and Walleye Pollock Trawl Catch indicate the number of Pacific Cod and Walleye Pollock caught in the AFSC Eastern Bering Sea Trawl Survey per unit effort. Trawl Fishing Effort is described as the number of sightings of bottom trawlers in the Eastern Bering Sea. EBS Bottom and Surface Temperature are the annual mean temperatures recorded during the AFSC Eastern Bering Sea Trawl Surveys.

\begin{tabular}{|c|ccc|}
\hline \multicolumn{1}{|c}{ Intercept } & $\boldsymbol{\beta}$ & $\mathbf{T}$ & $\mathbf{p}$ \\
\hline Alaskan Index & $4.08 \times 10^{1}$ & 4.859 & 0.0009 \\
Commercial Catch & $-1.01 \times 10^{0}$ & -1.490 & 0.1704 \\
Pacific Cod Catch & $-7.3 \times 10^{-7}$ & -0.211 & 0.8375 \\
Trawl Fishing Effort & $-6.90 \times 10^{-4}$ & -2.375 & 0.0416 \\
Ice Cover Index & $-6.66 \times 10^{-5}$ & -0.467 & 0.6514 \\
Ice Retreat Index & $-6.02 \times 10^{-1}$ & -1.109 & 0.2962 \\
Walleye Pollock Catch & $6.32 \times 10^{-2}$ & 1.493 & 0.1697 \\
EBS Bottom Temperature & $-6.28 \times 10^{-6}$ & -0.192 & 0.8522 \\
EBS Surface Temperature & $1.37 \times 10^{0}$ & 1.007 & 0.3401 \\
\hline
\end{tabular}

\subsubsection{Species Evenness}

Shannon Index values demonstrated little annual fluctuation, with a maximum of 2.1711 in 1988, a minimum of 1.5632 in 1982 (Figure 21). Linear regression revealed a significant trend of increasing Shannon Index value at a rate of 0.0076 units per year, $\mathrm{r}^{2}(30)=0.2903, \mathrm{p}=0.0021$. No significant correlations were evident between Shannon Index and fishing effort or climate (Appendix B). Multiple regression analysis of Shannon Index, single species abundance, climate, and fishing effort was not statistically significant, $F(18,9)=0.4602, p=0.8684$ (Appendix B). 


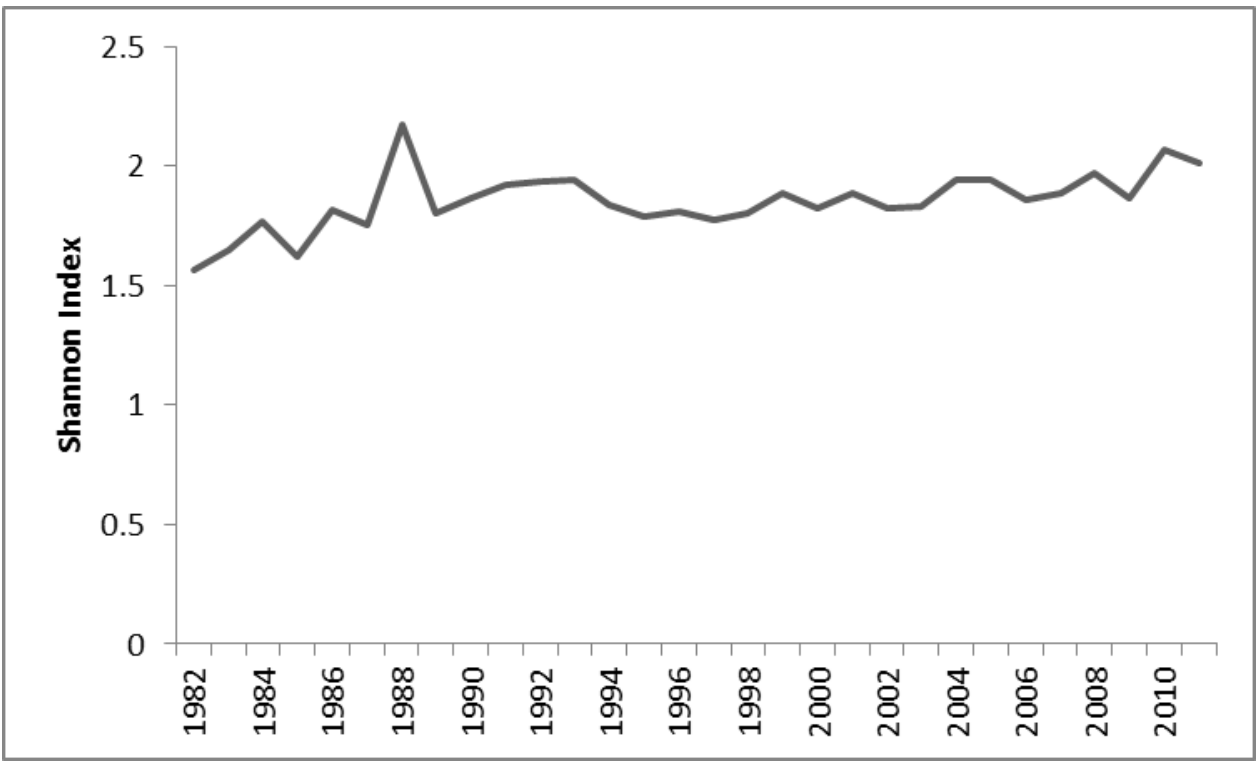

Figure 21. Shannon Diversity Index of catches from the AFSC Eastern Bering Sea Trawl Survey, 19822011.

\subsubsection{Trophic Diversity}

Mean Trophic Level demonstrated moderate annual variability (Figure 22). A maximum of 3.4099 occurred in 2003. A minimum of 3.3174 occurred in 1982. Linear regression revealed a significant trend of increasing MTL by 0.0016 levels per year, $\mathrm{r}^{2}(30)=0.4221, \mathrm{p}=0.0001$. No significant correlations were present between MTL and fishing effort or climate (Appendix B). Multiple regression analysis of MTL, single species abundance, climate, and fishing effort was not statistically significant, $\mathrm{F}(18,9)=2.291, \mathrm{p}=0.1164($ Appendix B $)$. 


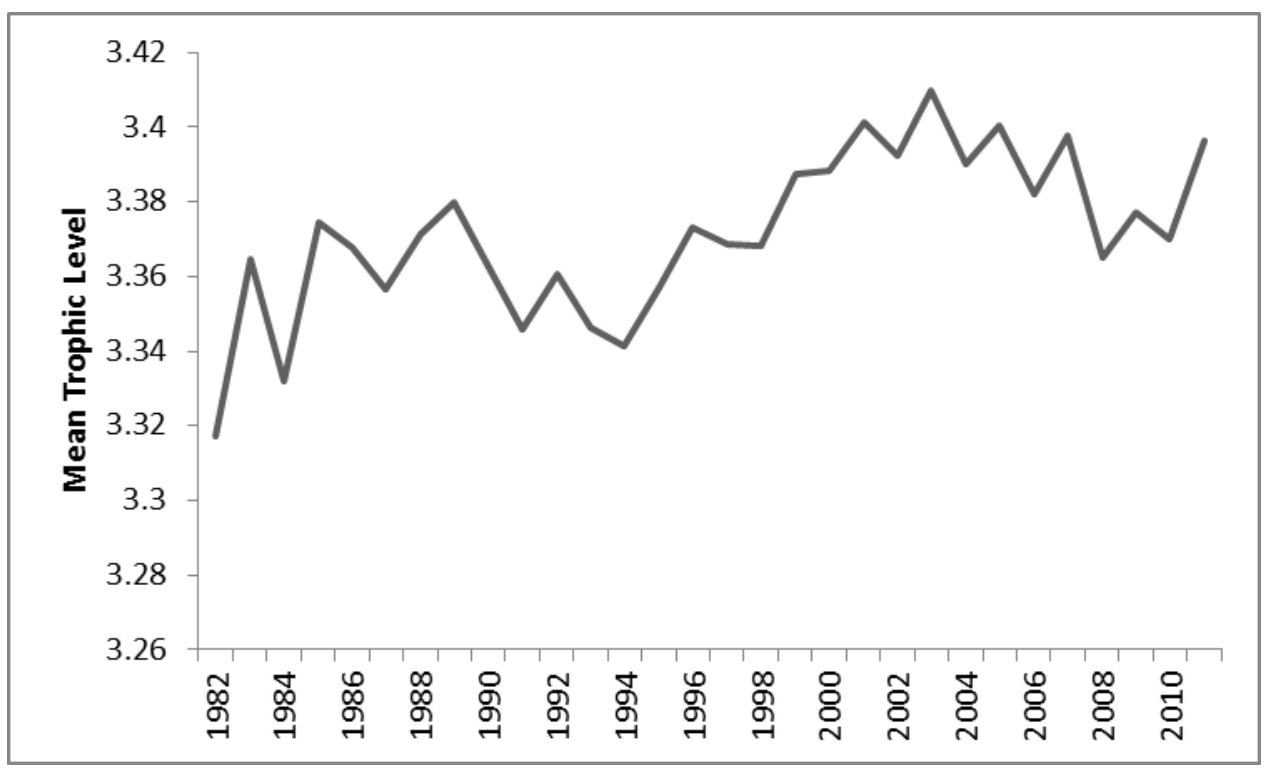

Figure 22. Mean Trophic Level of catches from the AFSC Eastern Bering Sea Trawl Survey, 19822011. This index evaluates the trophic diversity of communities. 


\section{ANALYSIS}

\subsection{COMPARISON OF GEORGES BANK AND EASTERN BERING SEA ECOSYSTEMS}

Due to the inherently complex nature of fisheries science and management, the interpretation of ecological data is often difficult. Thus, the results described in the preceding chapter should be interpreted in direct consideration of the research question addressed. While no single trend or discrepancy is apparent between the ecosystems, analysis would suggest that there are several interesting trends which may provide insight into the present discussion (Table 13, Table 14). 
Table 12. Correlations between length diversity, species diversity, fishing effort, and climate on Georges Bank. Cells indicated with an S indicate strong correlations, $\mathrm{M}$ indicates moderate correlations, and $\mathrm{W}$ indicates weak correlations. Symbols within parenthesis indicate the direction of the correlation, positive (+) or negative (-). Unmarked cells indicate no correlation.

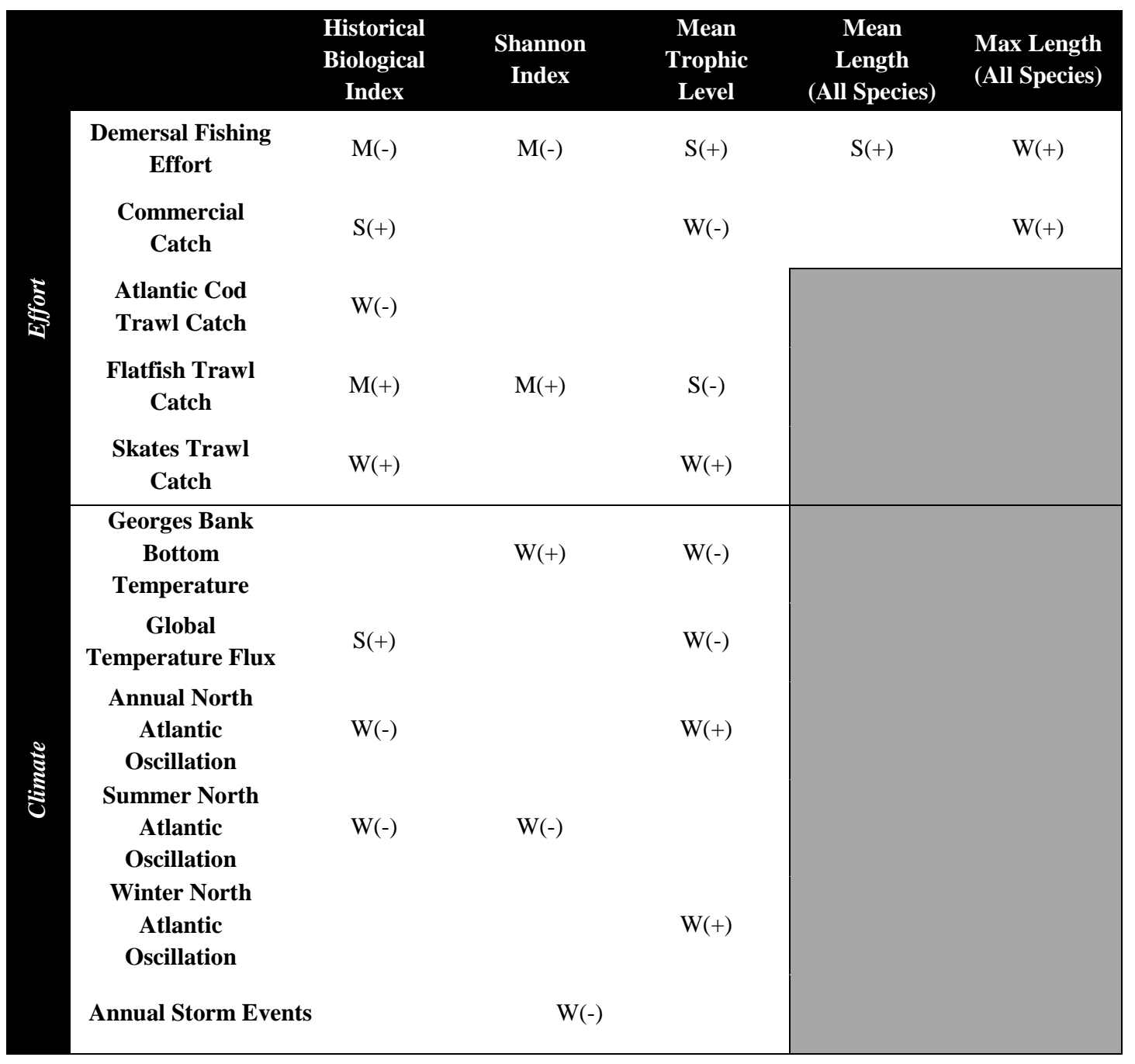


Table 13. Correlations between length diversity, species diversity, fishing effort, and climate in the Eastern Bering Sea. Cells indicated with an $\mathrm{S}$ indicate strong correlations, $\mathrm{M}$ indicates moderate correlations, and $\mathrm{W}$ indicates weak correlations. Symbols within parenthesis indicate the direction of the correlation, positive (+) or negative (-). Unmarked cells indicate no correlation.

\begin{tabular}{|c|c|c|c|c|c|}
\hline & $\begin{array}{l}\text { Historical } \\
\text { Biological } \\
\text { Index }\end{array}$ & $\begin{array}{c}\text { Shannon } \\
\text { Index }\end{array}$ & $\begin{array}{c}\text { Mean } \\
\text { Trophic } \\
\text { Level }\end{array}$ & $\begin{array}{c}\text { Mean } \\
\text { Length } \\
\text { (All Species) }\end{array}$ & $\begin{array}{l}\text { Maximum } \\
\text { Length } \\
\text { (All Species) }\end{array}$ \\
\hline Trawl Fishing Effort & $\mathrm{M}(-)$ & $\mathrm{W}(+)$ & $\mathrm{M}(-)$ & $\mathrm{S}(-)$ & $\mathrm{S}(+)$ \\
\hline Commercial Catch & $\mathrm{M}(-)$ & $\mathrm{W}(+)$ & & & \\
\hline $\begin{array}{c}\text { Pacific Cod Trawl } \\
\text { Catch }\end{array}$ & & & $\mathrm{W}(-)$ & & \\
\hline $\begin{array}{c}\text { Walleye Pollock Trawl } \\
\text { Catch }\end{array}$ & $\mathrm{M}(-)$ & $\mathrm{W}(-)$ & & & \\
\hline $\begin{array}{l}\text { EBS Bottom } \\
\text { Temperature }\end{array}$ & $\mathrm{S}(-)$ & $\mathrm{W}(-)$ & $\mathrm{W}(+)$ & & \\
\hline $\begin{array}{l}\text { EBS Surface } \\
\text { Temperature }\end{array}$ & $\mathrm{S}(-)$ & & & & \\
\hline Alaskan Index & $\mathrm{M}(-)$ & $\mathrm{W}(-)$ & & & \\
\hline Ice Cover Index & $\mathrm{S}(+)$ & & W(-) & & \\
\hline Ice Retreat Index & $\mathrm{S}(+)$ & $\mathrm{W}(+)$ & W(-) & & \\
\hline $\begin{array}{l}\text { May Sea Surface } \\
\text { Temperature }\end{array}$ & $\mathrm{S}(-)$ & & $\mathrm{W}(+)$ & & \\
\hline $\begin{array}{c}\text { Summer Bottom } \\
\text { Temperature }\end{array}$ & $\mathrm{M}(+)$ & & & & \\
\hline $\begin{array}{c}\text { Winter Sea Surface } \\
\text { Temperature }\end{array}$ & $\mathrm{M}(-)$ & $\mathrm{W}(-)$ & $\mathrm{M}(+)$ & & \\
\hline
\end{tabular}

\subsubsection{Fishing Effort and Climate Findings}

It is important to consider the effect of both human and climatic impacts on the ecosystem and species assemblages. To some degree, this can be accomplished through the evaluation of fishing effort and climate indices. In both ecosystems, there was a precipitous decline in fishing effort following 1990 (Figure 3, Figure 4). While direct comparison of the two datasets is not possible due to differences in sampling methodology, the trend of declining effort is apparent. Evaluation of the complete Georges Bank dataset demonstrates that this decline followed a dramatic increase in fishing effort through the mid-1980s, however effort data is not available for that 
period in the Eastern Bering Sea. Historical records, however, would suggest that there was a similar period of significant increases in effort during that period in the Eastern Bering Sea bottom fisheries (NWAFC 1985). An evaluation of the total commercial catch recorded in New England and Alaska highlights this similarity. Overall, catch remained fairly consistent during the study period in both ecosystems. Notably, New England catches were much more variable than those of Alaska. The Alaskan catch, while variable, showed much greater annual connectivity. These results suggest that the human use of both regions over the past forty years was likely quite similar.

While the evaluation of human fishing patterns is relatively clear, an evaluation of the changes associated with climate between the two regions is much more challenging. Georges Bank is located in a temperate region with water temperatures rarely falling below freezing (Flagg 1987). In contrast, the Eastern Bering Sea is crosses polar and subpolar regions. Ice cover is predictable, and extensive (Macklin, et al 2002). As such, comparisons between the two regions should be focused more on relative change rather than absolute differences in climate. Interestingly, despite the growing concern regarding increasing water temperatures due to climate change, in both ecosystems the mean annual bottom and surface temperatures recorded during the trawl surveys remained fairly constant (Figure 7, Figure 8). This finding is particularly interesting, as recent studies have noted that mean global sea surface temperature has increased by $0.59^{\circ} \mathrm{C}( \pm 0.12)$ in the last 135 years (Roemmich, et al 2012). Annual variation was present, however these datasets demonstrate no significant trend indicating climatic shift at this time scale. 
An evaluation of longer-term temperature changes, however, has suggested that larger-scale climatic changes are occurring in both ecosystems. The 2011 report on the Northeast Shelf Large Marine Ecosystem concluded that the region is subject to greater seasonal variation in water temperatures and demonstrates a mean increase in surface temperature of $1^{\circ} \mathrm{C}$ since 1854 (Ecosystem Assessment Program 2012). Additionally, recent studies focused on the Bering Sea have suggested that a climatic regime shift may currently be underway (Grebmeier, et al. 2006). Other studies have suggested that slight changes in temperature and ice cover may be due to the presence of a positive phase of the Arctic Oscillation (Grebmeier, et al. 2006). It is interesting to note, however, that the Eastern Bering Sea temperature data is heteroskedastic, with much greater annual variation occurring in more recent years. In contrast, the Georges Bank temperature data collected during the trawl survey demonstrate no signs of heteroskedasticity, but rather appear to demonstrate strong annual connectivity.

It is also important to consider the patterns of relative abundance in each ecosystem. On Georges Bank, species dominance appears to be occur in a phases (Figure 5). Punctuated periods of dogfish, haddock, and pollock dominance are all evident during the study period. Interestingly, these variable phases of species dominance suggest an overall instability of the system. In contrast, relative abundance in the Eastern Bering Sea is much more stable over the course of the study period (Figure 6). According to catches in the AFSC EBS Trawl Survey, the region is dominated by flatfish. It is important to consider, however, that this refers to a species complex rather than a single species. As such, when considering individual species dominance, it is more accurate to note the dominance of walleye pollock and Pacific 
cod. The relative abundance of both species, remained relatively even over the course of the study period, however an overall trend of decreasing abundance was apparent. These results suggest that even though fishing effort has been relatively equal in both systems, and climate has been more variable in the Eastern Bering Sea, on average, the Georges Bank ecosystem can be characterized by its relative instability while the Eastern Bering Sea ecosystem is characterized by a much more stable pattern of species dominance and community structure.

Since 2004, however, a trend of increasing instability in species dominance and community structure in the Eastern Bering Sea has become evident (Figure 6, Figure 23). It is particularly interesting to note that this change in stability occurred simultaneously with the climatic shifts. Prior to 2004, pollock and cod abundance remained fairly stable. Since that time, walleye pollock has maintained a near constant abundance, while Pacific cod numbers have continued to decline and flatfish abundance has increased exponentially. While this may indicate the beginning of a trend of increasing instability, it is important to note that this was a relatively short time period and continued evaluation will likely be necessary.

\subsubsection{Length Distributions Findings}

Further support for this observation regarding system stability is evident in the length distribution data. On Georges Bank, the length distributions of all species are highly variable, with very high annual variability (Figure 9). Additionally, both the mean and maximum lengths are moderately variable between years. In contrast, length distributions are very stable in the Eastern Bering Sea and only very minor annual variation is evident (Figure 13). Furthermore, the EBS mean length remained virtually 
unchanged over the course of the study period. The maximum length did, however, fluctuate greatly. These fluctuations, while great in magnitude, were generally not as active over shorter time periods. These results support the observation that the Eastern Bering Sea may be a more stable environment than Georges Bank when comparing length distributions.

An evaluation of length distributions among similar species further supports the observation that the Georges Bank demersal community tends to be more ecologically unstable than that of the Eastern Bering Sea. Length distributions of Atlantic cod on Georges Bank are very unstable, with great variations in the number of small- and large-sized fish between years (Figure 10). In contrast, length distributions of Pacific cod in the Eastern Bering Sea are much more stable with only minor annual fluctuation in the proportion of small- and large-bodied fish (Figure 15). Comparisons of mean and maximum lengths of the two species further support this observation. The flatfish species complex displayed the same trend. On Georges Bank, the proportion of small- and large-bodied flatfish is highly variable between years (Figure 11). Additionally maximum length is highly variable with periodic and dramatic spikes in maximum length. Mean length during this time period, however, remained relatively constant. Proportions of length distributions of flatfish caught in the AFSC EBS Trawl Survey were fairly constant over the duration of the study period with almost no annual variability (Figure 16). Mean length was also very stable during this period. Maximum length of EBS flatfish was moderately variable, however annual changes did not take the form of periodic spikes. Instead, changes in maximum length 
appeared to occur in multiannual cycles of higher length punctuated by periodic, consecutive years of depressed maximum length.

It is also interesting to note that in both Georges Bank and the Eastern Bering Sea, strong correlations were present between mean length and fishing effort, however the ecosystems display an opposite direction of change (Table 12, Table 13). There was also a strong, positive correlation between mean flatfish length and fishing effort in both ecosystems. Interestingly, on Georges Bank, Atlantic cod mean length is only weakly correlated to fishing effort. Instead, maximum length is strongly correlated to effort. In the Eastern Bering Sea, fishing effort is neither correlated to mean nor maximum Pacific cod length.

\subsubsection{Biodiversity}

It is also important to consider the effects of relative biodiversity change between the two communities. While a direct comparison of absolute values is inadvisable due to the inherent differences in data collection methodologies and ecosystem characteristics, a comparison of relative changes allows for valuable insights. Several measurements of biodiversity were presented in preceding chapters. Indices of species richness and evenness demonstrate an increasing trend across both ecosystems. There was greater potential species richness in the Eastern Bering Sea than on Georges Bank (Figure 28, Figure 31). This is particularly interesting, because the Georges Bank dataset consisted of more years of data, which arguably may allow for an increased potential of rare species capture. Despite this difference in magnitude, the two ecosystems appear to exhibit similar changes in species richness. In both systems, there is a general trend of increasing Historical Biological Index (Figure 17, 
Figure 20). Both ecosystems experienced a similar absolute change in HBI. Due to the shorter time series in the Eastern Bering Sea, however, this corresponded to a higher rate of change in that region. Species evenness, measured by Shannon Index also demonstrated a trend of increasing species richness across ecosystems (Figure 18, Figure 29, Figure 21, and Figure 32). These results, however, were supported by varying statistical power.

Evaluation of trophic diversity indices yielded contradictory results. On Georges Bank, Mean Trophic Level of the NEFSC Northeast Bottom Trawl Survey was highly variable, with a period of higher trophic level between 1984 and 1999 (Figure 19). An overall trend of declining MTL was present in the Georges Bank ecosystem. In the Eastern Bering Sea trawl, MTL was relatively more consistent and a trend of increasing trophic level was evident (Figure 22). The trophic diversity results demonstrated high annual variability in both ecosystems.

\subsubsection{Models of Biodiversity}

In both the Georges Bank and Eastern Bering Sea ecosystems, Historical Biological Index was correlated to various climatic factors and single species abundance. Multiple regressions of HBI and single species abundance, fishing effort, and climate yielded statistical significance and accounts for over $33 \%$ of HBI variability in both ecosystems. In both ecosystems, species richness was correlated to single species abundance and climate. Trends in Mean Trophic Level on Georges Bank also revealed interesting statistical relationships. While overall, conclusive results from the trophic diversity analyses are unclear, Georges Bank MTL was found to be strongly correlated to fishing effort. Multiple regression yielded statistical 
significance and accounted for over $30 \%$ of the variability in MTL data. This result, however, was not repeated in the Eastern Bering Sea data.

\subsubsection{Themes of Ecosystem Relationships and Change}

All diversity indices demonstrated much higher variability within the Georges Bank diversity scores than within Eastern Bering Sea diversity. Furthermore, all indices, with the exception of Mean Trophic Level revealed trends of increasing diversity in both regions (Figure 28 - Figure 33). In all of these cases, the rate of diversity increases was higher in the Eastern Bering Sea. Predictability of species richness change was higher for Georges Bank data than for Eastern Bering Sea data, however for species evenness change the opposite was true. This manner of generalization is difficult in regards to trophic diversity. The rate of change was always faster in the Georges Bank ecosystem. The directionality and predictability of these changes, however, remains unclear. This may suggest that the use of species richness and evenness indices are more reliable methods to evaluate system changes. This observation is supported by the literature. Previous examinations of the utility of species diversity indices have suggested that these less-derived measurements are less likely to likely to be more reliable than the more derived measurements of evenness and trophic diversity due to sampling bias (Gotelli 2001; Washington 1984). In particular, Historical Biological Index may provide the most reliable and repeatable results of ecosystem evaluations. This index demonstrated statistically significant trends in annual change and multiple regression results suggest that there is likely a predictable relationship between HBI and temperature for both ecosystems. 
Another theme that presented itself in the results is the trend of increasing variability in Eastern Bering Sea length distributions since 2004. Considering the diversity results in light of this observation provides additional insights. Since 2004, the Mean Trophic level trend has changed directions, from an increasing trend to a decreasing trend (Figure 23). Additionally, rate of change in Historical Biological Index has increased by over eight orders of magnitude ( 0.285 units per year 19822004, 2.321 units per year since 2004). Changes in the directionality and magnitude were not evident in Shannon Index values. Shannon Index, however, did show a decreased predictability of changes after 2004. These results may suggest accelerated changes in the Eastern Bering Sea ecosystem since 2004.

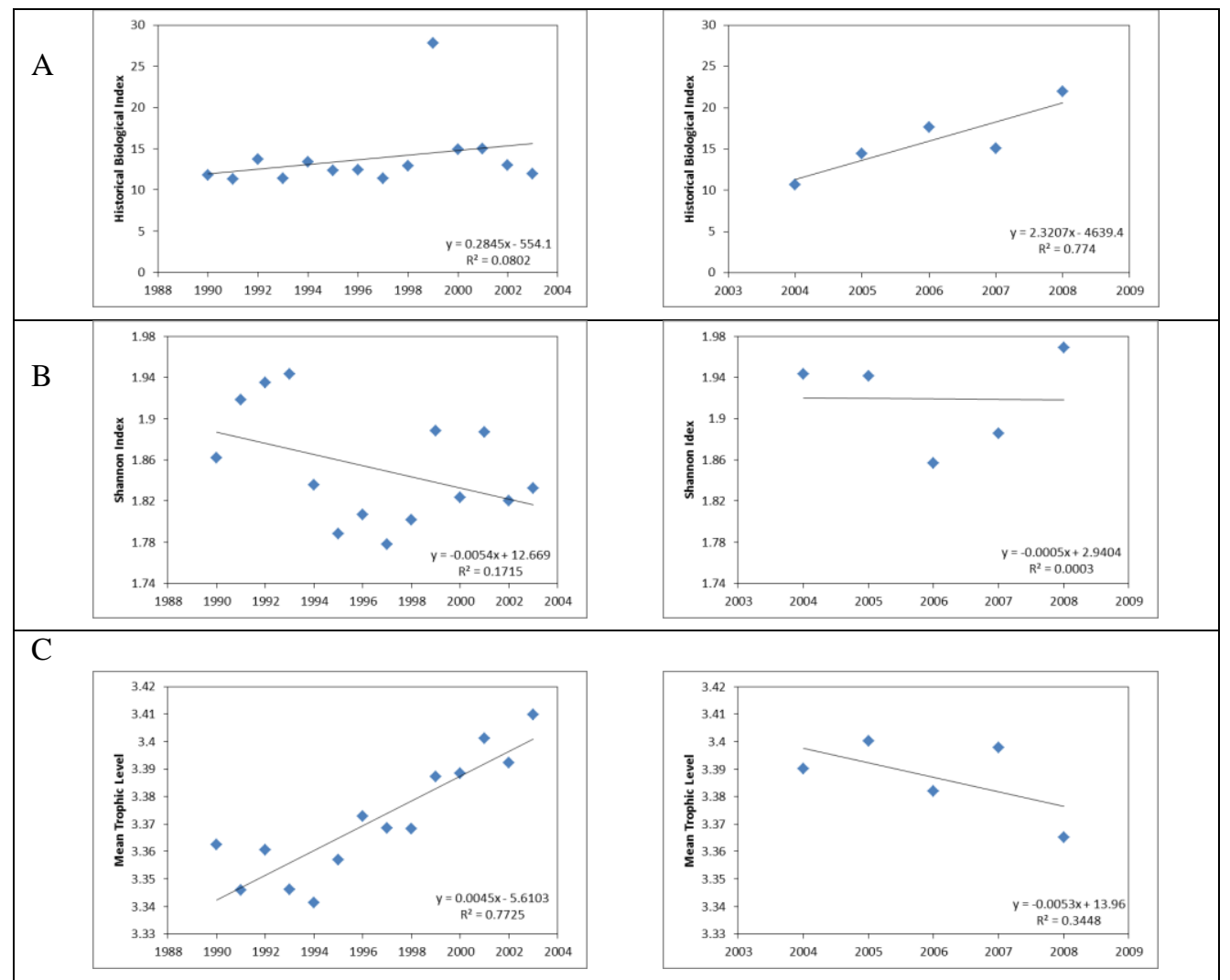

Figure 23. Changes in Eastern Bering Sea species diversity since 2004. Panel (A) indicates Historical Biological Index, (B) indicates Shannon Index, and (C) indicates Mean Trophic Level. 


\subsection{Ecosystem Structure ANd Fisheries Policies}

\subsubsection{Georges Bank}

An evaluation of fisheries management on Georges Bank identified eleven years where critical management actions occurred (Table 13). Included in these milestones was the adoption of new Fishery Management Plans (FMPs), significant FMP revisions, or legal proceedings directly affecting the management of Georges Bank groundfish. When juxtaposed with changes in the species or community composition of Georges Bank, five management actions are implicated as possible contributors to ecosystem changes. 
Table 14. Outline of significant developments in fisheries management policy on Georges Bank, 19762011.

\begin{tabular}{|c|c|c|}
\hline Year & Policy / Action & Management Action \\
\hline 1976 & $\begin{array}{l}\text { Magnuson Stevens Fishery } \\
\text { Conservation and Management Act }\end{array}$ & $\begin{array}{l}\text { Mandated development of regional } \\
\text { fishery management councils, closure } \\
\text { of U.S. EEZ to foreign fishing. }\end{array}$ \\
\hline 1977 & $\begin{array}{l}\text { First Fishery Management Plan } \\
\text { (FMP) for Atlantic cod, haddock, and } \\
\text { yellowtail flounder in New England. }\end{array}$ & $\begin{array}{l}\text { Primarily focused on catch quotas } \\
\text { and vessel trip limits. }\end{array}$ \\
\hline 1982 & Revised FMP & $\begin{array}{l}\text { Quotas and trip limits virtually } \\
\text { eliminated. }\end{array}$ \\
\hline 1984 & Creation of the Hague Line & $\begin{array}{l}\text { Divided Georges Bank into Canadian } \\
\text { and United States jurisdictional } \\
\text { waters. }\end{array}$ \\
\hline 1986 & First Multispecies Groundfish FMP & $\begin{array}{l}\text { Extended prior management efforts } \\
\text { to include all primary groundfish } \\
\text { species. }\end{array}$ \\
\hline 1989 & FCMA 301(b), “602 Guidelines” & $\begin{array}{l}\text { Establishment of an overfishing } \\
\text { definition. }\end{array}$ \\
\hline 1991 & $\begin{array}{l}\text { National Marine Fisheries Service } \\
\text { sued by the Conservation Law } \\
\text { Foundation for failure to prevent } \\
\text { overfishing of Atlantic cod, haddock, } \\
\text { and yellowtail flounder. }\end{array}$ & $\begin{array}{l}\text { Prompted discussions regarding } \\
\text { Amendment } 5 \text {. }\end{array}$ \\
\hline \multirow[t]{2}{*}{1994} & Amendment 5 & $\begin{array}{l}\text { Mandated decreases in fishing } \\
\text { mortality by } 50 \% \text { in } 5 \text { years, effort } \\
\text { limitation measures including } \\
\text { reduced fishing days and partial } \\
\text { closure of fishery entry. }\end{array}$ \\
\hline & Emergency Action & $\begin{array}{l}\text { Strict haddock trip limits and } \\
\text { Georges Bank closed areas } \\
\text { established. }\end{array}$ \\
\hline \multirow[t]{2}{*}{1996} & $\begin{array}{l}\text { Amendment } 7 \text { implemented in } \\
\text { response to the failure of the Atlantic } \\
\text { cod, haddock, and yellowtail } \\
\text { fisheries. }\end{array}$ & $\begin{array}{l}\text { Mandated decreases in fishing } \\
\text { mortality of } 80 \% \text { in two years, effort } \\
\text { reduction requirements. }\end{array}$ \\
\hline & Sustainable Fisheries Act & $\begin{array}{l}\text { Required additional action to ensure } \\
\text { sustainability of fisheries and prevent } \\
\text { overfishing. }\end{array}$ \\
\hline 2004 & Amendment 13 & $\begin{array}{l}\text { Sector Management pilot program } \\
\text { initiated. }\end{array}$ \\
\hline 2010 & Amendment 16 & $\begin{array}{l}\text { Full Sector Management policy } \\
\text { initiated. }\end{array}$ \\
\hline
\end{tabular}


The implementation of the Magnuson Stevens Fishery Conservation and Management Act in 1976 coincided with overall increases in the abundance most of the demersal species of commercial importance (i.e. Atlantic cod, haddock, yellowtail flounder) Error! Reference source not found.(Figure 24). During this period of increased single species abundance, a decreasing trend of system diversity was recorded in all diversity indices (Figure 25). In 1982, a revised FMP for the management of Atlantic cod, haddock, and yellowtail flounder was implemented. This FMP virtually eliminated the management actions established in an earlier version of the FMP. Following the implementation of this document, a decline in cod, flatfish, and haddock trawl catch occurred. This period was also associated with an increase in trophic diversity in Georges Bank trawl catches.

Perhaps one of the most critical years in terms of Georges Bank management was 1994. It was in this year that Amendment 5 to the Northeast Multispecies Fishery Management Plan was passed and an Emergency Action Plans for haddock management was implemented also resulted in an interesting trend of fish abundance. Amendment 5 included a provision mandating a decrease in fishing mortality by $50 \%$ within five years. Also in 1994, an Emergency Action was taken by the National Marine Fishery Service which resulted in strict trip limits of haddock catch and established the Georges Bank closed area. Following implementation, Atlantic cod, haddock, and flatfish catches in the NEFSC Northeast Bottom Trawl Survey progressively increased over the next two years. No significant changes in system diversity accompanied these changes. The passage of Amendment 7 in 1996 extended the required a $20 \%$ reduction in fishing mortality within two years. Following the 
implementation of Amendment 7, cod, haddock, and flatfish stocks remained relatively stable and no predictable changes in system diversity occurred. Interestingly, after 2004, catches of these species became increasingly unstable and all measurements of system diversity experienced a pronounced increase. 


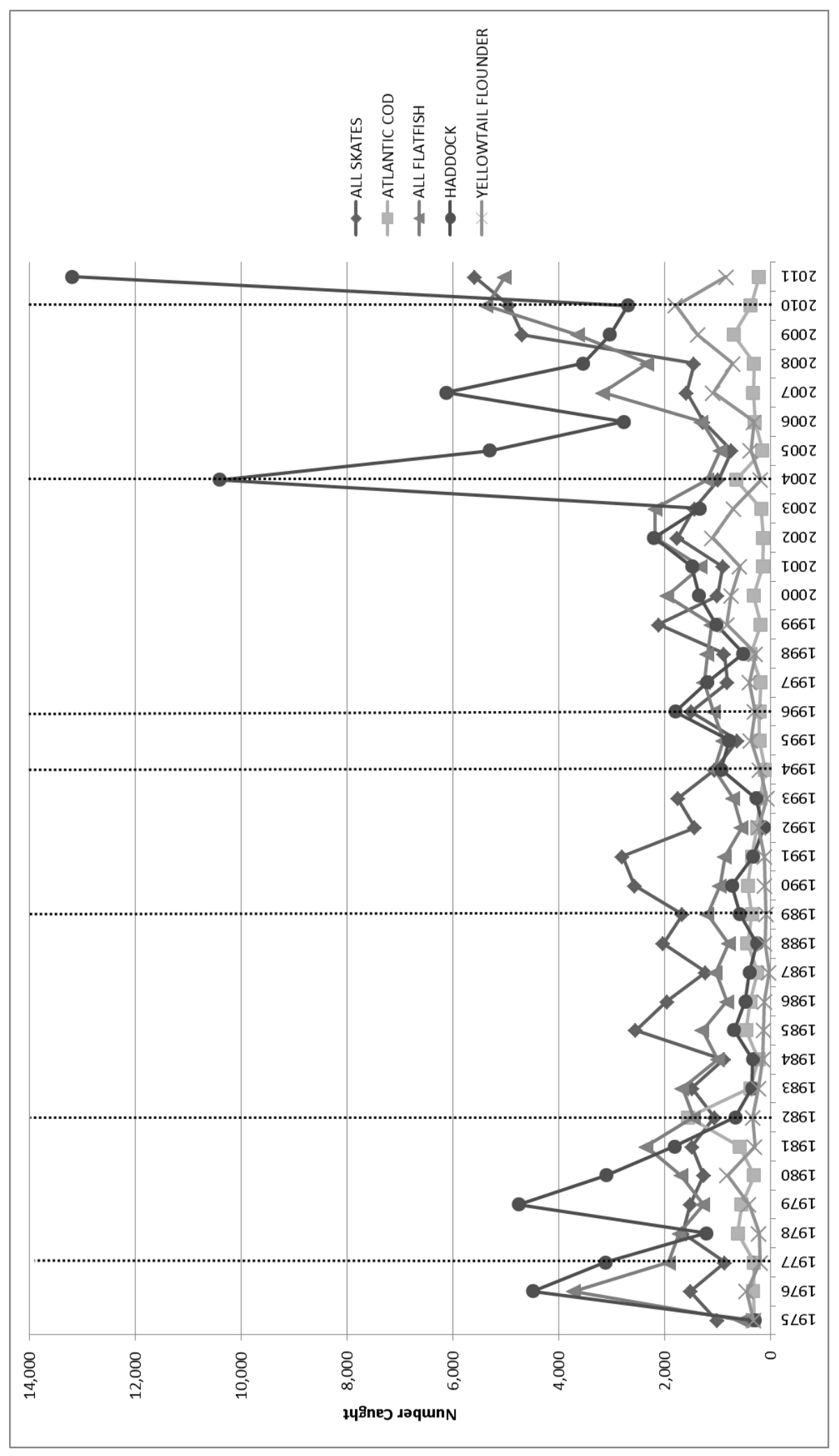

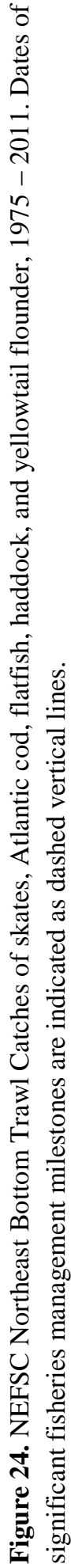




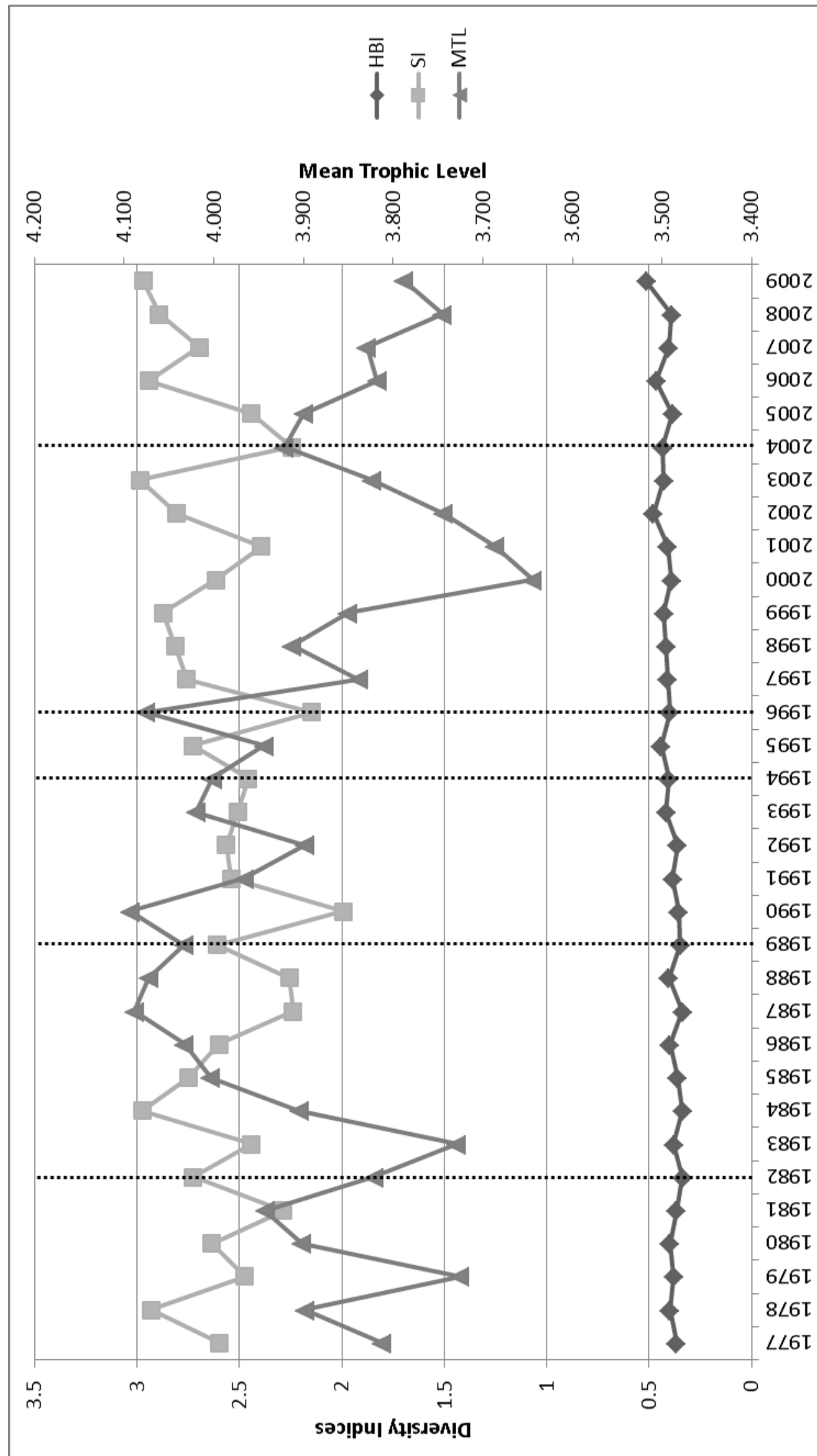

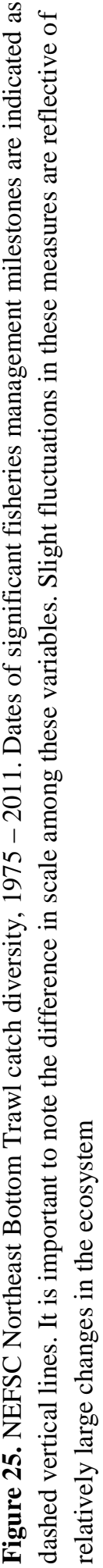


While these results may suggest that some management actions had a positive effect on single species abundances and system diversity, it is important to consider the latency period which would be necessary for a given management action to affect an ecosystem. Several of these actions occur within five years of each other, as such, it is difficult to attribute changes in abundance and diversity to a single management action. Because of this, the highlighted changes should be considered cautiously. It is interesting to note, however, that the most dramatic changes evident in the present study occurred following the 1977 establishment of the fishery's first FMP, the 1982 implementation of the revised FMP, the increases in conservation efforts associated with Amendments 5 and 7 in 1994 and 1996, respectively, and the establishment of hard TACs in the late 2000s associated with the implementation of Sectors. In general, prior to 2000, policies associated with stricter conservation (initial FMP implementation, mortality and fishing effort reductions, etc.) resulted in trends of increasing abundance and decreasing diversity. Policies associated with increased fishing (elimination of quotas and trip limits) generally resulted in trends of decreasing abundance and increasing diversity. Since the early 2000s, however, these trends appear to have become more unstable, with unpredictable variations in both abundance and diversity.

\subsubsection{Eastern Bering Sea}

In the Eastern Bering Sea region, a total of eight critical management actions were identified since 1975 (Table 15). These actions included the implementation of FCMA, establishment of FMPs, enacting limited entry and other effort limitation programs, and the establishment of TAC allocation programs. While these 
management actions produced new and sometimes groundbreaking management regimes, a comparison of implementation time frames with community changes revealed much less connectivity between policy and ecosystem response.

Table 15. Outline of significant developments in fisheries management policy in the Eastern Bering Sea, 1977-2011.

\begin{tabular}{|c|c|c|}
\hline Year & Policy / Action & Management Action \\
\hline 1977 & $\begin{array}{l}\text { Implementation of Magnuson Stevens } \\
\text { Fishery Conservation and Management } \\
\text { Act }\end{array}$ & $\begin{array}{l}\text { Exclude foreign fishing with limited } \\
\text { exceptions }\end{array}$ \\
\hline 1982 & $\begin{array}{l}\text { First FMP for Alaskan groundfish } \\
\text { species implemented }\end{array}$ & Prohibited foreign fishing \\
\hline 1989 & Amendment 12 & Permitting requirement \\
\hline 1992 & $\begin{array}{l}\text { Amendment } 18 \text { (further developed in } \\
\text { Amd. } 23 \text { and 51) }\end{array}$ & $\begin{array}{l}\text { Inshore/offshore management } \\
\text { Effort reduction }\end{array}$ \\
\hline 1998 & American Fisheries Act (AFA) & \\
\hline 2000 & Amendment 61 & $\begin{array}{l}\text { Implementation of AFA } \\
\text { requirements }\end{array}$ \\
\hline 2007 & Amendment 80 & Limited Access program \\
\hline 2009 & Amendment 92 & License revocation \\
\hline
\end{tabular}

The dataset used to evaluate Eastern Bering Sea community changes limited the evaluation of management responses to only those occurring after 1982. The first major policy action during this time period was the 1982 implementation of the first FMP for Alaskan groundfish. This plan created baseline TAC limits and served to essentially eliminate foreign fishing in the United States Exclusive Economic Zone in the Bering Sea. That year, however, marked no noticeable trend in either single species abundance or ecosystem biodiversity (Figure 26, Figure 27). In subsequent years, however, an increase in Historical Biological Index was apparent. Amendment 12, implemented in 1989, marked the first attempt at effort limitation within the Bering Sea fishery. This policy, requiring permitting of fishing and processing sectors, 
was the first step in a series of policies designed to rationalize the fishery. Interestingly, following the passage of Amendment 12, an increase in flatfish and cod abundance was apparent.

In perhaps the most significant management action of the study period, the American Fisheries Act (AFA) was passed in 1998, and subsequently implemented in 2000 through Amendment 61 to the FMP. Provisions of the AFA required stricter prohibitions regarding effort reductions, prohibited new entries into the fishery, and established a quasi-individual fishing quota (IFQ) program designed to more directly allocate TACs to specific individuals or fishing cooperatives. Following the implementation of Amendment 61, a dramatic increase in pollock abundance was evident. Furthermore, an increase in Historical Biological Index was evident, following a one-year lag period. 


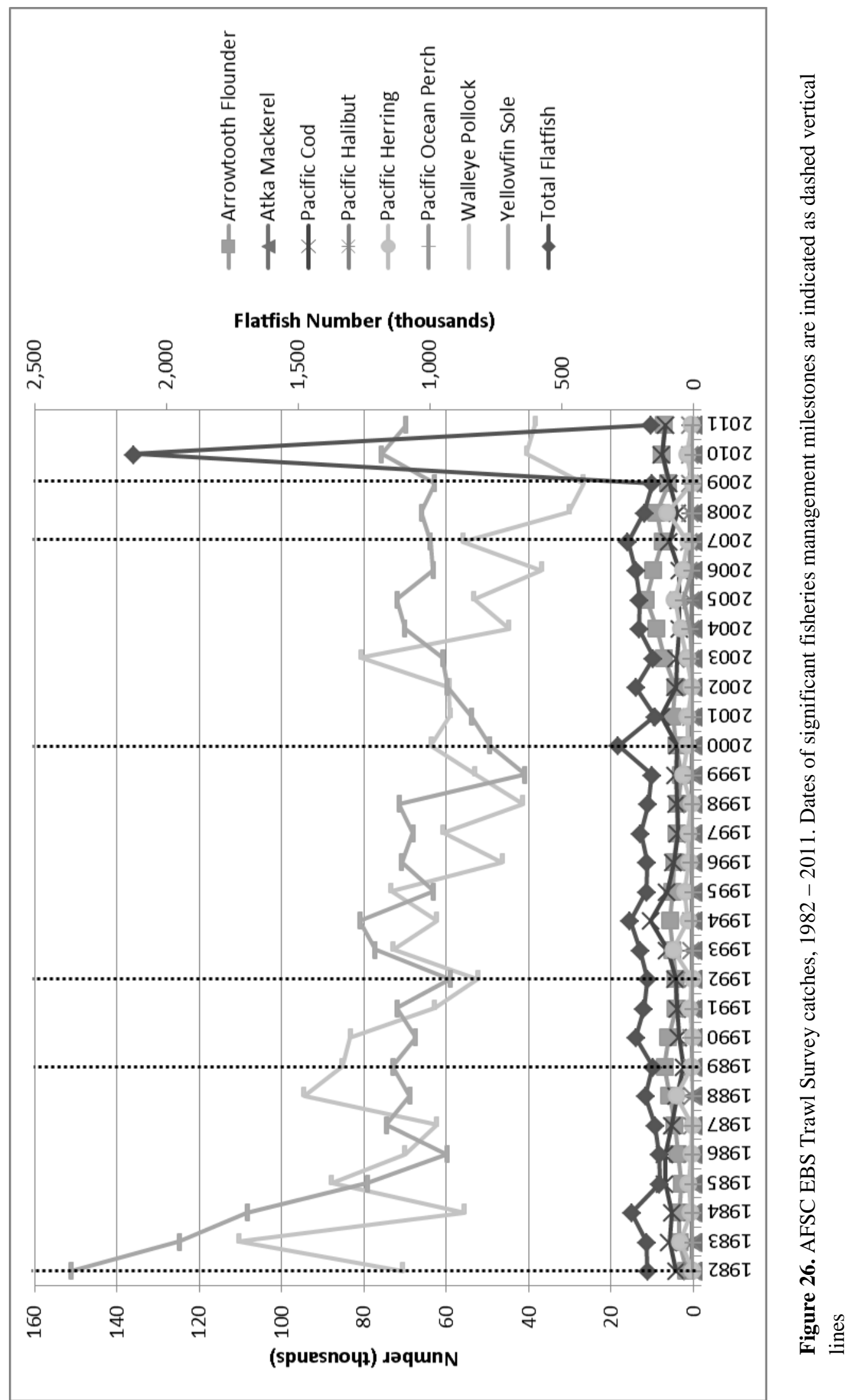




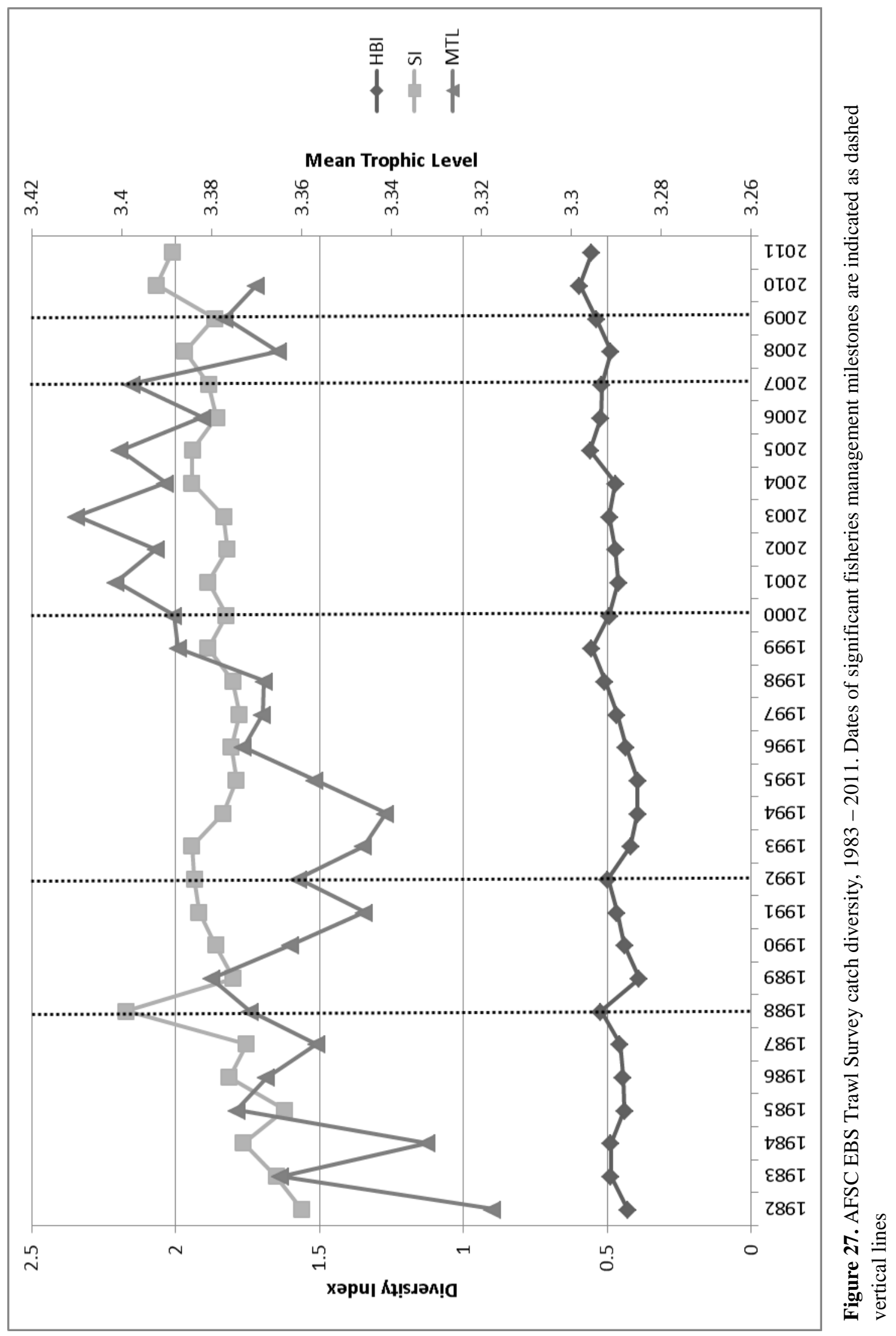


Overall, the critical management actions associated with the Eastern Bering Sea ecosystem appeared to have a much smaller impact on both single species abundance and system biodiversity than the Georges Bank actions. While the caveat discussed previously regarding latency periods following policy implementation should be considered, the lack of noticeable changes following management actions is telling. 


\section{DISCUSSION}

The goal of the present study was to evaluate the relationship between fishing pressure, length distributions, and species diversity on Georges Bank and in the Eastern Bering Sea and to evaluate how these trends should be evaluated in terms of fisheries management goals. The following sections discuss the relevant results and suggest their potential management implications.

\subsection{Fishing Pressure, Length Distributions, AND SPeCies Diversity}

Results indicate that fishing effort is positively correlated to mean fish length on Georges Bank and negatively correlated with fish length in the Eastern Bering Sea (Table 12, Table 13). This, is a counterintuitive finding. One would expect to find a decline in fish body size associated with size-selective fishery exploitation (Trippel 1995; Olsen et al. 2004; Conover and Munch 2002). This, however, only occurred in the Eastern Bering Sea. Studies have demonstrated an inverse relationship between fishing effort and body size. Results from the present study could be related to the mandated declines in fishing pressure observed in both ecosystems since the early 1990s. On Georges Bank, high levels of groundfish exploitation have occurred for several centuries prior to the time frame evaluated in the present study. It is very possible that this long-term, very strong selective pressure is still influencing the groundfish community even with decreased fishing effort. In their 2009 study, Conover, et al. demonstrated that evolutionary shifts associated with size-selective fisheries may be reversed if affected by morphological trade-offs, however the study was conducted for a much shorter duration and only documented evolutionary reversals when fishing pressure was eliminated. In both of the ecosystems evaluated in 
the present study, selective fishing pressure has greatly decreased in recent decades, but has not been eliminated. The Conover study suggests, however, that any fishingrelated decline in body size may still be reversible.

Table 16. Summary and comparison of significant correlations between fish length measurements and fishing effort. The significant length measurement (mean or maximum length) is indicated for each ecosystem and species/complex.

\begin{tabular}{|lcc|}
\hline Species/Complex & Georges Bank & Eastern Bering Sea \\
\hline All Species & Mean Length & Mean Length \\
Gadus sp. & Maximum Length & \\
Flatfish complex & & Mean Length \\
\hline
\end{tabular}

An evaluation of relationship between fishing effort and ecosystem biodiversity also garnered interesting results (Table 16, Table 17). In general, species richness tended to yield significant results more consistently than measures of species evenness or trophic diversity. Additionally, species richness tended to be more reliable than the more derived measurements of evenness and trophic diversity due to sampling bias (Gotelli 2001; Washington 1984). Interestingly, in both ecosystems, fishing pressure was not significantly correlated to species richness. In these evaluations, however, it is important to consider that both ecosystems have an extensive history of groundfish exploitation and fishing effort has been greatly reduced in recent years. It is reasonable to consider that many of the observed changes in community structure are related to past exploitation. 
Table 17. Summary and comparison of significant diversity index results. Indices with significant multiple regression results are indicated by checkmarks.

\begin{tabular}{|lcc|}
\hline Diversity Index & Georges Bank & Eastern Bering Sea \\
\hline Species Richness & & \\
Historical Biological Index & $\checkmark$ & \\
Species Evenness & & \\
Shannon Index & & \\
Trophic Diversity & \\
Mean Trophic Level & $\checkmark$ \\
\hline
\end{tabular}

These results suggest that the Historical Biological Index may be a useful tool for fishery managers to consider in evaluating changes in ecosystem. On both Georges Bank and in the Eastern Bering Sea multiple regression of HBI suggests that temperature is likely a significant contributor to ecosystem changes (Table 9, Table 11). As such, the use of this index may provide managers with some insight regarding witnessed changes in exploited fisheries. The specific variables of temperature, however, should be carefully evaluated if this index is to be implemented elsewhere. In the present analysis, the significant temperature variables were very different between the two ecosystems. On Georges Bank, global temperature anomalies were more significant than mean trawl temperature readings, however in the Eastern Bering Sea trawl surface temperature was the most important contributor to HBI. While it should be expected that these ecosystems display differing responses to temperature changes, this should highlight the need to thoroughly explore these relationships prior to evaluating HBI in other ecosystems. 


\subsection{IMPLICATIONS FOR FISHERIES MANAGEMENT}

Results of the present analyses highlight several interesting themes in the two datasets which should be considered in the evaluation of management options: (1) ecosystem volatility, (2) unexpected findings, and (3) importance of historic management. Lastly, general observations relevant to fisheries management will be discussed.

\subsubsection{Ecosystem Volatility}

This analysis suggests that there is a noticeable difference in the relative volatility of each ecosystem. All analyses of the Georges Bank length distributions and diversity demonstrate dramatic annual fluctuations (Figure 9). Eastern Bering Sea analyses generally display little annual fluctuation (Figure 13). These observations may be suggestive of inherent differences in stability of the two ecosystems. For the purposes of the present discussion, stability will be defined in terms of equilibrium stability. According to McCann (2000), equilibrium stability is a "measure that considers a system stable if it returns to its equilibrium after a small perturbation away from the equilibrium" (McCann 2000, 230). Marine ecosystems tend to be highly variable and as such, are likely to experience small perturbations quite frequently (McGowan, et al. 1998; Parsons and Lear 2001; Stabeno, et al. 2001). It is therefore possible to evaluate annual variability in both the length distribution and diversity datasets to determine overall stability.

It has been noted that on Georges Bank, length distributions fluctuate widely for all species and complexes analyzed. While it is possible that the high variability is due to sampling error associated with the trawl survey, it seems unlikely that such high 
rates of variability in sampling methodology would occur in nearly all sampling years. In the EBS, the annual variability associated with length distributions is greatly reduced in all analyses with the exception of maximum length. It should be considered, however, that maximum length corresponds to the presence of a single organism of large body size. Because of this strong dependence on a single individual, there is a greater chance that these fluctuations are indicative of outliers and should be considered cautiously. An evaluation of the variability evident in the diversity indices further supports the hypothesis of lower ecosystem stability on Georges Bank. In all indices except HBI, diversity on Georges Bank exhibited a wider range than in the Eastern Bering Sea. It is important to note the difference in time series duration between the two datasets, however these observations persist when evaluating series of the same duration. According to the definition of stability outlined previously, the observations regarding both length and diversity between the two ecosystems would support the conclusion that the Eastern Bering Sea appears to be more stable than the Georges Bank ecosystem. Review of the literature would suggest that both Georges Bank and the Eastern Bering Sea ecosystems are relatively stable, although prone to decadal regime shifts (Garrison and Link 2000; Worm et al. 2009). The present study, however does not seek to evaluate absolute stability, but rather relative stability. Worm, et al. (2009) supports this finding by arguing that the Eastern Bering Sea demonstrated relative stability, especially in comparison to Eastern Canadian and Northeast Shelf ecosystems.

Historically, ecosystem stability has proven to be a controversial topic and significant research has been dedicated to the relationship between stability and 
ecosystem diversity (McCann 2000). In a 2004 study evaluating the diversity of a sea grass population, Hughes and Stachowicz found that communities susceptible to increased stress tend to exhibit increased diversity, presumably to allow the population to conform to a wide range of environmental conditions (Hughes and Stachowicz 2004). If this hypothesis is applied to the present study, it may explain the differences in length distribution variability between the Georges Bank and EBS ecosystems. It has already been noted that the Georges Bank ecosystem appears to be comparatively unstable. In this context, greater instability in length distributions may suggest that Georges Bank populations are exposed to increased stress, relative to the Eastern Bering Sea.

It is also interesting to consider the observed differences in diversity in the context of the stability-time hypothesis. While this hypothesis is highly contentious, it remains among the most influential attempts to describe observed patterns in global marine diversity. The stability-time hypothesis argues that differences in ecosystem diversity may be explained by their exposure to abiotic variability (Sanders 1968). The hypothesis was developed to explain observed variation in the diversity of benthic invertebrates, however the basic principles may be applied to the demersal community as well. According to the stability-time hypothesis, communities tend to be more influenced by either physical stressors or biological stressors and these influences tend to be limiting factors to community growth (Sanders 1968). In systems exposed to greater environmental variability (physical stress), this hypothesis suggests that species richness will be suppressed (Sanders 1968). In contrast, communities controlled by biological stressors, such as competition and predation, are more likely 
to exhibit higher species diversity (Sanders 1968). This theory, however, is not supported by the current findings. An evaluation of environmental indices reveals that the Eastern Bering Sea tends to experience higher rates of environmental variability than Georges Bank as evident by the increased heteroskedasticity of mean bottom and surface temperature. Based on this observation, one would expect that the EBS ecosystem is controlled by physical stressors. In contrast, Georges Bank is a top-down controlled system and, as such, is controlled by biological stressors including high level predators (Frank, et al. 2005). If these assumptions are correct, according to the stability-time hypothesis, decreased species richness should be present in the EBS. This was not supported by the data.

The stability-time hypothesis gained considerable support prior to the 1970s, however throughout the 1970s and 1980s, the relationship between diversity and stability gained increasing research attention. During this time, theoretical ecologists maintained that systems characterized by reduced species richness and simple trophic interactions were subject to reduced community stability (Pimm 1984). In 1973, however, Robert May published a book evaluating the mathematical basis of these assumptions (May 1973a). May concluded that stability is a function of species richness, however the two variables share an inverse relationship: "All in all, rich trophic complexity and a diversity of different kinds of interaction between species is not conducive to qualitative stability... in general mathematical models, increased complexity tends to beget diminished stability" (May 1973b, 641). This stabilitycomplexity hypothesis would suggest that the Eastern Bering Sea ecosystem, which, according to the present study, has higher species richness, should exhibit greater 
ecosystem stability. The present study, however, does not support May's stability hypothesis.

\subsubsection{Unexpected Findings}

A second theme which emerged in the results was the frequency with which unexpected findings occurred. Perhaps the most surprising of these findings was the overwhelming trend of increasing species diversity in all indices of species richness and evenness. Other studies of species diversity in exploited ecosystems have reported a trend of decreasing diversity (Rijnsdorp, et al 1996; Solow 1994; Collie, et al. 2000; Gabriel 1992). In general, these studies have maintained statistically rigorous methods and attempted to control for potentially confounding variables including sampling variation, environmental changes, and the influence of species guilds. The present study utilized a comparatively simple methodology to assess more generalized changes in community structure, however because the effects of dominant species guilds and environmental variability are not expressly controlled for, this study may provide a different type of insight. Management goals regarding biodiversity have traditionally maintained the importance of increasing or maintaining diversity. The present study has found a trend of increasing biodiversity on Georges Bank, a system where the majority of exploited groundfish are currently overexploited. It is important to consider, however, that the exploitation of an ecosystem may allow for the creation of new niches for previously uncompetitive species or nonnative species to dominate. By failing to explicitly account for these situations, fishery managers may fail in objectives to maintain ecological sustainability and preserve natural communities. 
This study would suggest, however, that an evaluation of volatility of species diversity may be more representative of community-level changes.

Another unexpected finding evident in the results was the increasing instability of Eastern Bering Sea single species abundance and diversity measurements. Since 2004, a trend of increasing instability is readily apparent in all diversity indices many of the indices demonstrated a change in magnitude or direction (Figure 23). While this represents only a small subsample of the complete dataset, and is not a large enough sample to conclusively determine a persistent change, it should be highlighted as warranting continued monitoring. Additionally, it raises interesting questions regarding the success of management actions in Alaska to this point. Ludwig (2001) suggested that for complex issues in natural resource management, it is entirely possible that there will never be an adequate scientific approach to management. Because of its inherently complex and highly variable nature, all natural and social science "experts" will be unable to gain a truly comprehensive understanding of the system. As such, science-based management is, in actuality, based on supposition and guesswork (Ludwig 2001). Ecosystems which have experienced seemingly successful scientific management, Ludwig argues, are rare and their continued success unlikely (Ludwig 2001). If Ludwig is correct, it is possible that until recently, EBS fisheries management has been based on successful guesswork, which may not continue in the future. While this may be a controversial perspective on the utility of natural resource management, it does pose a provocative question to be considered by fishery managers. Indeed, if the trend of increased instability of the EBS ecosystem continues, this question is likely to gain more attention in the coming years. 


\subsubsection{Importance of Historic Management}

In general, one may categorize the groundfish management approach on Georges Bank to be highly reactive. Since the establishment of the first FMP, critical management actions have generally occurred in direct response to scientific evidence of failing stocks. In contrast, management in the EBS tends to be more proactive. The groundfish FMP for the region specifically states that management actions are designed to take a precautionary approach and to be proactive (NPFMC 2012). Considering the vastly different management approaches utilized in these ecosystems, it becomes especially interesting to compare the ecological responses to critical management actions between regions. By evaluating management actions and the associated changes in single species abundance and diversity, it seems that management efforts on Georges Bank are more closely associated with immediate ecosystem changes. In the EBS similar trends are not apparent. This may suggest that reactive management measures are more likely to produce immediate and visible results, however the lasting impact of these results are questionable. Additionally, it is important to note that these results occurred on Georges Bank, which, as has been demonstrated, is a fairly unstable ecosystem and may have a stronger and quicker reaction to perturbations.

In the Eastern Bering Sea, management actions have been precautionary and have been strongly supportive of scientific reference points of stock and ecosystem health. Perhaps it is because this ecosystem is relatively stable and healthy that management actions generally do not serve as significant system perturbations. The importance of continued proactive management, however, should not be 
underestimated. As a corollary to May's stability-complexity hypothesis, he argued that systems with increased species richness are likely to experience greater changes in biomass and community composition if a species is removed (May 1973b). The present study has demonstrated that the demersal community of the Eastern Bering Sea has relatively high species richness. As such, this finding may suggest that fishery management efforts may be more necessary in the more diverse EBS community to prevent dramatic changes in biomass and community composition.

\subsubsection{General Management Implications}

The policy implications of the present study are vast. Perhaps the most salient focuses on the complexity of ecosystem relationships. Numerous studies have commented on the complexity of ecosystem dynamics and discussed the current role of science in natural resource management (Ludwig, et al. 1993; Larkin 1977). Ludwig (2001) suggested that the complexity of natural resource management exceeds our ability to comprehensively understand the system as a whole. The present study effectively demonstrates the truth in this statement. While trends are readily apparent in the results, many of these findings do not conform to our current understanding of marine processes. Perhaps most noticeable is the unexpected finding of increasing diversity over time in both ecosystems. This is especially noteworthy when considering the current role biodiversity plays in national and international policy. The Convention of Biological Diversity, enacted in 1993, cites the maintenance of biodiversity as a principle goal (CBD 2011). The FAO's Code of Conduct for Responsible Fisheries discussed the need to maintain present and future biodiversity (FAO 1995). In the United States, NMFS has recognized the importance of 
biodiversity and has promoted the use of diversity indicators in the development of regional Fishery Ecosystem Plans (Ecosystem Advisory Panel 1999). While each of these political bodies has recognized the need to include ecosystem considerations in natural resource management, it may be beneficial to consider the adoption of more specialized goals. Instead, it may be wise to consider revising goals citing the need to maintain or increase biodiversity to evaluate diversity and community composition relative to natural states. The definition of "natural state" however, is likely to be quite contentious, as these ecosystems have been exploited for several decades (or centuries). Determination of unexploited structure may prove quite difficult. The inconsistency in goal-outcome coupling is especially apparent when considering the increasing diversity on Georges Bank in relation to the most recent estimates of stock status (NMFS 2012a). This comparison would suggest that the use of a biodiversity index alone is not a suitable replacement of single-species assessments.

It is also important for managers to consider exactly what the present results are indicating. These results demonstrate a tenuous relationship between fishing effort and ecosystem changes. The lack of a strongly significant correlation suggests that recent declines in fishing effort have not produced a substantial change in either ecosystem. This is particularly troublesome in regards to Georges Bank, where ten of the fifteen managed groundfish stocks are currently overfished or are in the process of rebuilding (NMFS 2012a). This result may suggest that even though fishing effort has decreased, further efforts must be undertaken to achieve a satisfactory result. In the Eastern Bering Sea, none of the stocks managed under the Bering Sea/Aleutian Islands 
Groundfish FMP are currently overfished, so the lack of ecosystem response to decreased fishing pressure is not likely to cause as much concern.

\subsection{Management Recommendations AND Future Directions}

The purpose of this study was to determine if the evaluation of length distributions and system diversity would allow for the development of a simple evaluative tool for the implementation of EBFM. The complexity of these ecosystems, however, makes the development of simple tools difficult. The examination of relative stability, however, offers interesting insights into ecosystem health and functioning. This study determined that Georges Bank, which is currently highly overfished, is an unstable system. It is extremely likely that this instability is due, in large part, to its history of long-term, heavy exploitation. The EBS, on the other hand, has a history of short-term heavy exploitation. The reduction and control of harvests in the EBS aided in its recovery, and the system has since exhibited remarkable stability, even in the face of variable climatic and environmental conditions. The more recent trend towards increasing instability in the EBS may prove to be an early warning of future system distress. Continued monitoring will be essential. This type of stability measurement may prove useful in future analyses of ecosystem health and due to its simple calculation; it may be readily employed in other systems.

This study also offered insights into the ecological responses of systems to proactive and reactive management styles. Georges Bank, which has been shown to be highly volatile, has been managed according to a reactive principle in recent years. Because all management actions are in reaction to dire predictions by scientists and managers, they tend to have immediate and widespread results. It is important to note, 
however, that even these more immediate responses were unable to reverse declines in stock statuses. The more proactive management technique employed in the EBS tends to produce more limited ecosystem reactions, but also aid in the maintenance of a more stable, and arguably healthier ecosystem. These results suggest that a more proactive management approach is likely to result in a healthier, stable ecosystem and managers should strive to implement a similar approach in other fisheries.

The predictive power of the current analyses should also be considered. The present study was a retrospective analysis and should not be widely employed for predictive purposes. The analyses employed simple quantitative principles to general trends in the two systems. These results may allow for easier recognition of repetitive trends, such as the relatively pronounced response of the Georges Bank ecosystem to management actions, however they should not be relied upon for prediction of future ecosystem-level responses. Additionally, the increased instability of the EBS ecosystem, while readily apparent, should be considered cautiously. These observations were made with a temporally limited dataset and continued monitoring should be conducted.

The present study should serve as a guide to direct future research. This study suggests that continued monitoring of both ecosystems is essential. Monitoring of changes in the stability of the Eastern Bering Sea ecosystem may be particularly important due to the observed changes in stability since 2004 . It would be particularly interesting to quantify the variability and stability in the two ecosystems to allow for statistically rigorous evaluation. More statistically rigorous methods would also be valuable in the analysis of system biodiversity (Solow 1994). Studies have suggested 
that the use of accumulation and rarification curves are useful standardize diversity indices across communities (Gotelli and Colwell 2001). Future studies should also consider implementing time lags in analyses of fishing effort. This was not possible in the present study due to the unavailability of historic effort data, however analyses performed in the future will have a longer record of effort data which may allow for this evaluation. Lastly, it would be interesting to quantitatively determine the specific impacts of critical policy actions on ecosystems. 


\section{CONCLUSION}

This study sought to evaluate the relationship between single-species and ecosystem-focused ecological outcomes in relation the Georges Bank and Eastern Bering Sea ecosystems. The study evaluated three primary research questions:

1. How does fishing pressure relate to changes in fish size distribution on Georges Bank and in the Eastern Bering Sea?

2. How does fishing pressure affect ecosystem biodiversity in both ecosystems?

3. What are the management implications of changes in ecosystem biodiversity and body size distributions for Georges Bank and the Eastern Bering Sea

To evaluate these goals, fishery independent trawl survey data was obtained from both ecosystems and changes in fish length and species richness, evenness, and trophic diversity were evaluated. Results indicated that fishing pressure is correlated to fish size distributions in both ecosystems. As fishing pressure decreases over the course of the study period, mean and maximum size decreases as well (Table 16, Table 17). The specific relationship and mechanism for this change, however, is unclear. Additionally, it was demonstrated that the relationship between fishing pressure and species diversity is minimal in both ecosystems (Table 16, Table 17). An important caveat to this observation, however, is the relationship between Historical Biological Index and demersal fishing effort on Georges Bank as demonstrated through the multiple regression analysis. These results indicate a strongly significant 
relationship (Table 29). These results were presumed to relate to the extended history of exploitation in both regions.

The management implications of these, and other, incidental findings were discussed. These results suggest that each ecosystem experienced a key management action during the study period: The 1994 approval of Amendment 5 and Emergency Actions regarding haddock management on Georges Bank and the 1998 approval of the American Fisheries Act in the Eastern Bering Sea. Each of these actions underscores the attitude toward management within the region. Georges Bank fisheries management has typically been reactive, responding to observed changes in stock health. As such, frequently these reactive management techniques resulted in more immediate responses in single species abundance and species diversity (Figures 2427). In the Eastern Bering Sea, management has been more proactive. Fisheries managers tend to address issues prior to the issues reaching emergency status. Because issues are addressed prior to this critical action point, ecosystem-wide responses are not as evident following the approval and implementation of management actions (Figure 26-27).

Lastly, comparisons between the two ecosystems highlighted relative differences in ecosystem stability. Length distribution and diversity data from Georges Bank indicate high annual variability, suggesting that the ecosystem is unstable (Figure 9, Figure 28 - Figure 30). Data from the Eastern Bering Sea suggest that prior to 2004, the ecosystem was highly stable (Figure 23). Since 2004, however, single species abundance and diversity indices have experienced increased instability, exhibiting a reversal in direction and/or a change in magnitude of all trends. This 
observation should be monitored carefully in coming years, as it may be indicative of a regime shift within the ecosystem. 


\section{APPENDIX A: SUPPLEMENTAL METHODS}

\section{Additional Species Diversity Calculations}

Realized species richness is defined as the number of species caught in a given year. For each ecosystem, realized species richness was calculated annually. Hurlbert's Evenness Index is a measurement of the relative evenness of species within a community. It takes into account the minimum and maximum diversity scores and is considered to be relatively insensitive to the appearance of rare taxa (Beisel, et. al. 2003). The Hurlbert Index ranges in score from 0 (low evenness) to 1 (high evenness). For each ecosystem, annual Hurlbert Index values were calculated according to the equation in Table 17. In response to concerns regarding the calculation and use of MTL, another index of trophic diversity was developed in 2005. The Fish in Balance Index (FiB) measures the balance between annual catches and trophic level (Pauly and Watson, 2005). Unlike MTL, the FiB is designed to remain constant if a decline in ecosystem MTL is associated with a simultaneous increase in catches. This index compares annual ecosystem MTL and catches to a baseline year. As such, all comparisons are relative to the baseline. For the Georges Bank ecosystem, MTL and trawl catches in 1975 were considered the baseline. FiB values were calculated annually for 1976 through 2011. For the EBS ecosystem, MTL and trawl catches in 1982 were considered the baseline. FiB values were calculated annually for 1983 through 2011 using the equation in Table 17. 
Table 18. Additional biodiversity indices and relevant calculations used for the current study.

\begin{tabular}{|l|l|}
\hline \multicolumn{1}{|c|}{ Index } & \multicolumn{1}{c|}{ Definition } \\
\hline $\begin{array}{l}\text { Species Richness } \\
\text { Realized Species Richness (RS) }\end{array}$ & Number of species per year \\
\hline $\begin{array}{l}\text { Species Evenness } \\
\text { Hurlbert's Evenness Index } \\
\left(E_{\text {Hurlbert })}\right.\end{array}$ & $E_{\text {Hurlbert }}=\frac{H-H_{\text {min }}}{H_{\max }-H_{\min }}$ \\
\hline $\begin{array}{l}\text { Trophic Diversity } \\
\text { Fish In Balance Index (FiB) }\end{array}$ & FiBy $=\log \left(C_{y} \times\left(\frac{1}{T E}\right)^{T_{y}}\right)$ \\
& $-\log \left(C_{0} \times\left(\frac{1}{T E}\right)^{T_{0}}\right)$ \\
& $\begin{array}{l}\text { Where } T E \text { is the transfer efficiency (specific to } \\
\text { an ecosystem; set to } 0.1 \text { for the purposes of this } \\
\text { study, see Collie, et. al. 2009) and } 0 \text { refers to } \\
\text { the baseline year }(1975 \text { for the purposes of this } \\
\text { study). }\end{array}$ \\
\hline
\end{tabular}




\section{APPENDIX B: SUPPLEMENTAL RESULTS}

\section{LENGTH DIVERSITY}

\section{Georges Bank}

All correlation analyses were performed using Bonferroni adjusted alpha levels of 0.0021 .

All Species: Overall, there was a slight, insignificant correlation between mean length and maximum length of all species per year, $r(33)=0.1897, p=0.2564$. Weak, insignificant correlations were present between maximum length and demersal fishing effort, $\mathrm{r}(33)=0.1625, \mathrm{p}=0.3204$, and total commercial catches in New England, $\mathrm{r}(33)=0.1953, \mathrm{p}=0.2469$

Table 19. Correlation matrix of fish length of all species and fishing pressure, 1977-2009. Length is represented by mean and maximum fish length of all catches in the NEFSC Northeast Bottom Trawls Survey Georges Bank stations. Demersal fishing effort is calculated as the total number of fishing days spent targeting demersal species on Georges Bank. Total commercial catches is calculated as the weight (mt) of all commercial catches in the New England region. Results indicate a strong correlation between mean length of survey catch and the demersal fishing effort. A slight negative correlation is also apparent between total commercial catches and demersal fishing effort.

\begin{tabular}{|c|cccc|}
\hline & $\begin{array}{c}\text { Maximum } \\
\text { Length }\end{array}$ & Mean Length & $\begin{array}{c}\text { Demersal } \\
\text { Fishing Effort }\end{array}$ & $\begin{array}{c}\text { Commercial } \\
\text { Catches }\end{array}$ \\
\hline Maximum Length & 1 & 0.1897 & 0.1625 & 0.1953 \\
Mean Length & 0.1897 & 1 & 0.6615 & -0.0232 \\
Demersal Fishing Effort & 0.1625 & 0.6615 & 1 & -0.2736 \\
Total Commercial Catches & 0.1953 & -0.0232 & -0.2736 & 1 \\
\hline
\end{tabular}

Atlantic cod: There was a moderate, insignificant correlation between mean and maximum cod body length, $\mathrm{r}(33)=0.4101, \mathrm{p}=0.7454$ Weak, insignificant correlations were present between annual New England commercial catches and both maximum length, $\mathrm{r}(33)=0.2423, \mathrm{p}=0.2555$, and mean length, $\mathrm{r}(33)=0.2700, \mathrm{p}=$ 0.1635 . 
Table 20. Correlation matrix of Atlantic cod length and fishing pressure, 1977-2009. Atlantic cod length is represented by mean and maximum fish length of all catches in the NEFSC Northeast Bottom Trawls Survey Georges Bank stations. Demersal fishing effort is calculated as the total number of fishing days spent targeting groundfish species on Georges Bank. Total commercial catches is calculated as the weight $(\mathrm{mt})$ of all commercial catches in the New England region. Results indicate a strong correlation between maximum cod length and demersal fishing effort and a moderate correlation between mean length and demersal fishing effort. Moderate correlations between total commercial catches and both mean and maximum length were evident. A slight negative correlation is also apparent between total commercial catches and demersal fishing effort.

\begin{tabular}{|c|cccc|}
\hline \multicolumn{2}{|c}{$\begin{array}{c}\text { Maximum } \\
\text { Length }\end{array}$} & $\begin{array}{c}\text { Cod Mean } \\
\text { Length }\end{array}$ & $\begin{array}{c}\text { Demersal } \\
\text { Fishing Effort }\end{array}$ & $\begin{array}{c}\text { Commercial } \\
\text { Catches }\end{array}$ \\
\hline Cod Maximum Length & 1 & 0.4101 & 0.627 & 0.2423 \\
Cod Mean Length & 0.4101 & 1 & 0.2669 & 0.27 \\
Demersal Fishing Effort & 0.627 & 0.2669 & 1 & -0.2736 \\
Total Commercial Catches & 0.2423 & 0.27 & -0.2736 & 1 \\
\hline
\end{tabular}

Flatfish: Weak, insignificant correlations were present between demersal fishing effort and both mean length, $\mathrm{r}(33)=-0.2506, \mathrm{p}=0.1528$, and maximum length, $\mathrm{r}(33)$ $=-0.1785, \mathrm{p}=0.3125$. Additionally, a weak, insignificant correlation was present between mean length and commercial catches, $r(33)=0.3334, p=0.0540$.

Table 21. Correlation matrix of flatfish length and fishing pressure, 1977-2009. Flatfish length is represented by mean and maximum fish length of individuals caught in the NEFSC Northeast Bottom Trawls Survey Georges Bank stations. Demersal fishing effort is calculated as the total number of fishing days spent targeting groundfish species on Georges Bank. Total commercial catches is calculated as the weight (mt) of all commercial catches in the New England region.

\begin{tabular}{|l|cccc|}
\hline \multicolumn{1}{|c}{} & $\begin{array}{c}\text { Maximum } \\
\text { Length }\end{array}$ & Mean Length & $\begin{array}{c}\text { Demersal } \\
\text { Fishing Effort }\end{array}$ & $\begin{array}{c}\text { Commercial } \\
\text { Catch }\end{array}$ \\
\hline Maximum Length & 1.0000 & 0.0827 & -0.1785 & 0.4065 \\
Mean Length & 0.0827 & 1.0000 & -0.2506 & 0.3334 \\
Demersal Fishing Effort & -0.1785 & -0.2506 & 1.0000 & -0.2736 \\
Commercial Catch (mt) & 0.4065 & 0.3334 & -0.2736 & 1.0000 \\
\hline
\end{tabular}

Skates: Statistical analyses suggest weak correlations between maximum length and both demersal fishing effort, $\mathrm{r}(33)=-0.2265, \mathrm{p}=0.1977$, and commercial catch, $\mathrm{r}(33)$ $=-0.3418, \mathrm{p}=0.0479$. Mean length was weakly correlated with demersal fishing effort, $\mathrm{r}(33)=0.3039, \mathrm{p}=0.1270$, and commercial catch, $\mathrm{r}(33)=-0.1754, \mathrm{p}=0.0806$. 
Table 22. Correlation matrix of skate length and fishing pressure, 1977-2009. Skate length is represented by mean and maximum fish length of individuals caught in the NEFSC Northeast Bottom Trawls Survey Georges Bank stations. Demersal fishing effort is calculated as the total number of fishing days spent targeting groundfish species on Georges Bank. Total commercial catches is calculated as the weight (mt) of all commercial catches in the New England region.

\begin{tabular}{|l|cccc|}
\hline & $\begin{array}{c}\text { Maximum } \\
\text { Length }\end{array}$ & Mean Length & $\begin{array}{c}\text { Demersal } \\
\text { Fishing Effort }\end{array}$ & $\begin{array}{c}\text { Commercial } \\
\text { Catch }\end{array}$ \\
\hline Maximum Length & 1.0000 & 0.0114 & -0.2265 & -0.3418 \\
Mean Length & 0.0114 & 1.0000 & 0.3039 & -0.1754 \\
Demersal Fishing Effort & -0.2265 & 0.3039 & 1.0000 & -0.2736 \\
Commercial Catch $(m t)$ & -0.3418 & -0.1754 & -0.2736 & 1.0000 \\
\hline
\end{tabular}

\section{Eastern Bering Sea}

All correlation analyses were performed using Bonferroni adjusted alpha levels of 0.0021

\section{All Species:}

Table 23. Correlation matrix of fish length (all species) and fishing pressure, 1990-2008. Fish length is represented by mean and maximum fish length of individuals caught in the EBS Trawls Survey. Fishing effort is defined as the number of observed trawls. Total commercial catches is calculated as the weight (mt) of all commercial catches in Alaska.

\begin{tabular}{|c|c|c|c|c|}
\hline & $\begin{array}{l}\text { Commercial } \\
\text { Catch }\end{array}$ & Fishing Effort & $\begin{array}{l}\text { Maximum } \\
\text { Length }\end{array}$ & Mean Length \\
\hline Commercial Catch & 1 & 0.2598 & 0.0391 & -0.1342 \\
\hline Fishing Effort & 0.2598 & 1 & -0.1549 & -0.6257 \\
\hline Maximum Length & 0.0391 & -0.1549 & 1 & 0.6215 \\
\hline Mean Length & -0.1342 & -0.6257 & 0.6215 & 1 \\
\hline
\end{tabular}

Walleye Pollock: A weak correlation was present between annual mean body length and maximum body length, $\mathrm{r}(18)=0.2335, \mathrm{p}=0.1411$. A weak correlation was also present between maximum length and annual commercial catch in Alaska, $r(18)=-$ $0.2878, \mathrm{p}=0.2321$ 
Table 24. Correlation matrix of walleye pollock length and fishing pressure, 1990-2008. Pollock length is represented by mean and maximum fish length of individuals caught in the EBS Trawls Survey. Fishing effort is defined as the number of observed trawls. Total commercial catches is calculated as the weight ( $\mathrm{mt})$ of all commercial catches in Alaska.

\begin{tabular}{|c|c|c|c|c|}
\hline & $\begin{array}{l}\text { Commercial } \\
\text { Catch }\end{array}$ & Fishing Effort & $\begin{array}{l}\text { Maximum } \\
\text { Length }\end{array}$ & Mean Length \\
\hline Commercial Catch & 1 & 0.2598 & -0.2878 & 0.1281 \\
\hline Fishing Effort & 0.2598 & 1 & 0.0168 & 0.0078 \\
\hline Maximum Length & -0.2878 & 0.0168 & 1 & 0.2335 \\
\hline Mean Length & 0.1281 & 0.0078 & 0.2335 & 1 \\
\hline
\end{tabular}

Pacific Cod: A weak correlation between maximum length and commercial catch was

present, $\mathrm{r}(18)=0.3211, \mathrm{p}=0.1801$.

Table 25. Correlation matrix Pacific cod length and fishing pressure, 1990-2008. Cod length is represented by mean and maximum fish length of individuals caught in the EBS Trawls Survey. Fishing effort is defined as the number of observed trawls. Total commercial catches is calculated as the weight (mt) of all commercial catches in Alaska.

\begin{tabular}{|c|c|c|c|c|}
\hline & $\begin{array}{l}\text { Commercial } \\
\text { Catch }\end{array}$ & Fishing Effort & $\begin{array}{l}\text { Maximum } \\
\text { Length }\end{array}$ & Mean Length \\
\hline Commercial Catch & 1 & 0.2598 & 0.3211 & -0.0263 \\
\hline Fishing Effort & 0.2598 & 1 & -0.0737 & -0.0080 \\
\hline Maximum Length & 0.3211 & -0.0737 & 1 & -0.1377 \\
\hline Mean Length & -0.0263 & -0.0080 & -0.1377 & 1 \\
\hline
\end{tabular}

Flatfish: Weak negative correlations were present between mean length and commercial catch, $\mathrm{r}(18)=-0.3061, \mathrm{p}=0.2024$, and between maximum length and fishing effort, $\mathrm{r}(18)=-0.1705, \mathrm{p}=0.4852$.

Table 26. Correlation matrix flatfish length and fishing pressure, 1990-2008. Flatfish length is represented by mean and maximum fish length of individuals caught in the EBS Trawls Survey. Fishing effort is defined as the number of observed trawls. Total commercial catches is calculated as the weight (mt) of all commercial catches in Alaska.

\begin{tabular}{|c|c|c|c|c|}
\hline & $\begin{array}{l}\text { Commercial } \\
\text { Catch }\end{array}$ & Fishing Effort & $\begin{array}{l}\text { Maximum } \\
\text { Length }\end{array}$ & Mean Length \\
\hline Commercial Catch & 1 & 0.2597532 & 0.03026621 & -0.3061464 \\
\hline Fishing Effort & 0.2597532 & 1 & -0.17052897 & -0.7033421 \\
\hline Maximum Length & 0.03026621 & -0.170529 & 1 & 0.1079875 \\
\hline Mean Length & -0.30614635 & -0.7033421 & 0.10798749 & 1 \\
\hline
\end{tabular}




\section{SPECIES DIVERSITY}

\section{Georges Bank}

All correlation analyses were conducted using Bonferroni adjusted alpha levels of 0.0024

Realized Species Richness: Between 1975 and 2011, realized SR ranged from 55 to 84 species, with a mean of 65.7 species. Linear regression revealed a significant trend of increasing species richness by 0.42 species per year, $\mathrm{r}^{2}(36)=0.4298, \mathrm{p}=0.00001$. Moderate correlations were present between realized SR and flatfish trawl catches, $\mathrm{r}(32)=0.3930, \mathrm{p}=0.0237$. Realized species richness was also strongly correlated to global surface temperature anomalies, $\mathrm{r}(32)=0.6314, \mathrm{p}=0.0001$. Weak, insignificant correlations were present with Atlantic cod trawl catch, $r(32)=-0.1906, p=0.2880$, and annual NAO, $\mathrm{r}(33)=-0.2901, \mathrm{p}=0.1016$. Multiple regression of species richness, single species abundance, climate, and fishing effort yielded significance at the macro level, $\mathrm{F}(32,7)=3.276, \mathrm{p}=0.01307$, and accounted for over $33 \%$ of the error $\left(r^{2}=0.3324\right) \quad($ Table 27). Correlation analyses of all variables indicated no multicollinearity, with all correlation coefficients less than 0.43 . 


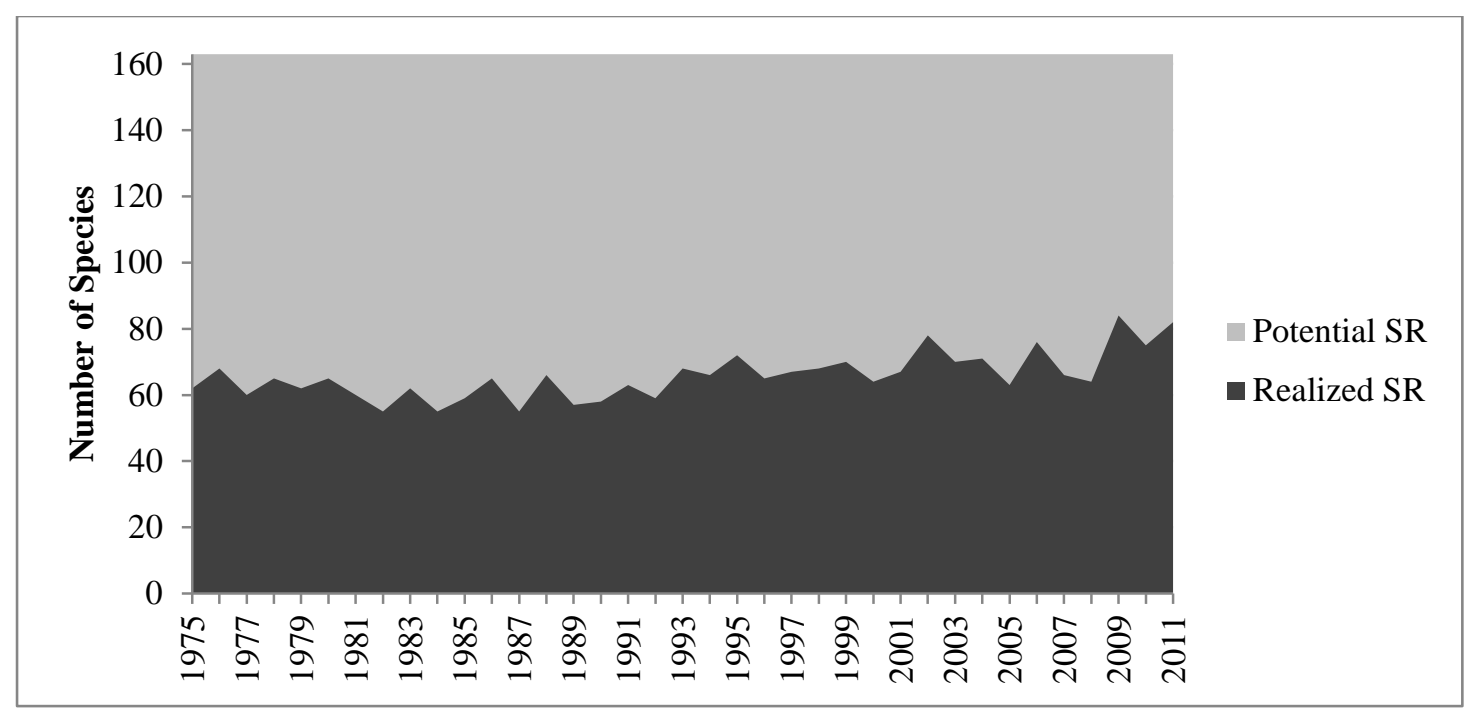

Figure 28. Potential and realized species richness of catches from the NEFSC Northeast Bottom Trawl Survey Georges Bank stations, 1975-2011.

Table 27. Multiple regression results to determine relationship of effort and environmental influences on realized species richness. The overall regression equation yielded statistical significance, $F(32,10)=$ $3.732, p=0.0047$, and accounted for over $46 \%$ of the error $\left(r^{2}=0.4605\right)$. Demersal fishing effort is defined as the cumulative number of days of demersal fishing on Georges Bank. Atlantic Cod Trawl catch is the number of individuals caught in the NEFSC Northeast Bottom Trawl Survey. Commercial catch is the total weight of all commercial catches in New England per year. Georges Bank bottom temperature is the mean annual bottom temperature at NEFSC Northeast Bottom Trawl Survey Georges Bank stations. $\beta$ indicates the standardized beta weight, $\mathrm{T}$ indicates the $\mathrm{T}$-score, and $\mathrm{p}$ indicates the significance for each variable included in the regression.

\begin{tabular}{|c|ccc|}
\hline Intercept & $\boldsymbol{\beta}$ & $\mathbf{T}$ & $\mathbf{p}$ \\
\hline Georges Bank Bottom Temperature & $6.69 \times 10^{1}$ & 3.471 & 0.0019 \\
Commercial Catch & $8.88 \times 10^{-2}$ & 0.058 & 0.9541 \\
Demersal Fishing Effort & $-4.64 \times 10^{-6}$ & -0.115 & 0.9096 \\
Global Temperature Anomalies & $-1.07 \times 10^{-5}$ & -1.062 & 0.2985 \\
North Atlantic Oscillation & $2.20 \times 10^{-1}$ & 3.165 & 0.0040 \\
Atlantic Cod Catch - Trawl & $-1.102 \times 10^{0}$ & -0.336 & 0.7397 \\
Storm Events & $-2.11 \times 10^{-3}$ & -0.484 & 0.6327 \\
\hline
\end{tabular}

Historical Biological Index: Weak, insignificant correlations were also present with

Atlantic cod trawl catch, $r(32)=-0.1906, p=0.2880$ and annual North Atlantic Oscillation, $\mathrm{r}(32)=-0.2901, \mathrm{p}=0.1016$.

Shannon Index: Weak correlations were also evident with Georges Bank Bottom Temperature, $\mathrm{r}(32)=0.1716, \mathrm{p}=0.3396$. Multiple regression was not statistically 
significant, $\mathrm{F}(32,7)=1.438, \mathrm{p}=0.2347$. Correlation analyses of all variables indicated no multicollinearity, with all correlation coefficients less than 0.43 .

Table 28. Multiple regression results to determine relationship of effort and environmental influences on Shannon Index values. The regression was not statistically significant, $F(32,10)=1.181, p=0.3543$. Demersal fishing effort is defined as the cumulative number of days of demersal fishing on Georges Bank. Atlantic Cod, Flatfish, and Skates Trawl catch is the number of each species caught in the NEFSC Northeast Bottom Trawl Survey. Survey catch is the total catch on the NEFSC Northeast Bottom Trawl Survey on Georges Bank. Commercial catch is the total weight of all commercial catches in New England per year. Georges Bank bottom temperature is the mean annual bottom temperature at NEFSC Northeast Bottom Trawl Survey Georges Bank stations.

\begin{tabular}{|c|ccc|}
\hline \multicolumn{1}{|c}{ Intercept } & $\boldsymbol{\beta}$ & $\mathbf{T}$ & $\mathbf{p}$ \\
\hline Georges Bank Bottom Temperature & $3.29 \times 10^{0}$ & 3.670 & 0.0012 \\
Commercial Catch & $-1.08 \times 10^{-2}$ & 0.575 & 0.5702 \\
Demersal Fishing Effort & $-1.28 \times 10 \mathrm{E}^{-6}$ & -0.681 & 0.5022 \\
Global Temperature Anomalies & $-1.14 \times 10^{-6}$ & -2.434 & 0.0224 \\
North Atlantic Oscillation - Annual & $-3.72 \times 10^{-3}$ & -0.115 & 0.9091 \\
Atlantic Cod Catch - Trawl & $-2.13 \times 10^{-2}$ & -0.140 & 0.8898 \\
Storm Events & $-4.53 \times 10^{-5}$ & -0.224 & 0.8248 \\
\hline
\end{tabular}

Hurlbert Index: Annual Hurlbert Index values ranged from a minimum of 5.8688 in 1990 to a maximum of 10.6478 in 1984 (Figure 29). Linear regression demonstrated an insignificant trend of increasing Hurlbert Index by 0.0107 per year, $\mathrm{r}^{2}(36)=0.0086$, $\mathrm{p}=0.5848$. Hurlbert Index was weakly correlated with commercial catch, $\mathrm{r}(32)=$ 0.1951, $\mathrm{p}=0.7988,$. Weak correlations were also evident with Georges Bank Bottom Temperature, $r(32)=0.1951, p=0.2765$. Multiple regression of Hurlbert Index, single species abundance, climate, and fishing effort was not statistically significant, $F(32,7)$ $=1.385, \mathrm{p}=0.2549$. 


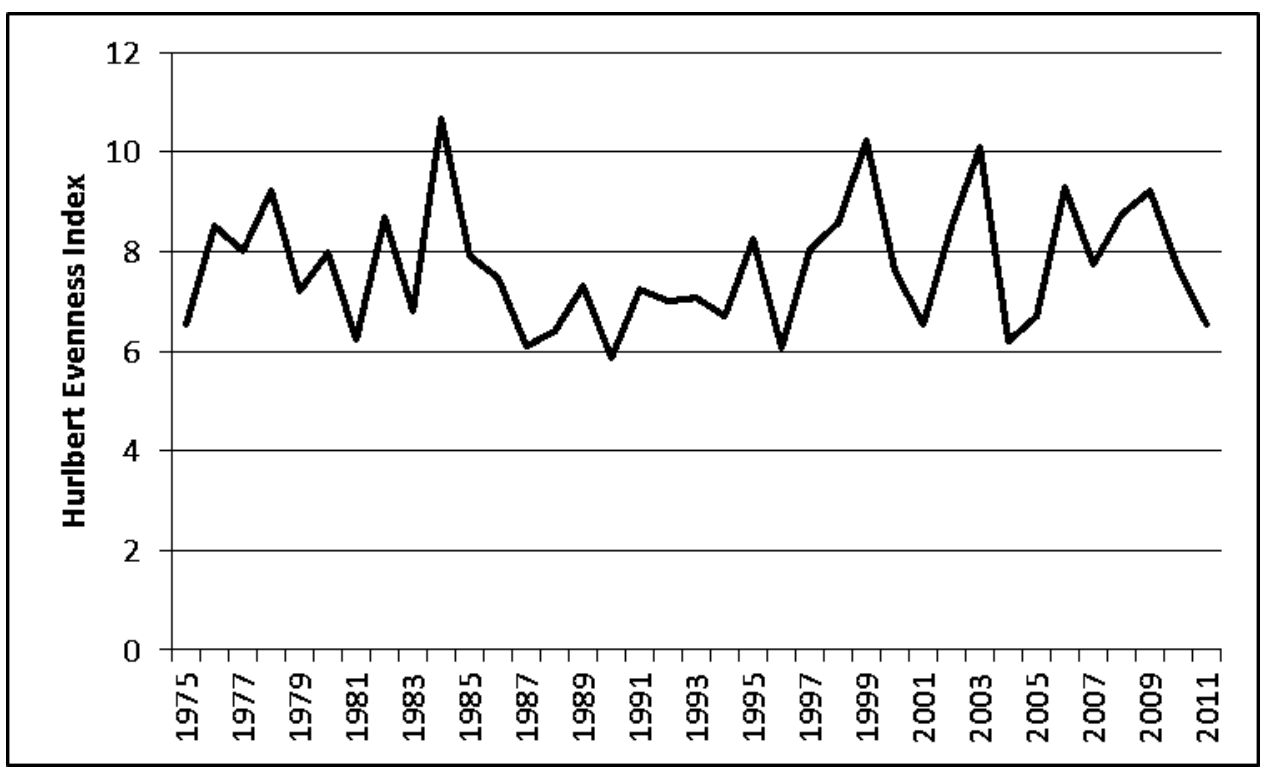

Figure 29. Hurlbert Evenness Index of catches from the NEFSC Northeast Bottom Trawl Survey Georges Bank stations, 1975-2011. This index evaluates the relative diversity and abundance of species.

Table 29. Multiple regression results to determine relationship of effort and environmental influences on Hurlbert Index values. The regression was not statistically significant, $F(32,10)=1.171$, p 0.3601 . Demersal fishing effort is defined as the cumulative number of days of bottom fishing on Georges Bank. Atlantic Cod Trawl catch is the number of individuals caught in the NEFSC Northeast Bottom Trawl Survey. Commercial catch is the total weight of all commercial catches in New England per year. Georges Bank bottom temperature is the mean annual bottom temperature at NEFSC Northeast Bottom Trawl Survey Georges Bank stations.

\begin{tabular}{|c|ccc|}
\hline \multicolumn{1}{|c}{ Intercept } & $\boldsymbol{\beta}$ & $\mathbf{T}$ & $\mathbf{P}$ \\
\hline Georges Bank Bottom Temperature & $9.05 \times 10^{0}$ & 2.050 & 0.0510 \\
Commercial Catch & $3.25 \times 10^{-1}$ & 0.929 & 0.3617 \\
Demersal Fishing Effort & $-2.32 \times 10^{-6}$ & -0.250 & 0.8044 \\
Global Temperature Anomalies & $-5.89 \times 10^{-6}$ & -2.542 & 0.0176 \\
North Atlantic Oscillation & $-3.57 \times 10^{-3}$ & -0.224 & 0.8248 \\
Atlantic Cod Catch - Trawl & $2.81 \times 10^{-1}$ & 0.374 & 0.7116 \\
Storm Events & $-1.64 \times 10^{-4}$ & -0.164 & 0.8711 \\
\hline
\end{tabular}

Mean Trophic Level: Weak correlations were present with demersal fishing effort, $\mathrm{r}(32)=-0.1779, \mathrm{p}=0.00001$ and commercial catch, $\mathrm{r}(32)=-0.1683, \mathrm{p}=0.3202$. Additionally, weak correlations were evident between MTL and Georges Bank bottom temperature, $\mathrm{r}(32)=-0.1683, \mathrm{p}=0.3502$, global surface temperature anomalies, $\mathrm{r}(32)$ $=-0.2744, \mathrm{p}=0.1218$, and mean annual NAO, $\mathrm{r}(32)=0.2111, \mathrm{p}=0.2372$. 
Fish in Balance Index: Fish in Balance (FiB) Index values demonstrated high annual variability, with a minimum of -0.553 in 1984 and a maximum of 0.566 in 2011 (Figure 30). Linear regression revealed an insignificant trend of increasing FiB index values of 0.0039 units per year, $\mathrm{r}^{2}(36)=0.0358, \mathrm{p}=0.2622$.. Weak correlations were present with demersal fishing effort, $r(32)=-0.1700, p=0.099$. Multiple regression of FiB, single species abundance, climate, and fishing effort was not statistically significant, $\mathrm{F}(32,7)=0.6316, \mathrm{p}=0.7254$.

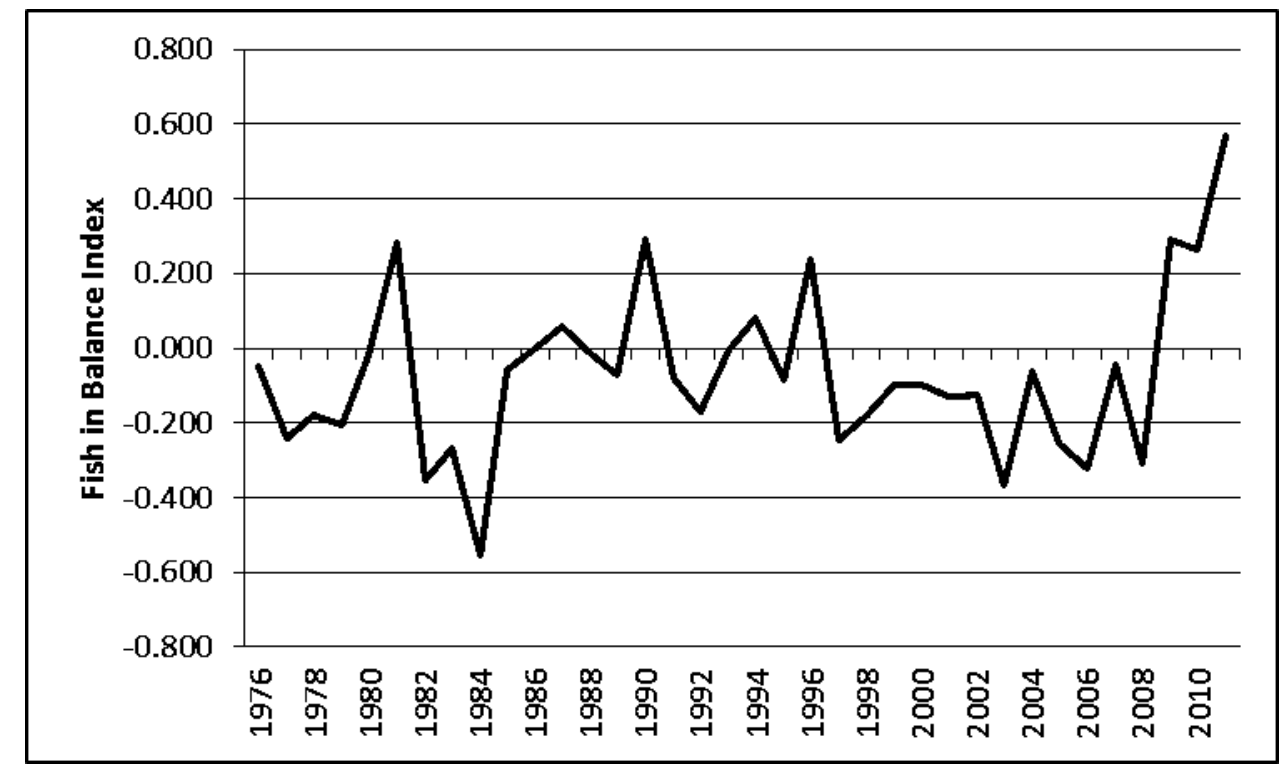

Figure 30. Fish in Balance Index of catches from the NEFSC Northeast Bottom Trawl Survey Georges Bank stations, 1976-2011. Catches from the Bottom Trawl Survey in 1975 were used as a baseline for all subsequent comparisons. The Fish in Balance Index evaluates the trophic diversity of a community relative to a specific baseline value. 
Table 30. Multiple regression results to determine relationship of effort and environmental influences on Fish in Balance Index values. Demersal fishing effort is defined as the cumulative number of days of bottom fishing on Georges Bank. Atlantic Cod Trawl catch is the number of individuals caught in the NEFSC Northeast Bottom Trawl Survey. Commercial catch is the total weight of all commercial catches in New England per year. Georges Bank bottom temperature is the mean annual bottom temperature at NEFSC Northeast Bottom Trawl Survey Georges Bank stations.

\begin{tabular}{|c|c|c|c|}
\hline & $\beta$ & $\mathbf{T}$ & p \\
\hline Intercept & $-2.27 \times 10^{-1}$ & -0.310 & 0.7589 \\
\hline Georges Bank Bottom Temperature & $-5.17 \times 10^{-3}$ & -0.089 & 0.9296 \\
\hline Commercial Catch & $-7.34 \times 10^{-7}$ & -0.477 & 0.6373 \\
\hline Demersal Fishing Effort & $6.73 \times 10^{-7}$ & 1.751 & 0.0923 \\
\hline Global Temperature Anomalies & $2.095 \times 10^{-3}$ & 0.793 & 0.4350 \\
\hline North Atlantic Oscillation & $-5.15 \times 10^{-2}$ & -0.413 & 0.6828 \\
\hline Atlantic Cod Catch - Trawl & $1.29 \times 10^{-4}$ & 0.777 & 0.4446 \\
\hline Storm Events & $4.99 \times 10^{-3}$ & 0.336 & 0.7399 \\
\hline
\end{tabular}

\section{Eastern Bering Sea}

Realized Species Richness: Realized species richness ranged from 75 to 115 species with a mean of 92.6 species. A fitted linear trend line revealed a significant trend of increasing species richness by 0.35 per year, $r^{2}(30)=0.3492, p=0.00059$. Realized species richness was insignificantly correlated to Pacific cod trawl catches, $r(18)=-$ 0.5816, $\mathrm{p}=0.0090$. Moderate, insignificant correlations were evident with walleye pollock trawl catch, $\mathrm{r}(18)=-0.4453, \mathrm{p}=0.0561$, and Alaskan Index, $\mathrm{r}(18)=-0.4207, \mathrm{p}$ $=0.0729$. Weak correlations were present between realized species richness and demersal fishing effort, $r(18)=-0.2320, p=0.3392$, ice cover index, $r(18)=0.1828, p$ $=0.4539$, and ice retreat index, $\mathrm{r}(18)=0.1593, \mathrm{p}=0.5147$. Multiple regression of species richness, single species abundance, climate, and fishing effort was not statistically significant, $\mathrm{F}(18,9)=2.291, \mathrm{p}=0.1164$. 


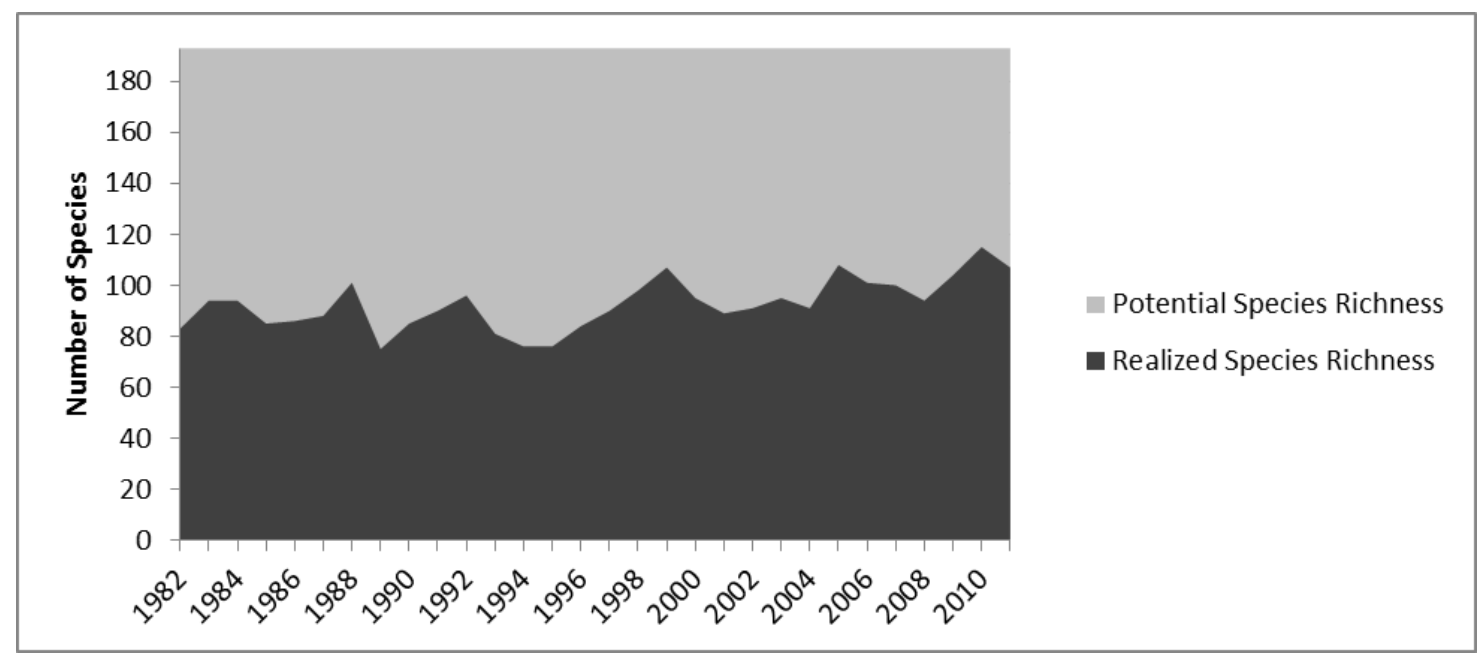

Figure 31. Potential and realized species richness of catches from the AFSC Eastern Bering Sea Trawl Survey, 1982-2011.

Table 31. Multiple regression results to determine relationship of effort and environmental influences on Realized Species Richness. Pacific Cod Trawl Catch and Walleye Pollock Trawl Catch indicate the number of Pacific Cod and Walleye Pollock caught in the AFSC Eastern Bering Sea Trawl Survey per unit effort. Trawl Fishing Effort is described as the number of sightings of bottom trawlers in the Eastern Bering Sea. EBS Bottom and Surface Temperature are the annual mean temperatures recorded during the AFSC Eastern Bering Sea Trawl Surveys.

\begin{tabular}{|c|ccc|}
\hline \multicolumn{1}{|c}{$\boldsymbol{\beta}$} & $\mathbf{T}$ & $\mathbf{p}$ \\
\hline Intercept & $1.24 \times 10^{2}$ & 3.257 & 0.0099 \\
Alaskan Index & $-3.94 \times 10^{0}$ & -1.279 & 0.2330 \\
Commercial Catch & $1.11 \times 10^{-5}$ & 0.710 & 0.4956 \\
Pacific Cod Catch - Trawl & $-3.58 \times 10^{-3}$ & -2.720 & 0.0236 \\
Trawl Fishing Effort & $-8.53 \times 10^{-4}$ & -1.322 & 0.2187 \\
Ice Cover Index & $-2.48 \times 10^{0}$ & -1.011 & 0.3384 \\
Ice Retreat Index & $-9.94 \times 10^{-2}$ & -0.518 & 0.6169 \\
Walleye Pollock Catch & $-1.11 \times 10^{-4}$ & -0.745 & 0.4750 \\
EBS Bottom Temperature & $-5.52 \times 10^{-1}$ & -0.089 & 0.9308 \\
EBS Surface Temperature & $-2.68 \times 10^{0}$ & -0.824 & 0.4312 \\
\hline
\end{tabular}

Historical Biological Index: Strong, insignificant correlations were evident between HBI and EBS bottom temperature, $r(19)=-0.6558, p=0.0023$, , ice cover index, $r(19)$ $=0.5683, \mathrm{p}=0.0111$, and ice retreat index, $\mathrm{r}(19)=-0.6392, \mathrm{p}=0.0061$. Moderate, insignificant correlations were also present between HBI and Alaskan Index, r(19) = $0.4893, \mathrm{p}=0.0335$. 
Shannon Index: Shannon Index was weakly correlated to fishing effort, $r(19)=$ $0.2029, \mathrm{p}=0.4048$, commercial catches, $\mathrm{r}(19)=0.2581, \mathrm{p}=0.2860$, and walleye pollock trawl catches, $\mathrm{r}(19)=-0.2715, \mathrm{p}=0.2608$. Weak correlations were present between Shannon Index and EBS bottom temperature, $r(19)=-0.1765, p=0.4697$, Alaskan Index, $r(19)=-0.2137, p=0.3796$, and Ice Retreat Index, $r(30)=0.2142, p=$ 0.3786. Multiple regression analysis of Shannon Index, single species abundance, climate, and fishing effort was not statistically significant, $F(18,9)=0.4602, p=$ 0.8684 .

Table 32. Multiple regression results to determine relationship of effort and environmental influences on the Shannon Index. Pacific Cod Trawl Catch and Walleye Pollock Trawl Catch indicate the number of Pacific Cod and Walleye Pollock caught in the AFSC Eastern Bering Sea Trawl Survey per unit effort. Trawl Fishing Effort is described as the number of sightings of bottom trawlers in the Eastern Bering Sea. EBS Bottom and Surface Temperature are the annual mean temperatures recorded during the AFSC Eastern Bering Sea Trawl Surveys.

\begin{tabular}{|c|ccc|}
\hline \multicolumn{1}{|c}{ Intercept } & $\boldsymbol{\beta}$ & $\mathbf{T}$ & $\mathbf{p}$ \\
Alaskan Index & $1.53 \times 10^{0}$ & 4.165 & 0.0024 \\
Commercial Catch & $-1.18 \times 10^{-2}$ & -0.395 & 0.7024 \\
Pacific Cod Catch & $1.65 \times 10^{-7}$ & 1.089 & 0.3046 \\
Trawl Fishing Effort & $-1.74 \times 10^{-6}$ & -0.136 & 0.8949 \\
Ice Cover Index & $6.13 \times 10^{-6}$ & 0.979 & 0.3530 \\
Ice Retreat Index & $2.09 \times 10^{-3}$ & 0.087 & 0.9322 \\
Walleye Pollock Catch & $7.65 \times 10^{-4}$ & 0.411 & 0.6907 \\
EBS Bottom Temperature & $-7.47 \times 10^{-7}$ & -0.5119 & 0.6164 \\
EBS Surface Temperature & $2.49 \times 10^{-2}$ & 0.415 & 0.6870 \\
\hline
\end{tabular}

Hurlbert Index: Hurlbert Index values demonstrated little annual fluctuation (Figure 32). A maximum Hurlbert value of 5.9741 was calculated for 1988. A minimum of 4.4078 was calculated for 1985. Linear regression revealed a significant trend of increasing Hurlbert Index by 0.0196 units per year, $\mathrm{r}^{2}(30)=0.2606, \mathrm{p}=0.0039$. No significant correlations were evident between Hurlbert Index and fishing effort or climate. Hurlbert Evenness Index was weakly correlated to fishing effort, $r(19)=$ 
$0.3401, \mathrm{p}=0.1542$, commercial catches $\mathrm{r}(19)=0.3531, \mathrm{p}=0.1381$, and walleye pollock trawl catches, $\mathrm{r}(19)=-0.1729, \mathrm{p}=0.4791$. Multiple regression analysis of Hurlbert Index, single species abundance, climate, and fishing effort was not statistically significant, $F(18,9)=0.5234, p=0.8255$.

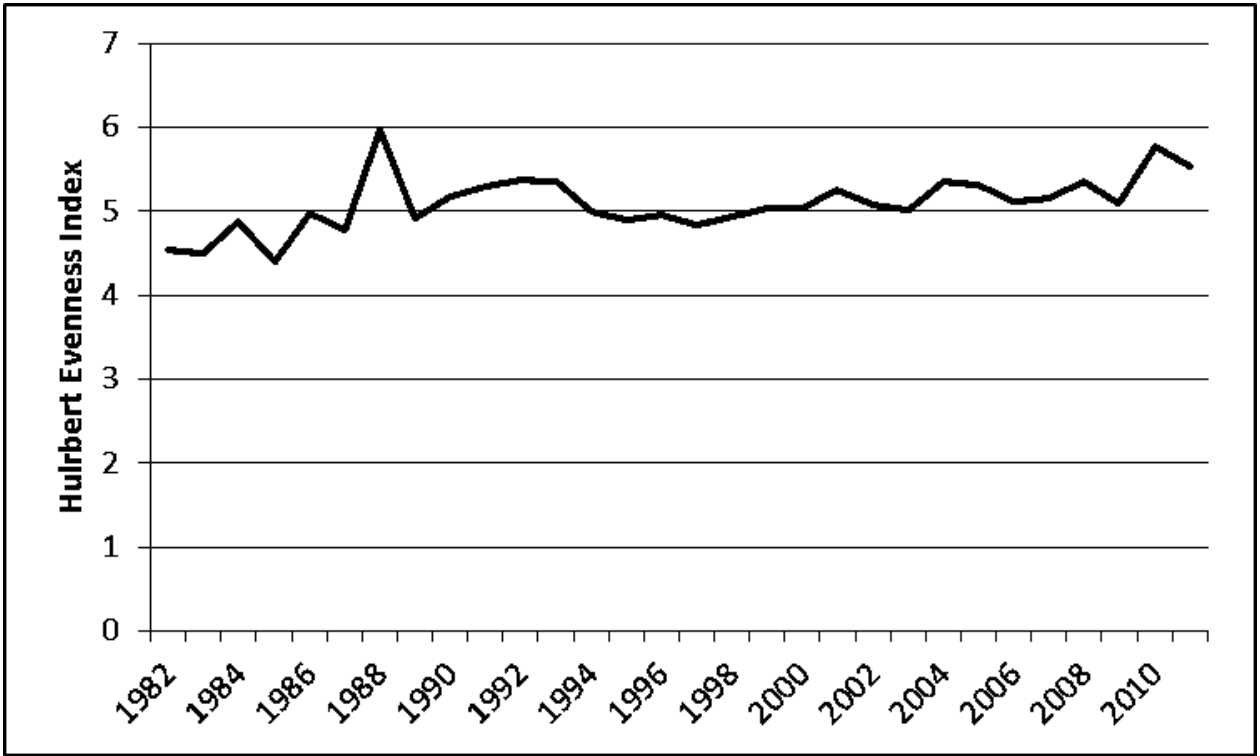

Figure 32. Hurlbert Evenness Index of catches from the AFSC Eastern Bering Sea Trawl Survey, 19822011. This index evaluates the relative diversity and abundance of species.

Table 33. Multiple regression results to determine relationship of effort and environmental influences on the Hurlbert Index. Pacific Cod Trawl Catch and Walleye Pollock Trawl Catch indicate the number of Pacific Cod and Walleye Pollock caught in the AFSC Eastern Bering Sea Trawl Survey per unit effort. Trawl Fishing Effort is described as the number of sightings of bottom trawlers in the Eastern Bering Sea. EBS Bottom and Surface Temperature are the annual mean temperatures recorded during the AFSC Eastern Bering Sea Trawl Surveys.

\begin{tabular}{|c|ccc|}
\hline \multicolumn{1}{|c}{ B } & T & p \\
\hline Intercept) & $4.00 \times 10^{0}$ & 3.792 & 0.0043 \\
Alaskan Index & $-4.49 \times 10^{-2}$ & -0.527 & 0.6110 \\
Commercial Catch & $5.34 \times 10^{-7}$ & 1.233 & 0.2487 \\
Pacific Cod Catch & $-5.34 \times 10^{-6}$ & -0.146 & 0.8869 \\
Trawl Fishing Effort & $2.12 \times 10^{-5}$ & 1.183 & 0.2672 \\
Ice Cover Index & $6.77 \times 10^{-3}$ & 0.099 & 0.9229 \\
Ice Retreat Index & $-4.39 \times 10^{-4}$ & -0.083 & 0.9360 \\
Walleye Pollock Catch & $-1.72 \times 10^{-6}$ & -0.418 & 0.6859 \\
EBS Bottom Temperature & $-5.62 \times 10^{-2}$ & 0.328 & 0.7503 \\
EBS Surface Temperature & $-6.50 \times 10^{-2}$ & -0.720 & 0.4897 \\
\hline \multicolumn{4}{|c}{} \\
\hline
\end{tabular}


Mean Trophic Level: Mean Trophic Level was weakly correlated with Pacific cod trawl catches, $\mathrm{r}(19)=-0.3108, \mathrm{p}=0.1953$. Weak correlations were present between MTL and EBS bottom temperature, $\mathrm{r}(19)=0.3071, \mathrm{p}=0.2010$, Ice Cover Index r(19) $=-0.3275, \mathrm{p}=0.1712$, and Ice Retreat Index, $\mathrm{r}(19)=-0.1623, \mathrm{p}=0.5067$. Multiple regression analysis of MTL, single species abundance, climate, and fishing effort was not statistically significant, $F(18,9)=2.291, \mathrm{p}=0.1164$.

Table 34. Multiple regression results to determine relationship of effort and environmental influences on Mean Trophic Level. Pacific Cod Trawl Catch and Walleye Pollock Trawl Catch indicate the number of Pacific Cod and Walleye Pollock caught in the AFSC Eastern Bering Sea Trawl Survey per unit effort. Trawl Fishing Effort is described as the number of sightings of bottom trawlers in the Eastern Bering Sea. EBS Bottom and Surface Temperature are the annual mean temperatures recorded during the AFSC Eastern Bering Sea Trawl Surveys.

\begin{tabular}{|c|ccc|}
\hline \multicolumn{1}{c}{ (Intercept) } & $\boldsymbol{\beta}$ & $\mathbf{T}$ & $\mathbf{p}$ \\
\hline Alaskan Index & $3.51 \times 10^{0}$ & 41.474 & $1.37 \times 10^{-11}$ \\
& $-18.45 \times 10^{-}$ & -1.233 & 0.2489 \\
Commercial Catch & $-6.83 \times 10^{-9}$ & -0.196 & 0.8487 \\
Pacific Cod Catch & $-6.76 \times 10^{-6}$ & -2.307 & 0.0464 \\
Trawl Fishing Effort & $-3.24 \times 10^{-6}$ & -2.256 & 0.0505 \\
Ice Cover Index & $-1.32 \times 10^{-2}$ & -2.406 & 0.0395 \\
Ice Retreat Index & $-1.03 \times 10^{-4}$ & -0.242 & 0.8144 \\
Walleye Pollock Catch & $6.24 \times 10^{-8}$ & 0.189 & 0.8544 \\
EBS Bottom Temperature & $3.02 \times 10^{-3}$ & 0.219 & 0.8312 \\
EBS Surface Temperature & $-6.89 \times 10^{-3}$ & -0.951 & 0.3665 \\
\hline
\end{tabular}

Fish in Balance Index: Fish in Balance Index demonstrated considerable annual fluctuations (Figure 33). A maximum of 0.0779 occurred in 1983, while a minimum of -0.1275 occurred in 1999 . Linear regression revealed a slight, insignificant trend of decreasing $\mathrm{FiB}, \mathrm{r}^{2}(29)=0.0031, \mathrm{p}=0.7740$. Strong, insignificant correlations were present between FiB and commercial catches, $r(19)=0.5719, \mathrm{p}=0.0105$, and Alaskan Index, $\mathrm{r}(19)=0.5361, \mathrm{p}=0.0180$. A moderate, insignificant correlations was present with Ice Cover Index, $r(19)=-0.4942, p=0.0316$, EBS surface temperature, $r(19)=$ 
$0.3645, p=0.1250$. Weak correlations were present between FiB and Pacific cod trawl catches, $r(19)=0.2911, p=0.2265$, and walleye pollock trawl catch, $r(19)=0.2989, p$ $=0.2139$. Additionally, weak correlations were present with EBS bottom temperature, $\mathrm{r}(19)=0.2033, \mathrm{p}=0.2526$, and Ice Retreat Index, $\mathrm{r}(19)=-0.2962, \mathrm{p}=0.2183$. Multiple regression analysis of MTL, single species abundance, climate, and fishing effort were not statistically significant, $\mathrm{F}(18,9)=2.295, \mathrm{p}=0.1159$.

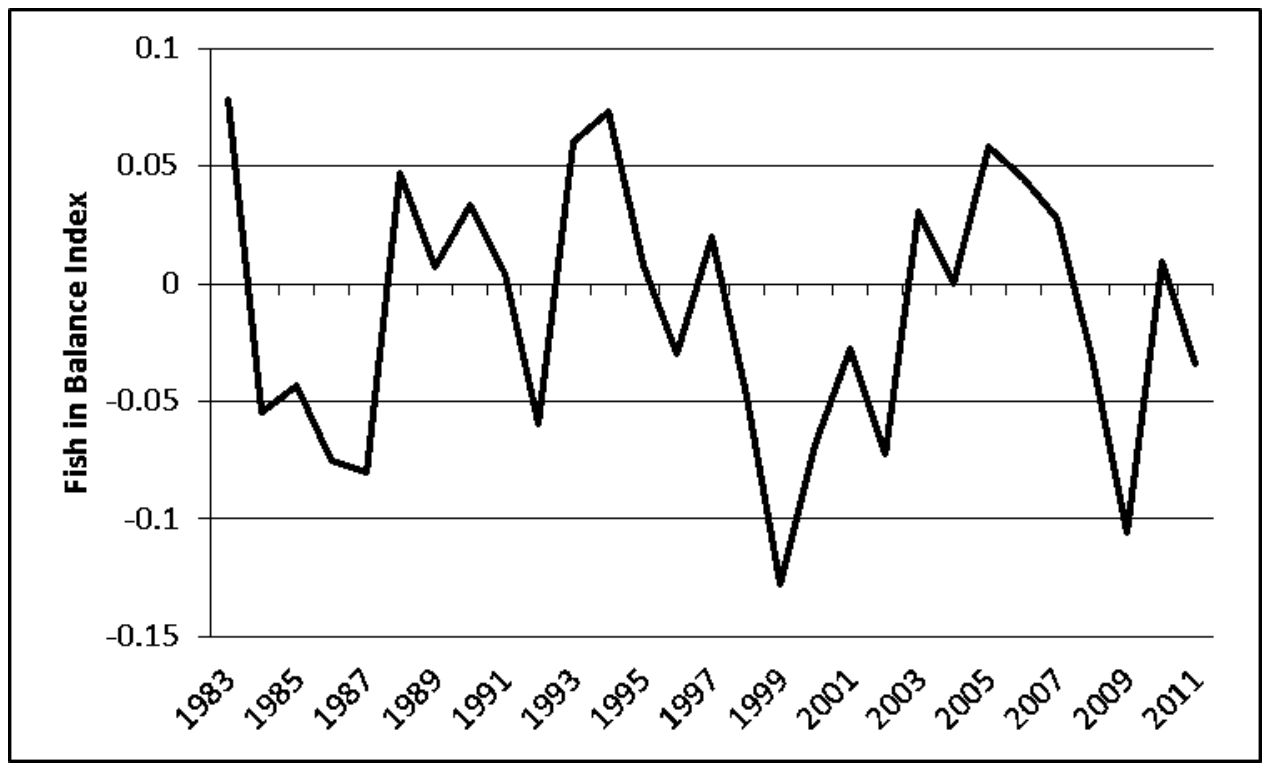

Figure 33. Fish in Balance Index of catches from the AFSC Eastern Bering Sea Trawl Survey, 19832011. Catches from the Trawl Survey in 1982 were used as a baseline for all subsequent comparisons. The Fish in Balance Index evaluates the trophic diversity of a community relative to a specific baseline value. 
Table 35. Multiple regression results to determine relationship of effort and environmental influences on the Fish in Balance Index. Pacific Cod Trawl Catch and Walleye Pollock Trawl Catch indicate the number of Pacific Cod and Walleye Pollock caught in the AFSC Eastern Bering Sea Trawl Survey per unit effort. Trawl Fishing Effort is described as the number of sightings of bottom trawlers in the Eastern Bering Sea. EBS Bottom and Surface Temperature are the annual mean temperatures recorded during the AFSC Eastern Bering Sea Trawl Surveys.

\begin{tabular}{|c|ccc|}
\hline \multicolumn{1}{|c}{ (Intercept) } & $\boldsymbol{\beta}$ & $\mathbf{T}$ & $\mathbf{p}$ \\
\hline Alaskan Index & $-2.48 \times 10^{-1}$ & -1.129 & 0.2883 \\
Commercial Catch & $4.37 \times 10^{-2}$ & 2.454 & 0.0365 \\
Pacific Cod Catch & $1.21 \times 10^{-7}$ & 1.342 & 0.2123 \\
Trawl Fishing Effort & $-1.62 \times 10^{-6}$ & -0.212 & 0.8366 \\
Ice Cover Index & $-3.88 \times 10^{-6}$ & -1.038 & 0.3263 \\
Ice Retreat Index & $8.14 \times 10^{-4}$ & 0.057 & 0.9556 \\
Walleye Pollock Catch & $-1.23 \times 10^{-3}$ & -1.111 & 0.2956 \\
EBS Bottom Temperature & $-8.26 \times 10^{-8}$ & -0.096 & 0.9255 \\
EBS Surface Temperature & $-7.21 \times 10^{-2}$ & -2.020 & 0.0742 \\
\hline
\end{tabular}




\section{BIBLIOGRAPHY}

Anderson, E.D. 1998 "The history of fisheries management and scientific advice - the ICNAF/NAFO history from the end of World War II to the present". Journal of Northwest Fisheries Science, 23: 75-94.

"An Evaluation of the Bottom Trawl Survey Program of the Northeast Fisheries Center." Survey working Group, Northeast Fisheries Center.1998. NOAA Technical Memorandum NMFS-F/NED-52.

At-sea Processors Association (APA). 1999. Preliminary assessment of the pollock conservation cooperative. At-sea Processors Association: Seattle, WA.

Attrill, M.J. and M. Power. 2002. "Climatic influence on a marine fish assemblage". Nature, 417: 275 - 278.

Bakkala, R.G. 1993. "Structure and historical changes in the groundfish complex of the Eastern Bering Sea". NMFS Tech Report NMFS 114.

Biesel, J-N., P. Usseglio-Polatera, V. Bachman, and J-C. Moreteau. 2003. "A comparative analysis of evenness index sensitivity." International Review of Hydrobiology, 88(1): 3-15.

Brereton, J. "A brief and true relation of the discovery of the North part of Virginia". The Fish and Fisheries of Colonial North America: A Documentary History of the Fishery Resources of the United States and Canada. Ed. J.C. Pearson. United States: National Marine Fisheries Service. 1972.

Buckland, S.T., A.E. Magurran, R.E. Green, and R.M. Fewster. 2005. "Monitoring change in biodiversity through composite indices." Philosophical Transactions of the Royal Society B, 360: 243-254.

Burroughs, R. 2011. Coastal Governance. Island Press: Washington, D.C.

Casini, M., J. Hjelm, J.C. Molinero, J. Lovgren, M. Cardinale, V. Bartolino, A. Belgrano, and G. Kornilovs. 2009. "Trophic cascades promote threshold-like shifts in pelagic marine ecosystems". Proceedings of the National Academy of Sciences, 106(1): 197-202.

Charles, A.T. 1998. Fisheries in Transition. Ocean Yearbook 13. Eds. E.M. Borges, A. Chircop, M. McConnell, \& J.R. Morgan. University of Chicago Press, Chicago, IL.

Checkley, D.M., S. Raman, G. L. Maillet, and K.M. Mason. 1988. "Winter storm effects on the spawning and larval drift of a pelagic fish." Nature, 335:22, 346348. 
Collie, J.S., G.A. Escanero, and P.C. Valentine. 2000. "Photographic evaluation of the impacts of bottom fishing on benthic epifauna." ICES Journal of Marine Science, 57(4): 987-1001.

Collie, J.S., D.J. Gifford, and J.H. Steele. 2009. "End-to-End Foodweb Control of Fish Production on Georges Bank". ICES Journal of Marine Science 66:2223-2232.

Conover, D.O. and S.B. Munch. 2002. "Sustaining fisheries yields over evolutionary time scales". Science, 297: 94 - 96.

Conover, D.O., S.B Munch, and S.A. Arnott. 2009. "Reversal of evolutionary downsizing caused by selective harvest of large fish". Proceedings of the Royal Society B, 276: 2015 - 2020.

Convention of Biological Diversity (CBD). 2010. "Strategic Plan for Biodiversity 2011-2012. COP 10 Decision X/2.

Convention on Biological Diversity (CBD). 2011. "About the Convention." http://www.cbd.int/convention/about.shtml.

Criddle, K.R. 2008. "The legal context of United States fisheries management and the evolution of rights-based management in Alaska". In Case studies in fisheries self governance. Ed. R. Townsend, R. Shotton, and H. Uchida. FAO Fisheries Technical Paper 504. Food and Agriculture Organization of the United Nations: Rome.

DiCosimo, J. 2001. Summary of the Gulf of Alaska Groundfish Fishery Management Plan. Prepared for the North Pacific Fishery Management Council.

Ecosystem Assessment Program. 2012. "Ecosystem Status Report for the Northeast Shelf Large Marine Ecosystem - 2011”. Northeast Fisheries Science Center Ref Doc 12-07.

Ecosystem Principles Advisory Panel. 1999. Ecosystem-Based Fishery Management, A Report to Congress. Washington, D.C.

Fang, Z., and J.M.J. Wallace, 1994: Arctic sea ice variability on a time scale of weeks and its relation to atmospheric forcing, J. Climate, 7, 1897-1914.

Federal Register. 2011. "Fisheries of the Exclusive Economic Zone Off Alaska; Pacific Cod Allocations in the Gulf of Alaska; Amendment 83." 76 FR 143: $44700-44728$.

Fisheries Resource Conservation Council (FRCC). 2011. Towards Recovered and Sustainable Groundfish Fisheries in Eastern Canada: A Report to the Minister 
of Fisheries and Oceans. Minister of Public Works and Government Services: Ottawa, ON.

Fissel, B., M. Dalton, R. Felthoven, B. Garber-Yonts, A. Haynie, A. Himes-Cornell, S. Kasperski, J. Lee, D. Lew, L. Pfieffer, J. Sepez, and C. Seung. 2012. "Stock Assessment and Fishery Evaluation Report for the Groundfish Fisheries of the Gulf of Alaska and Bering Sea/Aleutian Islands Area: Economic Status of the Groundfish Fisheries off Alaska, 2011.” Alaska Fisheries Science Center: Seattle, WA.

Flagg, C.N. 1987. "Hydrographic Structure and Variability” in Georges Bank. Ed. R.H. Backus and D.W. Bourne. The MIT Press, Cambridge.

Fogarty, M.J. and Murawski, S.A. 1998. "Large scale disturbances and the structure of marine systems: fishery impacts on Georges Bank". Ecological Applications, 8 (Suppl. 1): S6 - 22.

Fogarty, M., L. Incze, K. Hayhoe,. D. Mountain, and J. Manning. 2008. "Potential Climate Change Impacts on Atlantic Cod (Gadus morhua) off the Northeastern USA”. Mitigating Adaptive Strategies of Global Change 13:453-466.

Folke, C., S. Carpenter, B. Walker, M. Schefferm T. Elmqvist, L. Gunderson, and C.S. Holling. 2004. "Regime Shifts, Resilience, and Biodiversity in Ecosystem Management". Annual Review of Ecology, Evolution, and Systematics 35:557-581.

Food and Agriculture Organization (FAO). 1995. The Code of Conduct for Responsible Fisheries. Food and Agriculture Organization of the United Nations: Rome.

Food and Agriculture Organization (FAO). 2010. The State of World Fisheries and Aquaculture. Rome: Food and Agriculture Organization of the United Nations.

Frank, Kenneth T., Brian Petrie, Jae S. Choi, William C. Leggett. 2005. "Trophic Cascades in a Formerly Cod-Dominated Ecosystem.” Science 308(5728):16211623.

Froese, R. and D. Pauly. Editors. 2103. FishBase. World Wide Web electronic publication. www.fishbase.org, version (04/2013).

Fulton, E.A., A.D.M. Smith, and C.R. Johnson. 2003. "Effect of complexity on marine ecosystem models". Marine Ecology Progress Series, 253: 1-16.

Gabriel, W. 1994. "Persistence of demersal fish assemblages between Cape Hatteras and Nova Scotia, Northwest Atlantic". Journal of Northwest Atlantic Fisheries Science, 14: $29-46$. 
Goldsmith, S. 2008. "What Drives the Alaska Economy?" Investing for Alaska's Future. Institute of Social and Economic Research.

Gotelli, N.J. and R.K. Colwell. 2001. "Quantifying biodiversity: procedures and pitfalls in the measurement and comparison of species richness". Ecology Letters, 4(4): 379 - 391.

Grasso, G.M. 2008. "What Appeared Limitless Plenty: The Rise and Fall of the Nineteenth-Century Atlantic Halibut Fishery". Environmental History 13(1): 66-91.

Gray, J.S. 2001. "Marine diversity: the paradigms in patterns of species richness examined". Scientia Marina, 65 (Suppl. 2): 41-56.

Grebmeir, J.M., J.E. Overland, S.E. Moore, E.V. Farley, E.C. Carmack, L.W. Cooper, K.E. Frey, J.H. Helle, F.A. McLaughlin, and S. L. McNutt. 2006. "A major ecosystem shift in the Northern Bering Sea". Science, 311: 1461 - 1464.

Hall S.J. and B. Mainprize. 2004. "Towards Ecosystem-Based Fisheries Management". Fish and Fisheries 5(1):1-20.

Harlow, L. 2005. The Essence of Multivariate Thinking: Basic Themes and Methods. Second Ed. Lawrence Erlbaum Associates: London.

Heip, C., R. Warwick, and L. d'Ozouville (Eds.). 1998. A European science plan on marine biodiversity. European Science Foundation, Strasbourg.

Helbig, J., G. Mertz, and P. Pepin. 1992. "Environmental influences on the recruitment of Newfoundland/Labrador cod." Fisheries Oceanography, 1, 3956

Hiddink, J.G., S. Jennings, and M.J. Kaiser. 2006. "Indicators of the ecological impact of bottom-trawl disturbances on seabed communities". Ecosystems, 9:11901199.

Hilborn, R. 2007. "Defining Success in Fisheries and Conflicts in Objectives". Marine Policy 31:153-158.

Hinckley, S., A.J. Hermann, and B.A. Megrey. 1996. "Development of a spatially explicit, individual-based model of marine fish early life history". Marine Ecology Progress Series, 139: 47 - 68.

Hoagland, P., D. Jin, E. Thunberg, and S. Steinback. 2005. "Economic Activity Associated with the Northeast Shelf Large Marine Ecosystem: Application of 
an Input-Output Approach". In Hennessy, T.M. and J.G. Sutinen (Eds.), Large Marine Ecosystems, vol 13: 157-179.

Hughes, A.R. and J.J. Stachowicz. 2004. "Genetic diversity enhances the resistance of a seagrass ecosystem to disturbance". Proceedings of the National Academy of Sciences, 10(24): 8998 - 9002 .

Huxley, T. H., 1883. "Inaugural address". International Fisheries Exhibition, London, UK.

ILO. 2004. "Danger at sea - Working in the Fishing Sector" International Labour Organization. http://www.ilo.org/global/about-the-ilo/press-and-mediacentre/news/WCMS_075579/lang--en/index.htm.

Jennings, S., J.K. Pinnegar, N.V.C. Polunin, and T.W. Boon. 2001. "Weak CrossSpecies Relationships Between Body Size and Trophic Level Belie Powerful Size-Based Trophic Structuring in Fish Communities". Journal of Animal Ecology 70(6): 934-944.

Johnston, Douglas M. The Theory and History of Ocean BoundaryMaking. Montreal: Canada. Mcgill-Queen's University Press. 1988.

Jones, G.P., M. Srinivasan, and G.R. Almany. 2007. "Population Connectivity and Conservation of Marine Biodiversity”. Oceanography 20(3): 100-111.

Karpov, Konstantin, Peter Haaker, Ian Taniguchi, and Laura Rogers-Bennett. 2000. "Serial Depletion and the Collapse of the California Abalone (Haliotis spp.) fishery." NRC Research Press 11-24.

King, Michael. 2007. Fisheries Biology, Assessment and Management. Oxford, UK: Blackwell Publishing.

Kitts, A., E. Bing-Sawyer, J. Walden, C. Demarest, M. McPherson, P. Christman, S. Steinback, J. Olsen, and P. Clay. 2011. 2010 Final Report on the Performance of the Northeast Multispecies (Groundfish) Fishery (May 2010-April 2011), 2nd Edition. US Dept Commer, Northeast Fish Sci Cent Ref Doc. 11-19.

Kuparinen, A. and J. Merila.2007. "Detecting and managing fisheries-induced evolution". Trends in Ecology and Evolution, 22(12): 652 - 659.

Larkin, Paul. 1977. "An Epitaph for the Concept of Maximum Sustainable Yield". Transactions of the American Fisheries Society 106(1): 1-11.

Lauth, R. R. 2010. Results of the 2009 eastern Bering Sea continental shelf bottom trawl survey of groundfish and invertebrate resources. U.S. Dep. Commer., NOAA Tech. Memo. NMFS-AFSC-204, 228 p. 
Law, R. 2000. "Fishing, selection, and phenotypic evolution". ICES Journal of Marine Science, 57: $659-668$.

Law, R. 2007. "Fisheries-induced evolution: present status and future directions". Marine Ecology Progress Series, 335: 271 - 277.

Legault, C.M., L. Alade, and H.H. Stone. 2011. "Stock Assessment of Georges Bank Yellowtail Flounder for 2011.” Transboundary Resources Assessment Committee Ref Doc 2011/01.

Link, Jason. 2002. "What Does Ecosystem-Based Fisheries Management Mean?" Fisheries 27(4):18-21.

Link, J., B. Bogstad, H. Sparholt, and G.R. Lilly. 2008. "Trophic Role of Atlantic Cod in the Ecosystem". Fish and Fisheries 10(1):58-87.

Ludwig, D., R. Hillborn, and C. Walters. 1993. "Uncertainty, resource exploitation and conservation: Lessons from history". Science, 260: 36 - 37.

Ludwig, D.R. 2001. “The era of management is over”. Ecosystems, 4(8): 758 - 764.

Mace, Pamela. 2001. “A New Role for MSY". Fish and Fisheries 2(1): 2-32.

Macklin, S.A., V.I. Radchenko, S. Saitoh, and P.J. Stabeno. 2002. "Variability in the Bering Sea Ecosystem.” Progress in Oceanography, 55, 1-4.

Magnuson-Stevens Fishery Conservation and Management Act.

May, R.M. 1973a. “Qualitative Stability in Model Ecosystems”. Ecology, 54(3): 638 641.

May, R.M. 1973b. Stability and complexity in model ecosystems. Monographs in Population Biology, no 6. Princeton University Press, Princeton, NJ.

McCann, K.S. 2000. “The diversity-stability debate”. Nature, 405: 228 - 233.

McGowan, J.A., D.R. Cayan, and L.M. Dorman. 1998. "Climate-ocean variability and ecosystem response in the Northeast Pacific". Science, 281: $210-217$.

Milon, J.W. 1993. "U.S. Fisheries Management and Economic Analysis: Implications of the Alaskan Groundfish Controversy" American Journal of Agricultural Economics 75(5): 1177-1182.

Mullon, Christian, Pierre Freon, and Philippe Cury. 2005. "The Dynamics of Collapse in World Fisheries." Fish and Fisheries 6:111-120. 
National Marine Fisheries Service (NMFS). 2012a. 1st Quarter 2012 Summary of Stock Status for FSSI Stocks. Available at http://www.nmfs.noaa.gov/sfa/statusoffisheries/2012/first/Q1\%202012\%20FS SI\%20and\%20nonFSSI\%20StockStatus.pdf (last accessed July 2, 2012).

New England Fishery Management Council (NEFMC). 1985. Northeast Multispecies Fishery Management Plan.

New England Fishery Management Council. 1993. Final Amendment \#5 to the Northeast Multispecies Fishery Management Plan incorporating the Supplemental Environmental Impact Statement.

New England Fishery Management Council. 2009. Northeast Multispecies FMP Amendment 16.

New England Fishery Management Council (NEFMC). 2011. Framework Adjustment to the Northeast Multispecies Fishery Management Plan.

New England Fishery Management Council (NEFMC). 2012a. "Groundfish Committee Report Con'td from Previous Day” 2 Feb 2012.

New England Fishery Management Council. 2012c. "Groundfish Committee Report." 21 June 2012.

Northeast Fisheries Science Center. 2011. "Brief History of the Groundfishing Industry of New England." http://www.nefsc.noaa.gov/history/stories/groundfish/grndfsh1.html.

Northeast Fisheries Science Center. 2012a. 53rd Northeast Regional Stock Assessment Workshop (53rd SAW) Assessment Report. US Dept Commer, Northeast Fish Sci Cent Ref Doc. 12-05; 559p.

Northeast Fisheries Science Center. 2012b. 53rd Northeast Regional Stock Assessment Workshop (53rd SAW) Assessment Summary Report. US Dept Commer, Northeast Fish Sci Cent Ref Doc. 12-03; 33p.

Northeast Fisheries Science Center. 2012c. Assessment of Rata Updates of the 13 Northeast Groundfish Stocks through 2010. US Dept Commer, Northeast Fish Sci Cent Ref Doc 12-06; 789p.

Northern Demersal Working Group. 2011. "Stock Assessment Workshop (SAW 53) A. Gulf of Maine Atlantic cod (Gadus morhua) stock assessment updated through 2010." 
North Pacific Fishery Management Council. 2012. Fishery Management Plan for Groundfish of the Gulf of Alaska.

NWAFC. 1985. Fishing Efforts by Net Fisheries in the North Pacific Ocean and Bering Sea Since the 1950s. Northwest and Alaska Fisheries Center Report 8502 .

Olsen, E.M., M. Heino, G.R. Lilly, M.J. Morgan, G. Brattey, B. Ernande, and U. Dieckmann. 2004. "Maturation trends indicative of rapid evolution preceded the collapse of northern cod". Nature, 428: $932-935$.

Parsons, L.S. and Lear, W.H. 2001. "Climate variability and marine ecosystem impacts: a North Atlantic perspective". Progress in Oceanography, 49(1-4): 167-188.

Pauly, D. 1988. "Fisheries research and the demersal fisheries of Southeast Asia". In Fish Population Dynamics, ed. J.A. Gulland. John Wiley and Sons: London.

Pauly, D., V. Christensen, S .Guenette, T.J. Pitcher, U.R. Sumaila, C.J. Walters, R. Watson, and D. Zeller. 2002. "Towards sustainability in world fisheries". Nature, 418: $689-695$.

Pauly, D. and R. Watson. 2005. "Background and interpretation of the "Marine Trophic Index' as a measure of biodiversity." Philosophical Transactions of the Royal Society B, 360:1454, 415-423.

Peet, R.K. 1975. “Relative Diversity Indices.” Ecology, 56(2): 496-498.

Pikitch, E.K., C. Santora, E.A. Babcock, A. Bakun, R. Bonfil, D.O. Conover, P. Dayton, P. Doukakis, D. Fluharty, B. Heneman, E.D. Houde, J. Link, P.A. Livingston, M. Mangel, M.K. McAllister, J. Pope, and K.J. Sainsbury. 2004. "Ecosystem-Based Fishery Management". Science 305(5628: 346-347.

Pimm, S.L. 1984. "the complexity and stability of ecosystems". Nature, 307(5949): $321-326$.

Radovich, John. 1982. "The Collapse of the California Sardine Fishery: What Have We Learned?." CalCOFI Rep. 80:56-77.

Rijnsdorp, A.D., P.I. van Leeuwen, N. Daan, and H.J.L. Heesen. 1996. "Changes in abundance of demersal fish species in the North Sea between 1906-1909 and 1990-1995”. ICES Journal of Marine Science, 53: 1054 - 1062. 
Roemmich, D., W.J. Gould, and J. Gilson. 2012. "135 years of global ocean warming between the Challenger expedition and the Argo Programme". Nature Climate Change, 2: $425-428$.

Ruckelshaus, M., T. Klinger, N. Knowlton, and D.P. DeMaster. 2008. "Marine ecosystem-based management in practice: scientific and governance challenges". BioScience, 58(1): 53-63.

Ryan, J.J. "The Cod Family and its Utilization" Marine Fisheries Review, 41.11 (1979): 25-36.

Ryther, John. 1969. "Photosynthesis and Fish Production in the Sea." Science 166(3901):72-76.

Sabine, L. 1853. "Report on the Principal Fisheries of the American Seas"

Salamon, M., A. Coppa, M. McCormick, M. Rubini, R Vargiu, and N. Tuross. 2008. "The consilience of historical and isotopic approaches in reconstructing the medieval Mediterranean diet". Journal of Archeological Science, 35(6): 16671672.

Sanders, H.L. 1968. "Marine benthic diversity: a comparative study". The American Naturalist, 102(925): $243-282$.

Sepez, J.A., B.D. Tilt, C.L. Package, H.M. Lazrus, and I. Vaccaro. 2005. Community Profiles for North Pacific Fisheries - Alaska. NOAA Tech Mem NMFSAFSC-160.

Serchuk, F.M. and S.E. Wigley. 1993. "Assessment and Management of the Georges Bank Cod Fishery: An Historical Review and Evaluation". Journal of Northwest Atlantic Fishery Science 13:25-52.

Shannon, C. E., and W. Weaver. 1949. The mathematical theory of communication. Univ. Illinois Press, Urbana. 117 p.

Shaw, P. 2003. Multivariate Statistics for the Environmental Sciences. New York: Oxford University Press.

Shin, Y., M. Rochet, S. Jennings, J.G. Field, and H. Gislason. 2004. "Using SizeBased Indicators to Evaluate the Ecosystem Effects of Fishing". ICES Journal of Marine Science 62(3): 384-396.

Smith, T. 1994. Scaling Fisheries: The Science of Measuring the Effects of Fishing, 1855-1955. Cambridge: Cambridge University Press.

Solow, A.R. 1994. "Detecting change in the composition of a multispecies community". Biometrics, 50(2): $556-565$. 
Stabeno, P.J., N.A. Bond, N.B. Kachel, S.A. Salo, and J.D. Schumacher. 2001. "On the temporal variability of the physical environment over the south-eastern Bering Sea". Fisheries Oceanography, 10(1): 81-98.

State of Alaska, Alaska Department of Fish and Game. 2009. Sustaining Alaska's Fisheries: Fifty Years of Statehood. Juneau, AK.

Subsidiary Body on Scientific, Technical and Technological Advice (SBSTTA). 2012. "Sixteenth meeting of the Subsidiary Body on Scientific, Technical and Technological Advice, 30 April - 5 May 2012 - Montreal, Canada Recommendation Report" SBSTTA 16 Recommendations.

Sutinen, J. 2000. "Economic Perspectives on New England Fisheries Management". Northeastern Naturalist 7(4): 361-372.

Trippel, E.A. 1995. “Age at maturity as a stress indicator in fisheries”. Bioscience, 45: $759-771$.

U.S. Department of Commerce (USDOC). 2012. National Marine Fisheries Service Annual Commercial Landings Statistics [Data file]. Retrieved from http://www.st.nmfs.noaa.gov/st1/commercial/landings/annual_landings.html

U.S. Department of Commerce (USDOC). 2011. National Marine Fishery Service 2010 Report to Congress: The Status of U.S. Fisheries. Washington, D.C.

U.S. Department of Commerce (USDOC). 2009. Report to Congress: the state of science to support and ecosystem approach to regional fishery management. NOAA Tech. Memo. NMFS-F/SPO-96,24p. Washington, D.C.

U.S. Department of Commerce (USDOC). 2004. Alaska Groundfish Fisheries Final Programmatic Supplemental Environmental Impact Statement. USDC National Oceanic and Atmospheric Administration National Marine Fisheries Service.

Vellend, M. and M.A. Geber. 2005. "Connections between species diversity and genetic diversity". Ecology Letters, 8: 767 - 781.

Walsh, M.R., S.B. Munch, S. Chiba, and D.O. Conover. 2006. "Maladaptive Changes in Multiple Traits Caused by Fishing: Impediments to Population Recovery". Ecology Letters 9(2): 142-148,

Walters, C.J. V. Christensen, S.J. Martell, J.F. Kitchell. 2004. "Possible Ecosystem Impacts of Applying MSY Policies From Single-Species Assessment”. ICES Journal of Marine Sciences 62(3):558-568. 
Walther, G.R. "Community and ecosystem responses to recent climate change". Philosophical Transactions of the Royal Society B, 365(1549): 2019-2024.

Warren, J. 2010. "Employment in the Seafood Industry: Alaska Region Saw Mix of Losses and Gains in 2009". Alaska Economic Trends.

Washington, H.G. 1984. "Diversity, biotic and similarity indices: A review with special relevance to aquatic ecosystems". Water Research, 18(6): 653 - 694.

Witherell, D., M. Fey, and M. Fina. 2012. Fishing Fleet Profiles. North Pacific Fishery Management Council: Anchorage, AK.

Witherell, D., C. Pautzke, and D. Fluharty. 2000. "An ecosystem-based approach for Alaska groundfish fisheries". ICES Journal of Marine Science, 57: 771 - 777.

Whitmore, W. 2010. An expectancy theory analysis of catch shares : identifying outcomes, preferences, and potential co-management changes in New England groundfish management. Ph.D. Thesis. University of Rhode Island.

Worm, B., E. Barbier, N. Beaumont, J.E. Duffy, C. Folke, B.S. Halpern, J.B.C. Jackson, H.K. Lotze, F. Micheli, S.R. Palumbi, E. Sala, K.S. Selkoe, J.J. Stachowicz, and R. Watson. 2006. "Impacts of Biodiversity Loss on Ocean Ecosystem Services”. Science 314(5800): 787-790.

Worm, B., R. Hilborn, J.K. Baum, T.A. Branch, J.S. Collie, C. Costello, M.J. Fogarty, E.A. Fulton, J.A. Hutchings, S. Jennings, O.P. Jensen, H.K. Lotze, P.M. Mace, T.R. McClanahan, C. Minto, S.R. Palumbi, A.M. Parma, D. Ricard, A.A. Rosenberg, R. Watson, and D. Zeller. 2009. "Rebuilding Global Fisheries". Science 325(5940):578-585.

Wright, P.J. 2007. "Understanding the maturation process for field investigations of fisheries-induced evolution”. Marine Ecology Progress Series, 335: 279 - 283. 